
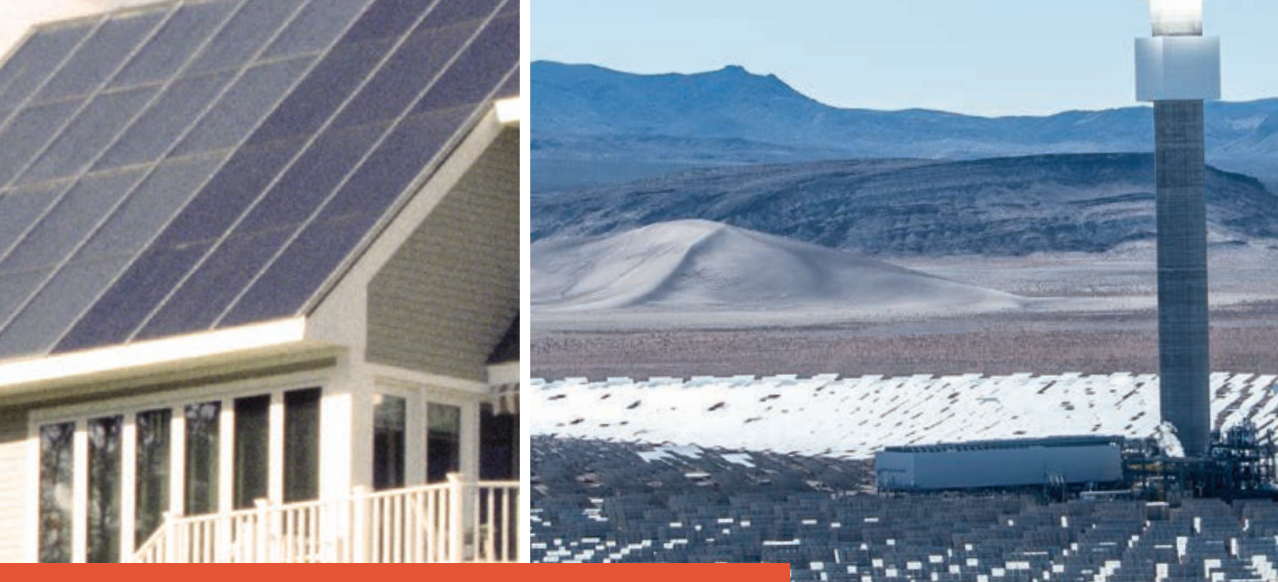

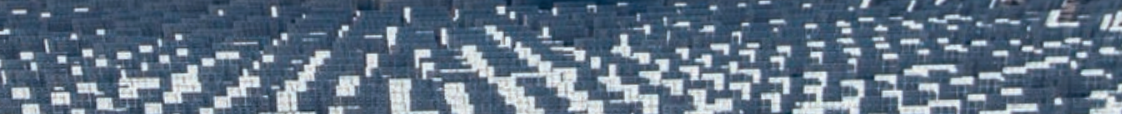
ON THE PATH TO SUNSHOT $10 \%$ fin

Emerging Issues and Challenges in Integrating High Levels of Solar into the Electrical Generation and Transmission System

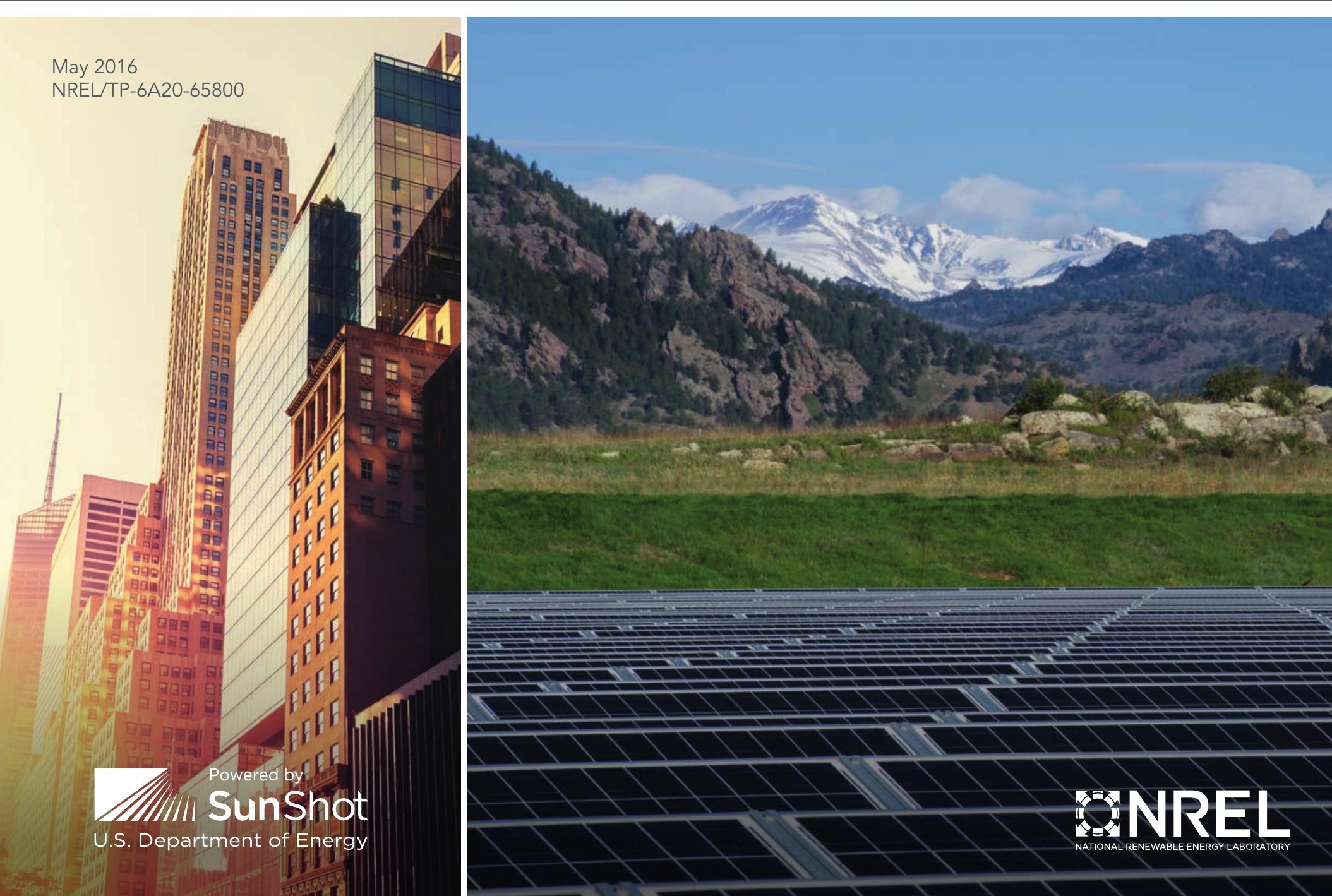




\section{On the Path to SunShot: Emerging Issues and Challenges in Integrating High Levels of Solar into the Electrical Generation and Transmission System}

Paul Denholm, Kara Clark, and Matt O'Connell

National Renewable Energy Laboratory

NREL is a national laboratory of the U.S. Department of Energy, Office of

Energy Efficiency and Renewable Energy, operated by the Alliance for

Sustainable Energy, LLC. 


\section{NOTICE}

This report was prepared as an account of work sponsored by an agency of the United States government. Neither the United States government nor any agency thereof, nor any of their employees, makes any warranty, express or implied, or assumes any legal liability or responsibility for the accuracy, completeness, or usefulness of any information, apparatus, product, or process disclosed, or represents that its use would not infringe privately owned rights. Reference herein to any specific commercial product, process, or service by trade name, trademark, manufacturer, or otherwise does not necessarily constitute or imply its endorsement, recommendation, or favoring by the United States government or any agency thereof. The views and opinions of authors expressed herein do not necessarily state or reflect those of the United States government or any agency thereof.

This report is available at no cost from the National Renewable Energy Laboratory (NREL) at www.nrel.gov/publications.

Available electronically at SciTech Connect http:/www.osti.gov/scitech Available for a processing fee to U.S. Department of Energy and its contractors, in paper, from:

\section{U.S. Department of Energy}

Office of Scientific and Technical Information

P.O. Box 62

Oak Ridge, TN 37831-0062

OSTI http://www.osti.gov

Phone: 865.576 .8401

Fax: 865.576.5728

Email: reports@osti.gov

Available for sale to the public, in paper, from:

\section{U.S. Department of Commerce}

National Technical Information Service

5301 Shawnee Road

Alexandria, VA 22312

NTIS http://www.ntis.gov

Phone: 800.553 .6847 or 703.605 .6000

Fax: 703.605 .6900

Email: orders@ntis.gov 


\section{Preface}

The U.S. Department of Energy launched the SunShot Initiative in 2011 with the goal of making solar electricity cost-competitive with conventionally generated electricity by 2020 . At the time this meant reducing photovoltaic and concentrating solar power prices by approximately $75 \%$ relative to 2010 costs - across the residential, commercial, and utility-scale sectors. To examine the implications of this ambitious goal, the Department of Energy's Solar Energy Technologies Office (SETO) published the SunShot Vision Study in 2012. The study projected that achieving the SunShot price-reduction targets could result in solar meeting roughly $14 \%$ of U.S. electricity demand by 2030 and $27 \%$ by 2050 - while reducing fossil fuel use, cutting emissions of greenhouse gases and other pollutants, creating solar-related jobs, and lowering consumer electricity bills.

The SunShot Vision Study also acknowledged, however, that realizing the solar price and deployment targets would face a number of challenges. Both evolutionary and revolutionary technological changes would be required to hit the cost targets, as well as the capacity to manufacture these improved technologies at scale in the U.S. Additionally, operating the U.S. transmission and distribution grids with increasing quantities of solar energy would require advances in grid-integration technologies and techniques. Serious consideration would also have to be given to solar siting, regulation, and water use. Finally, substantial new financial resources and strategies would need to be directed toward solar deployment of this magnitude in a relatively short period of time. Still the study suggested that the resources required to overcome these challenges were well within the capabilities of the public and private sectors. SunShot-level price reductions, the study concluded, could accelerate the evolution toward a cleaner, more costeffective and more secure U.S. energy system.

That was the assessment in 2012. Today, at the halfway mark to the SunShot Initiative's 2020 target date, it is a good time to take stock: How much progress has been made? What have we learned? What barriers and opportunities must still be addressed to ensure that solar technologies achieve cost parity in 2020 and realize their full potential in the decades beyond?

To answer these questions, SETO launched the On the Path to SunShot series in early 2015 in collaboration with the National Renewable Energy Laboratory (NREL) and with contributions from Lawrence Berkeley National Laboratory (LBNL), Sandia National Laboratories (SNL), and Argonne National Laboratory (ANL). The series of technical reports focuses on the areas of grid integration, technology improvements, finance and policy evolution, and environment impacts and benefits. The resulting reports examine key topics that must be addressed to achieve the SunShot Initiative's price-reduction and deployment goals. The On the Path to SunShot series includes the following reports:

- Emerging Issues and Challenges with Integrating High Levels of Solar into the Electrical Generation and Transmission Systems (Denholm et al. 2016)

- Emerging Issues and Challenges with Integrating High Levels of Solar into the Distribution System (Palmintier et al. 2016)

- Emerging Opportunities and Challenges in Financing Solar (Feldman and Bolinger 2016) 
- Utility Regulatory and Business Model Reforms for Addressing the Financial Impacts of Distributed Solar on Utilities (Barbose et al. 2016)

- The Role of Advancements in Photovoltaic Efficiency, Reliability, and Costs (Woodhouse et al. 2016)

- Advancing Concentrating Solar Power Technology, Performance, and Dispatchability (Mehos et al. 2016)

- Emerging Opportunities and Challenges in U.S. Solar Manufacturing (Chung et al. 2016)

- The Environmental and Public Health Benefits of Achieving High Penetrations of Solar Energy in the United States (Wiser et al. 2016).

Solar technology, solar markets, and the solar industry have changed dramatically over the past five years. Cumulative U.S. solar deployment has increased more than tenfold, while solar's levelized cost of energy (LCOE) has dropped by as much as $65 \%$. New challenges and opportunities have emerged as solar has become much more affordable, and we have learned much as solar technologies have been deployed at increasing scale both in the U.S. and abroad. The reports included in this series, explore the remaining challenges to realizing widely available, cost-competitive solar in the United States. In conjunction with key stakeholders, SETO will use the results from the On the Path to SunShot series to aid the development of its solar price reduction and deployment strategies for the second half of the SunShot period and beyond. 


\section{Acknowledgments}

The authors thank the Solar Energy Technologies Office team for its support of this report and Robert Margolis of NREL for his management and oversight of the On the Path to SunShot report series. And, we acknowledge and thank the following individuals for their reviews and comments: Mark Ahlstrom (WindLogics Inc), Aaron Bloom (NREL), Jaquelin Cochran (NREL), Barbara Goodman (NREL), Udi Helman (Helman Analytics), Bri-Mathias Hodge (NREL), Jennie Jorgenson (NREL), Chuck Kutscher (NREL), Ookie Ma (DOE), Robert Margolis (NREL), Mark Mehos (NREL), Mackay Miller (National Grid), David Mooney (NREL), Odette Mucha (DOE), Jimmy Nelson (Energy \& Environmental Economics), Robin Newmark (NREL), Gian Porro (NREL), Charlie Smith (Utility Variable Generation Integration Group), Mary Werner (NREL), Patrick Young (California Public Utilities Commission), Meredith Younghein (California Public Utilities Commission), and Guohui Yuan (DOE). The authors also thank Jarett Zuboy (consultant) and Mike Meshek (NREL) for editorial assistance.

This work was funded by the Solar Energy Technologies Office of the U.S. Department of Energy (DOE) Office of Energy Efficiency and Renewable Energy (EERE) under Contract No. DE-AC36-08GO28308.

John Frenzl of NREL designed the covers for the On the Path to SunShot report series. 


\section{List of Acronyms}

$\mathrm{AC}$

$\mathrm{ACE}$

AGC

CAES

CAISO

CCGT

CPUC

CSP

CT

DOE

DR

ERCOT

FERC

ISO

kWh

LCOE

LOLP

LTPP

MISO

MWac

MWh

NERC

NREL

PFR

PV

RE

RPS

RTO

TEPPC

TES

TWh

VG

WECC

WWSIS alternating current

area control error

automatic generation control

compressed-air energy storage

California Independent System Operator

combined cycle gas turbine

California Public Utilities Commission

concentrating solar power

combustion turbine

U.S. Department of Energy

demand response

Electric Reliability Council of Texas

Federal Energy Regulatory Commission

independent system operator

kilowatt-hour

levelized cost of energy

loss of load probability

long-term procurement plan

Midcontinent Independent System Operator

megawatts alternating current

megawatt-hour

North American Electric Reliability Corporation

National Renewable Energy Laboratory

primary frequency response

photovoltaic(s)

renewable energy

renewable portfolio standard

regional transmission organization

Transmission Expansion Planning Policy Committee

thermal energy storage

terawatt-hour

variable generation

Western Electricity Coordinating Council

Western Wind and Solar Integration Study 


\section{Executive Summary}

Achieving the U.S. Department of Energy's SunShot Initiative cost targets could greatly accelerate deployment of grid-integrated solar technologies. Global experience with increasing amounts of wind and solar on power systems has shown that variable generation resources can be integrated into the grid at penetrations well beyond current capacity. However, the prospect of dramatically increased photovoltaic (PV) deployment requires detailed examination to ensure that high-penetration solar technologies will provide their intended benefits, including reducing fossil fuel use and reducing the conventional capacity needed for reliable service. This report examines several aspects of how the bulk power system (consisting of traditional generators and the high-voltage transmission network) may need to evolve to accommodate the increased PV penetration resulting from achievement of the SunShot cost targets.

The characteristics of PV-generated electricity - including variability, uncertainty, and nonsynchronous generation - present challenges to large-scale, cost-effective grid integration by reducing PV's energy value (and thus its ability to displace fossil fuel use) and capacity value (and thus its ability to replace conventional capacity). One challenge to realizing the full energy value of $\mathrm{PV}$ is the need to accommodate the changing net load (normal load minus generation from variable solar and wind sources) associated with high midday PV generation and low electricity demand. This situation can create "overgeneration," when conventional dispatchable resources cannot be backed down further to accommodate the supply of PV and other variable generation (VG). Because of the threat of system disruptions from power supply exceeding demand, system operators might curtail PV output and thus reduce the economic and environmental benefits of PV energy. Similarly, the net load changes due to high PV penetration reduce PV's ability to displace conventional generation capacity during high-demand periods.

Accommodating the changes in net load resulting from increased VG penetration requires enhancements to a power system's "flexibility," or the ability of the grid and generation fleet to balance supply and demand over multiple time scales. Numerous technologies and strategies for increasing flexibility have been implemented already, are being implemented today, or are being developed. These approaches allow VG to be used directly to offset demand and increase instantaneous VG penetration, or they improve the alignment of VG supply and demand. We describe six of these flexibility options:

- System operation - Changing the way the grid is scheduled and dispatched, including changes to market rules, does not require new technologies and often represents the "least cost" way to aid VG integration.

- Flexible generation-Generators can respond better to the net load shape created by additional PV via increased ramp rates and ranges as well as the ability to start and stop more frequently.

- Reserves and stability services from VG-Inverter-based wind and solar plants can provide the grid's frequency response needs as these plants become a larger proportion of the generation fleet and new mechanisms are developed.

- Transmission and coordination-Balancing supply and demand over larger areas reduces net variability of both load and renewable resources such as PV owing to greater spatial diversity of $\mathrm{VG}$ resources. 
- Demand response-Voluntary load reduction or load shifting can provide multiple benefits to integrating solar and reducing curtailment, including reducing the dependence on partially loaded synchronous generators for providing frequency stability and operating reserves and changing the shape of the net load, which can reduce ramp rates, better align solar supply with demand, and reduce peak capacity needs.

- Energy storage - Like DR, energy storage can provide reserves, change net load shape to minimize ramping requirements, and shift supply of VG to periods of increased net load.

Deploying such grid-flexibility options can increase the energy and capacity value of PV to the grid. We use grid simulations to examine the impact of "near term" flexibility options in California, likely the first large region in the U.S. to experience significant impacts of PV on the transmission network; for this reason, we use California as a case study to examine how flexibility effects cost-effective integration of solar resources. Lessons learned from this region may assist other regions in developing strategies to mitigate the impacts of variability and uncertainty of the solar resource. Figure ES-1 demonstrates the levelized cost of energy (LCOE) from PV in California under two scenarios. The first is a limited-flexibility scenario, which reflects many historical grid operation practices that restrict participation of PV and other distributed resources in participation of grid services. The second is an enhanced-flexibility scenario which includes several grid-management techniques and technologies that will be or could be deployed by 2020. The base cost of PV assumes achievement of the SunShot target of 6 $\notin / \mathrm{kWh}$ as well as zero curtailment. The figure shows the steep increase in marginal PV LCOE (the incremental cost of an added unit of PV energy) due to curtailment at penetrations beyond about $10 \%$. Marginal costs are particularly important when comparing PV to other generating options - by the time PV provides $20 \%$ of annual electricity demand, marginal curtailmentrelated costs erase the benefits of achieving the SunShot targets. The figure also shows, however, that flexibility enhancements can minimize curtailment and keep PV competitive at penetrations at least as high as $25 \%$. Similarly, flexibility options such as demand response and energy storage can mitigate declines in capacity credit by exploiting how PV reduces the length of peak demand periods while also reducing the time between on- and off-peak periods. 


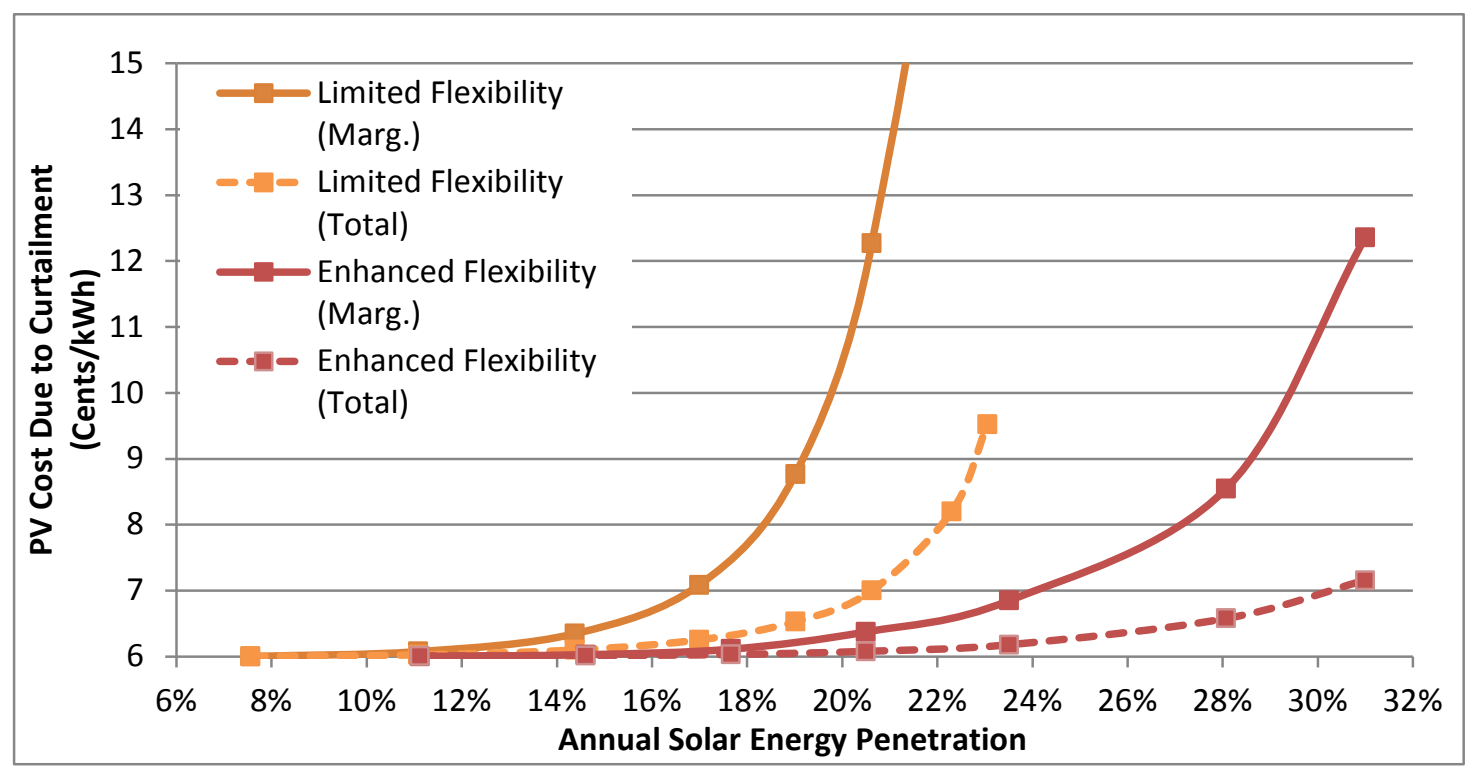

Figure ES-1. Marginal and average PV LCOE (based on SunShot goals) due to curtailment under increasing penetration of PV in California with low and enhanced grid flexibility

Looking beyond the 2020 timeframe, our analysis shows how energy storage could facilitate the cost-effective integration of even higher PV penetration. Figure ES-2 shows the marginal curtailment curve when concentrating solar power (CSP) with thermal energy storage (TES) is added to a system with significant PV. In this case, CSP is added starting when solar provides about $28 \%$ of total demand and marginal curtailment of PV is $30 \%$. Adding significantly more PV to this system will produce very high curtailment (greater than 50\%). The dashed line shows the transition to the addition of CSP with TES. Adding a unit of CSP with 6 hours of TES and enough capacity to provide about $1 \%$ of additional solar generation will reduce marginal curtailment to about $10 \%$, and this value could be lower with greater amounts of TES. This is one of many possible deployment scenarios - a more comprehensive analysis of renewable portfolios and flexibility options would help with determining the most cost-effective mix of technologies and strategies. 


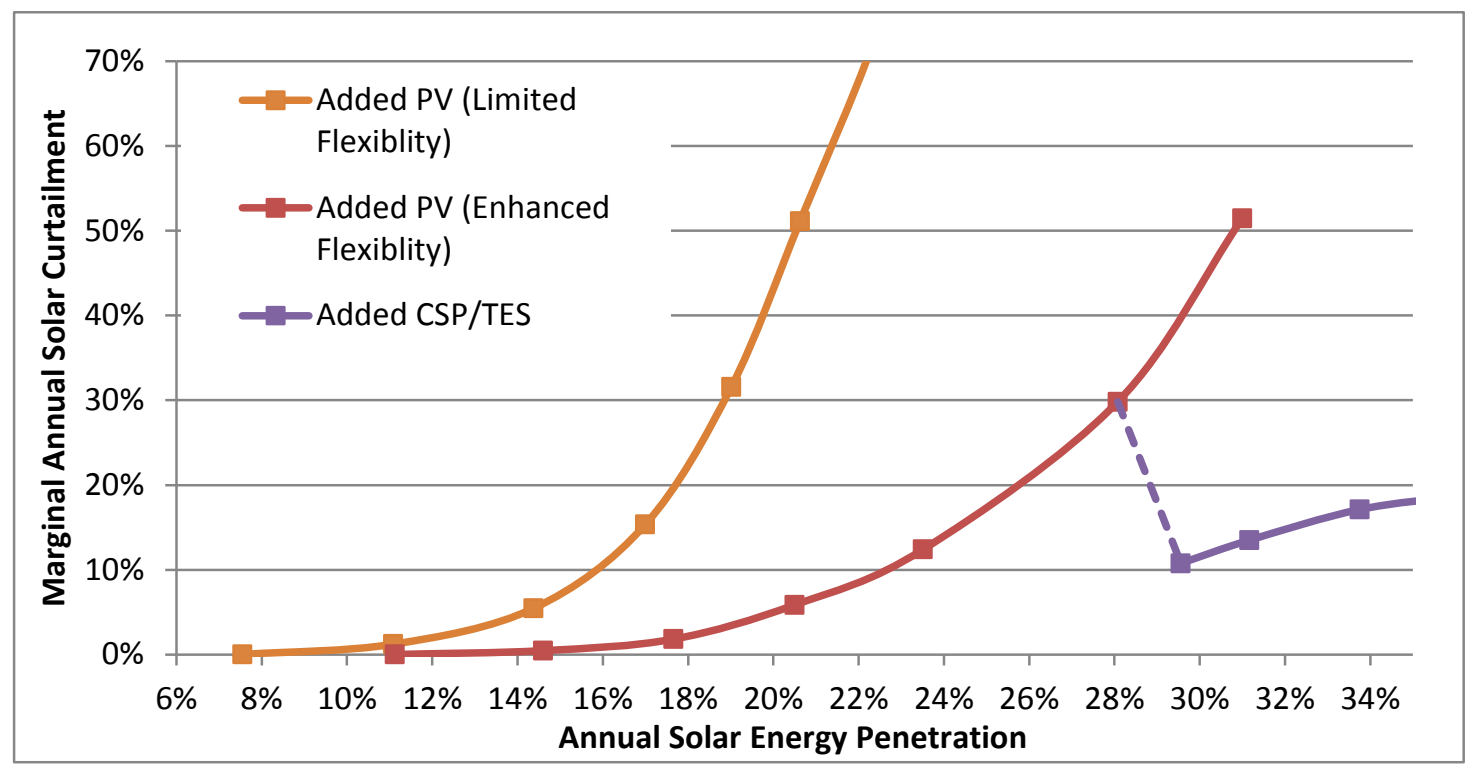

Figure ES-2. Marginal solar curtailment due to overgeneration under increasing penetration of solar when adding PV or PV and CSP with TES

Clearly, implementation of appropriate flexibility resources is critical to making high-penetration PV part of a reliable, cost-effective, and low-carbon electric power system. This includes ensuring generation resources on the grid are committed and dispatched economically, with the ability to respond to variations in net demand. Operating the generation fleet in the most economic manner will unlock inherent flexibility in the system. Such insights will increase the value of solar generation in terms of both energy and capacity.

Orderly and economic deployment of flexibility options will require a variety of stakeholder actions, including new market rules and mechanisms. Distributed resources, including rooftop PV and distributed storage, must be made visible to system operators, and operators might need the ability to control the output of these resources to maintain a reliable grid. Updated grid codes and use of existing technologies such as smart inverters will allow PV to participate in system dispatch and the maintaining of grid frequency and voltage. Accelerating the participation of demand loads in providing grid services can further accelerate cost-effective integration of solar resources. Finally, storage technologies, including CSP with TES, can drive solar technologies toward SunShot-level deployment and beyond - enabling solar to become a primary component of the de-carbonized electricity future. 


\section{Table of Contents}

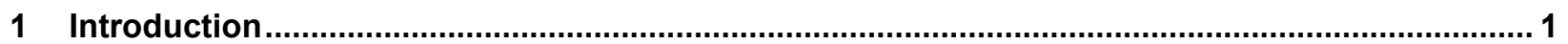

2 Challenges of Economic PV Grid Integration and the Need for Flexibility .................................. 2

2.1 Energy Value, Grid Flexibility, and the Challenge of Curtailment..........................................2

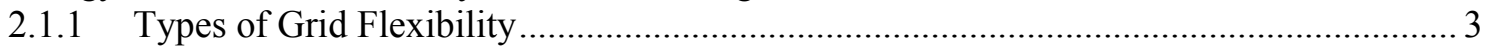

2.1.2 Impacts of PV on Net Load and the Problem of Overgeneration................................... 4

2.1.3 Modeling PV Generation and Curtailment with Limited Grid Flexibility ........................ 6

2.2 Capacity Value - The Challenge of Meeting Peak Demand ................................................... 13

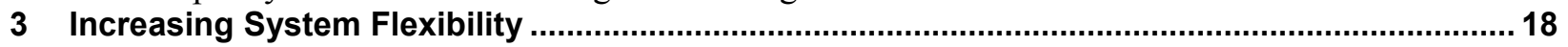

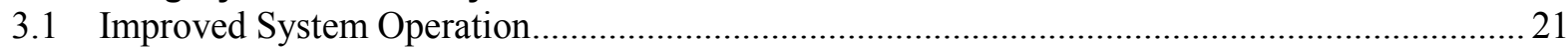

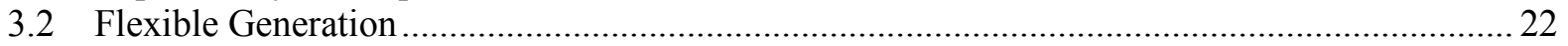

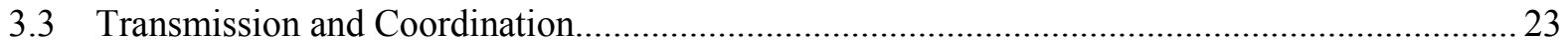

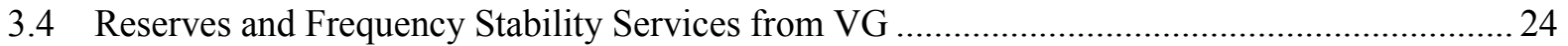

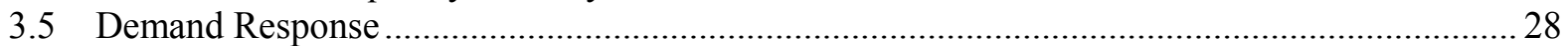

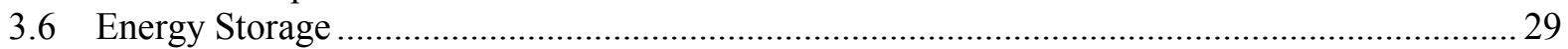

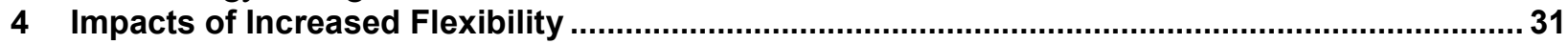

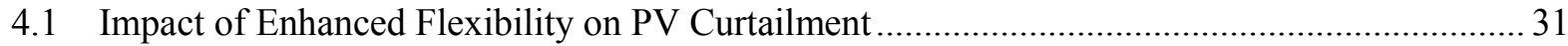

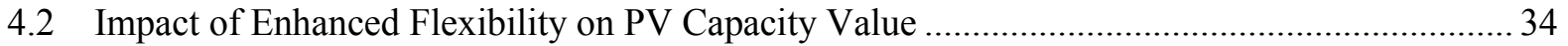

4.3 Beyond SunShot: Further Increasing Solar Deployment ..................................................... 38

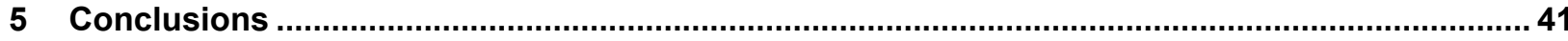

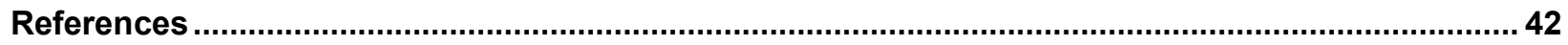

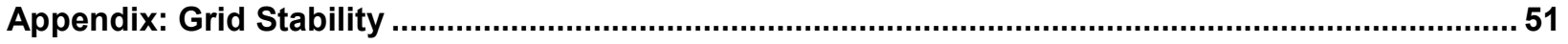




\section{List of Figures}

Figure ES-1. Marginal and average PV LCOE (based on SunShot goals) due to curtailment under increasing penetration of PV in California with low and enhanced grid flexibility..... ix

Figure ES-2. Marginal solar curtailment due to overgeneration under increasing penetration of solar when adding PV or PV and CSP with TES ........

Figure 1. The CAISO duck chart.....

Figure 2. Net load profiles for California on March 29 in a scenario with increasing penetration of solar, assuming no curtailment (penetrations are based on annual potential) ................................ 7

Figure 3. Modeled net load in California on March 29 in a scenario with $11 \%$ annual wind and $11 \%$ annual solar in a system with limited grid flexibility...........................................................

Figure 4. Used and curtailed solar in California on March 29 in a scenario with $11 \%$ annual wind and $11 \%$ annual solar in a system with limited grid flexibility ............................................... 9

Figure 5. Fraction of daily solar energy potential curtailed in a scenario with $11 \%$ and $15 \%$ annual solar considering operational constraints in a system with limited grid flexibility ....................... 10

Figure 6. Annual marginal and total solar curtailment due to overgeneration under increasing penetration of PV in California in a system with limited grid flexibility ............................................... 11

Figure 7. Marginal and average PV LCOE (based on SunShot goals) due to overgeneration under increasing penetration of PV in California in a system with limited grid flexibility ............. 12

Figure 8. Load and net load profiles for increasing levels of PV in California, July 27-29................... 13

Figure 9. Impact of increased PV on net load in California and decline in capacity credit, July 28 ......... 15

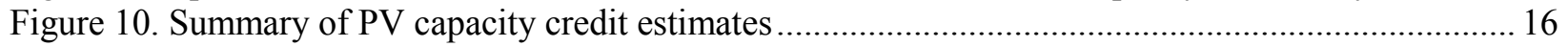

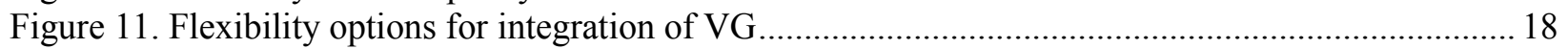

Figure 12. Reduction in solar variability due to spatial diversity ......................................................... 23

Figure 13. Impact of existing pumped-hydro storage in California on March 29th in a simulated system

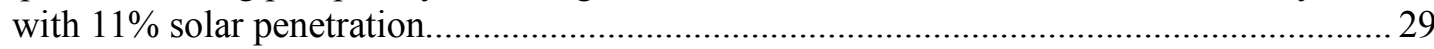

Figure 14. Net load on March 29 in a scenario with 15\% annual solar and limited or enhanced

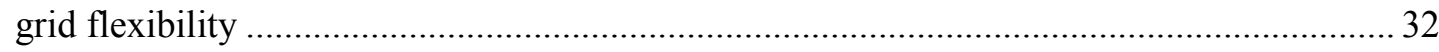

Figure 15. Impact of enhanced flexibility on PV curtailment on March 29 in a scenario with $15 \%$ annual

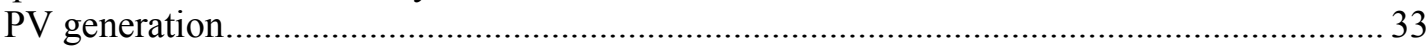

Figure 16. Marginal and average curtailment due to overgeneration under increasing penetration of PV

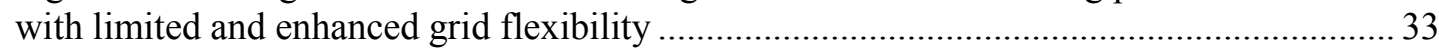

Figure 17. Marginal and average PV LCOE (based on SunShot goals) due to overgeneration under increasing penetration of PV in California with limited and enhanced grid flexibility .......... 34

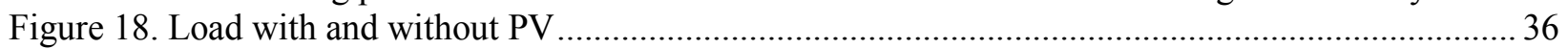

Figure 19. Narrowing of net peak and amount of storage needed to deliver a 1,325-MW peak demand

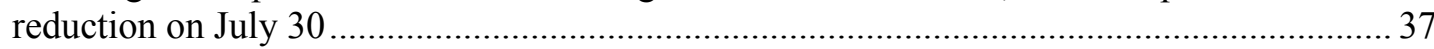

Figure 20. Hours of storage needed to reduce peak demand by 1,325 MW and 2,650 MW as a function of

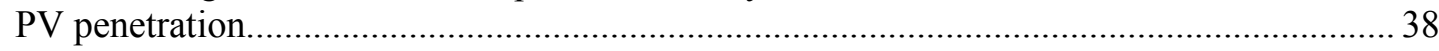

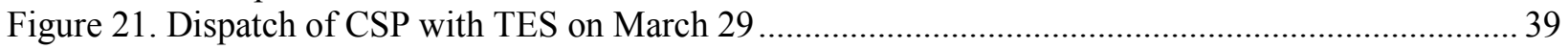

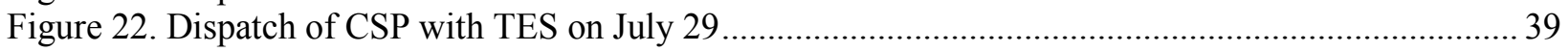

Figure 23. Marginal solar curtailment due to overgeneration under increasing penetration of solar when

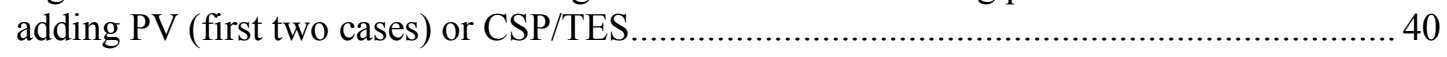

Figure 24. Electricity demand exceeds electricity generation, and frequency drops .............................. 52

Figure 25. Visualization of transient stability with synchronous generators and wind power plants......... 53

\section{List of Tables}

Table 1. Characteristics of PV Electricity Generation and Associated Integration Challenges................... 2

Table 2. Types of Grid Flexibility .................................................................................................. 3

Table 3. Six Grid Flexibility Options and How They Mitigate Challenges that Lead to Solar Curtailment20 


\section{Introduction}

Achieving the U.S. Department of Energy's SunShot cost targets for photovoltaics (PV) and concentrating solar power (CSP) could greatly accelerate economic deployment of solar technologies onto the grid. The SunShot Vision Study (DOE 2012) projected that achieving SunShot cost-reduction goals could increase the deployment of solar technologies in the United States to $330 \mathrm{GW}$, or $14 \%$ of total electricity demand, by 2030 (DOE 2012). However, this growth will occur at different rates, with early adoption in states such as California, which combines aggressive renewable targets with an excellent solar resource. In 2014, solar energy contributed about $6 \%$ of electricity demand in the state, and projections estimate this could approach $20 \%$ by $2020 .{ }^{1}$ As PV becomes a significant source of generation in various regions, utilities and system operators ${ }^{2}$ must ensure that the grid is operated to maintain reliable service while maximizing the usefulness of solar energy. Lessons learned in one region can be applied to others, helping ease the integration of solar in regions with less experience. More than a decade of U.S. and international experience with increasing penetration of wind and solar on grid systems has provided evidence that such variable generation (VG) resources can be integrated into the grid at penetrations well beyond current levels. However, the prospect of dramatically increased PV deployment requires more detailed examination to ensure that solar technologies will provide their intended benefits, including reducing fossil fuel use and reducing the conventional capacity needed for reliable service.

This report examines several aspects of how the bulk power system (consisting of traditional generators and the high-voltage transmission network) may need to evolve to accommodate the increased PV penetration resulting from achievement of the SunShot cost targets. ${ }^{3}$ Specifically, the report first discusses the challenges of operating the grid with increased penetration of PV in a "business as usual" future. It identifies the key challenge of curtailment - the need to reduce PV output to maintain power system reliability - that could result if the grid is not operated in a more flexible manner. Increased curtailment, along with decreased capacity value (the ability of PV to replace conventional capacity), could reduce the economic competitiveness of PV, increasing its costs and decreasing its benefits. Next, the report discusses six sources of grid flexibility that are being deployed or can be deployed in the near future: improved system operation, flexible generation, reserves and stability services from VG, transmission and regional coordination, demand response (DR), and energy storage. Finally, the impact of improved grid flexibility is evaluated, showing how annual solar penetrations of $25 \%$ and beyond are achievable while maintaining a stable and reliable grid. While we use California as a specific case study, many of the strategies used to cost-effectively integrate solar are generally applicable, and lessons learned for a specific region can provide insights that can be applied to power system throughout the United States and internationally.

\footnotetext{
${ }^{1}$ The 2014 estimate includes 12.6 TWh of utility-scale (PV + CSP) generation (CEC 2014) and about 5.1 TWh from rooftop PV (GTM \& SEIA 2015).

${ }^{2}$ Throughout this document, we use the term "system operator" to refer to the balancing area authorities responsible for balancing supply and demand through generator scheduling and dispatch. In areas with wholesale markets, these authorities are referred to as "independent system operators" (ISOs) or "regional transmission organizations" (RTOs). In regions without markets, balancing authorities are typically large vertically integrated utilities or federal power marketing administrations.

${ }^{3}$ Another On the Path to SunShot report (Palmintier et al. 2016) discusses the integration of PV on the distribution system.
} 


\section{Challenges of Economic PV Grid Integration and the Need for Flexibility}

Solar-generated electricity, particularly from PV, has a number of characteristics that present challenges to cost-effective grid integration. Table 1 summarizes three key characteristics of PV generation, including variability, uncertainty, and non-synchronous generation. ${ }^{4}$ Each of these characteristics produces an economic challenge to $\mathrm{PV}$ integration - reducing the energy value (such as the ability to avoid fossil fuel use) and capacity value (the ability to replace conventional capacity) of PV. Note that CSP, particularly when deployed with thermal energy storage (TES), does not present the same challenges. The potential opportunities for CSP to increase overall solar penetration are discussed in Section 4.

Table 1. Characteristics of PV Electricity Generation and Associated Integration Challenges

\begin{tabular}{llll}
\hline \multirow{2}{*}{ Solar Characteristic } & \multicolumn{2}{c}{ Potential Economic Challenge to Integration } \\
Eariability & $\begin{array}{l}\text { PV output can vary } \\
\text { as underlying } \\
\text { resource fluctuates. }\end{array}$ & $\begin{array}{l}\text { Supply/demand mismatch } \\
\text { coupled with generator } \\
\text { inflexibility leads to } \\
\text { curtailment. }\end{array}$ & $\begin{array}{l}\text { PV may not be able to replace } \\
\text { conventional capacity during } \\
\text { periods of peak demand. }\end{array}$ \\
\hline Uncertainty & $\begin{array}{l}\text { PV output cannot be } \\
\text { predicted with perfect } \\
\text { accuracy. }\end{array}$ & $\begin{array}{l}\text { Part-load operation of thermal } \\
\text { plants for operating reserves } \\
\text { leads to curtailment. }\end{array}$ & $\begin{array}{l}\text { Capacity needed for provision } \\
\text { of operating reserves. }\end{array}$ \\
\hline $\begin{array}{l}\text { Non- } \\
\text { synchronous } \\
\text { generation }\end{array}$ & $\begin{array}{l}\text { PV does not currently } \\
\text { help maintain system } \\
\text { frequency. }\end{array}$ & $\begin{array}{l}\text { Part-load operation of thermal } \\
\text { plants for provision of } \\
\text { frequency response leads to } \\
\text { curtailment. }\end{array}$ & $\begin{array}{l}\text { Capacity needed for provision } \\
\text { of frequency response. }\end{array}$ \\
\hline
\end{tabular}

The following subsections discuss each of the two economic challenges to PV deployment identified in Table 1, including the origin of the economic challenge and how the challenge is related to grid flexibility (the ability of system operators to respond to increased variability and uncertainty). Finally, each subsection provides an example of how PV's benefits can decline in an inflexible grid.

\subsection{Energy Value, Grid Flexibility, and the Challenge of Curtailment}

This subsection discusses the ability of PV to provide energy and replace fossil fuel generation. As described in Table 1, PV's generating characteristics present challenges to realizing PV's full energy value. With high penetrations of VG resources, and without measures to enhance grid flexibility, not all of the electricity generated by PV can serve demand. As a result, some PV electricity must be curtailed, forcing the overall levelized cost of energy (LCOE) of PV resources to rise. Below, Section 2.1.1 describes how power system operators use different sources of grid flexibility to balance supply and demand. Section 2.1.2 discusses the potential limits to these sources of flexibility associated with high-penetration PV in a power system, and how these

\footnotetext{
${ }^{4}$ Non-synchronous generation means that PV does not generate electricity via a large rotating turbine. The implications of this, as well as an introduction to frequency stability are discussed in more detail in Section 3.3 and the Appendix.
} 
limits can result in curtailment. Section 2.1.3 models PV generation and curtailment in a system with limited grid flexibility. This information provides context for the presentation of options for maintaining PV's energy value in Sections 3 and 4.

\subsubsection{Types of Grid Flexibility}

Power system operators maintain a reliable grid by constantly balancing consumer demand for energy with generation from a variety of resources. The ability of a power system to accommodate the changes in electricity demand is often expressed in terms of its "flexibility." While there is no uniform definition of grid flexibility, it generally refers to the ability of the grid and generation fleet to balance supply and demand over multiple time scales, which becomes particularly important with increased variability and uncertainty of net load (Ela et al. 2014). Table 2 summarizes four categories of grid flexibility, which are described briefly below and discussed in Section 3.

Table 2. Types of Grid Flexibility

\begin{tabular}{ll}
\hline Type & Description \\
\hline Generator flexibility & Ability of conventional generation to vary output over various time scales \\
\hline Storage flexibility & $\begin{array}{l}\text { Ability to store energy during periods of low demand and release that } \\
\text { energy during periods of high demand }\end{array}$ \\
\hline Geographic flexibility & $\begin{array}{l}\text { Ability to use transmission to share energy and capacity across multiple } \\
\text { regions }\end{array}$ \\
\hline Load flexibility & Ability to vary electricity demand in response to grid conditions \\
\hline
\end{tabular}

Generator flexibility reflects the ability of conventional power plants to vary output to serve variations in electricity demand. The ability of generators to vary output is based on a host of technical, economic, and institutional factors. Most thermal plants have a maximum ramp rate (ability to rapidly change output) and ramp range (minimum and maximum output). The ramp range is limited by the plant's minimum stable operating point, below which the plant cannot run. Because certain plant types cannot be started and stopped quickly, they are forced to remain online and operating above this minimum generation level. Finally, there are also minimum generation constraints due to the need to provide online (spinning) capacity for addressing uncertainty over multiple time frames. This includes operating reserves needed to maintain frequency stability - that is, the ability of the power system to remain operational after large, sudden mismatches between generation and load. A primer on frequency stability is provided in the appendix, while additional discussion of operating reserves is provided in Section 3.3. These services are typically provided by partially loaded thermal and hydroelectric units. The energy generated by these units when providing operating reserves represents energy that cannot be provided by $\mathrm{PV}$.

Storage flexibility represents the ability to store energy during periods of low demand, and releasing this storage energy at a later time. In this manner, storage changes both the load (providing load flexibility) and acts as a generator (providing generator flexibility). 
Geographic flexibility reflects the ability to share energy and capacity across regions, which requires both transmission capacity and institutions that allow this transfer. Institutions include markets or some other mechanism to buy and sell energy.

Finally, load flexibility reflects the ability to change the demand for electricity in response to grid conditions. This includes a variety of market mechanisms to incentivize consumers to use electricity when it is cheapest. These mechanisms are detailed in Section 3.

Combined, these four grid flexibility options are used by system operators to balance the supply of generation with demand.

\subsubsection{Impacts of PV on Net Load and the Problem of Overgeneration}

One challenge to realizing the full energy value of PV is accommodating the change in net load (normal load minus generation from VG solar ${ }^{5}$ and wind) associated with high midday PV generation and low electricity demand. This situation can create "overgeneration" conditions, during which conventional dispatchable resources cannot be backed down further to accommodate the supply of VG, and the supply of power could exceed demand (Younghein and Martinot 2015). Without intervention, generators and certain motors connected to the grid would increase rotational speed, which can cause damage. To avoid overgeneration, system operators may curtail wind or PV output. PV generation is curtailed by either reducing output from the inverter or disconnecting the plant. This requires that a plant or system operator have physical control of the generation resource, which is typical for large renewable power plants but uncommon for smaller systems, particularly distributed or rooftop PV systems. Curtailment has the undesirable trait of reducing the economic and environmental benefits of VG. Each unit of VG energy curtailed represents a unit not sold to the grid and a unit of fossil fuel energy not avoided. As the amount of curtailment increases, the overall benefits of additional PV may drop to the point where additional installations are not worth the cost (Cochran et al. 2015).

The change in net load shape and associated challenge of grid operation were highlighted in 2013, when the California Independent System Operator (CAISO) published a "duck chart" showing the potential for overgeneration at relatively high PV penetration, especially considering the host of technical and institutional constraints on power system operation (CAISO 2013). ${ }^{6}$ Although California likely will be the first place in the continental United States that must address the challenges of operating a large grid with high PV deployment, these issues will arise elsewhere as PV becomes more cost competitive in locations with lower-quality solar resources. ${ }^{7}$ Identifying and addressing the challenges illustrated in the duck chart in a region such as California will provide examples for other regions as PV becomes more cost competitive in locations with lower quality solar resources.

\footnotetext{
${ }^{5}$ VG solar includes PV and CSP without TES.

${ }^{6}$ The name is derived from the chart's resemblance to the profile of a duck. Details on the modeling that led to creation of the duck chart are in CAISO studies (CAISO 2010, 2011a, 2011b; Liu 2014a, 2014b, 2014c).

${ }^{7}$ Smaller grids, such as those in Hawaii have seen significant penetration of PV (Schuerger et al. 2013) as have other regions of the world such as Germany (Stetz et al. 2015). Many of the flexibility options discussed in this document are being deployed in those regions to successfully integrate PV.
} 
Figure 1 shows the duck chart, in which each line represents the net load. Note that this chart represents only the part of California grid operated by the CAISO, which represents about $80 \%$ of the total state demand. ${ }^{8}$ The "belly" of the duck represents the period of lowest net load, when PV generation is at a maximum. The belly grows as PV installations increase between 2012 and 2020. As a result, it may become increasingly challenging to have sufficient capacity online to meet the increased ramp rate of net load that occurs when PV output drops in the evenings. In the 2020 projection, starting at about $9 \mathrm{am}$, the system operator must be able to reduce generator output from about $20,000 \mathrm{MW}$ to $12,000 \mathrm{MW}$ by turning generators down or off. However, the operator must also be able to ramp back up to the peak demand of about 26,000 MW occurring at $8 \mathrm{pm}$. The operator may not be able to back down sufficient generation, which would force PV curtailment. Addressing this issue requires increased grid flexibility.

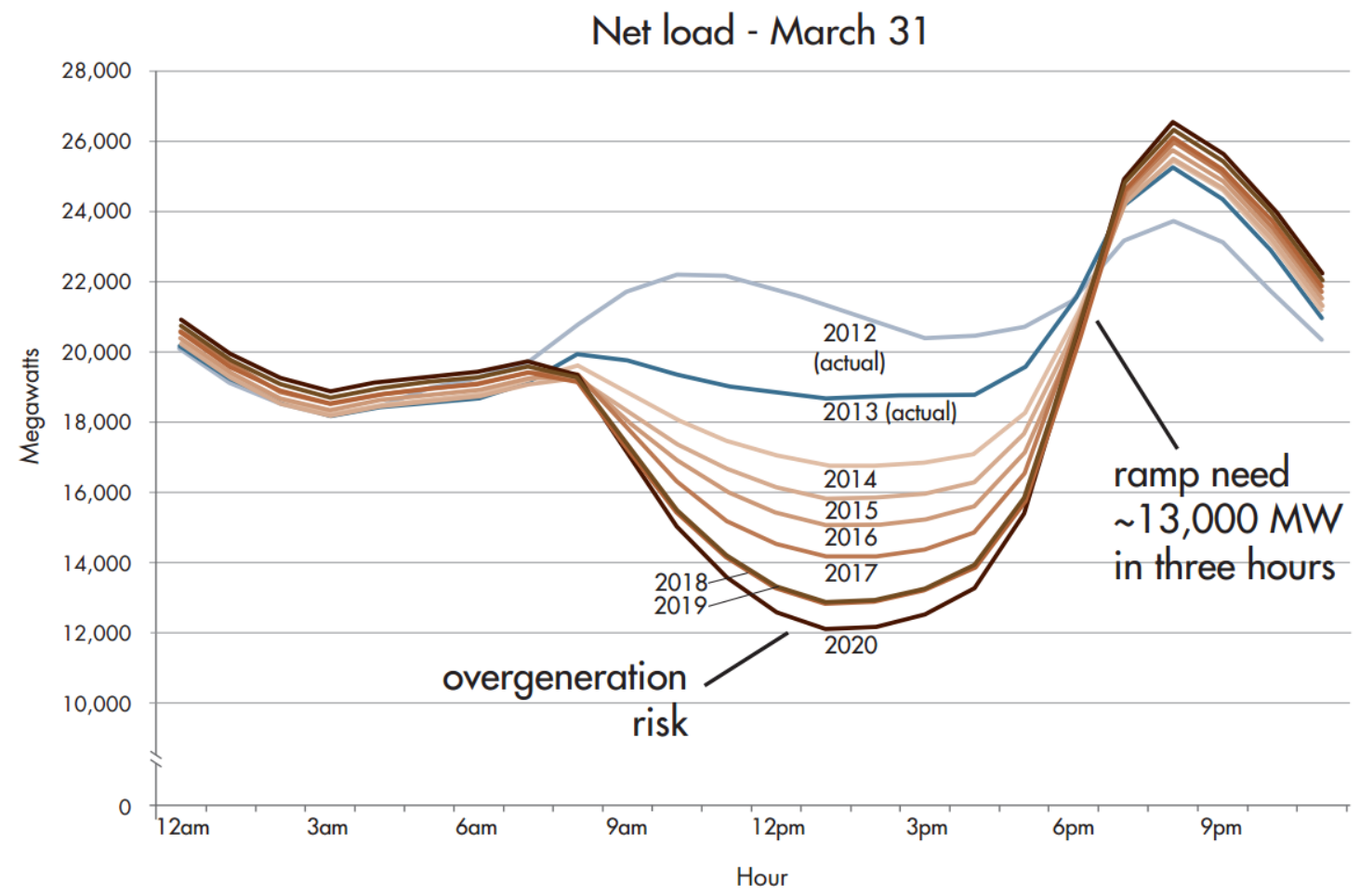

Figure 1. The CAISO duck chart

Source: CAISO 2013

In addition to technical challenges of meeting increased variability, additional factors that limit generator flexibility include contractual and institutional restrictions on plant operation, including long-term "must take" contracts, self-scheduling, and combined heat and power plants (Younghein and Martinot 2015). These constraints also apply to imports of out-of-state generation, which may have established contracts and restrictions on flexible operation (Lew et al. 2015).

Examining the relationship between system flexibility and curtailment can help determine the potential of PV to economically supply substantial amounts of energy to a power system.

\footnotetext{
${ }^{8}$ For more details about CAISO, see http://www.caiso.com/Pages/default.aspx.
} 


\subsubsection{Modeling PV Generation and Curtailment with Limited Grid Flexibility}

This subsection demonstrates the impact of limited grid flexibility on curtailment and the economics of PV energy in a SunShot future. We start by generating scenarios of increased solar penetration, and then we examine the resulting impacts on system operation and corresponding curtailment.

Figure 2 shows normal load and net load with wind and solar (combined PV and CSP) profiles in California. The scenario assumes a fixed amount of wind with the potential to meet $11 \%$ of the state's annual demand. ${ }^{9}$ Three potential penetration levels of solar are also included: zero, $7.5 \%$, and $11 \% .{ }^{10}$ Each case assumes $1.5 \%$ of total demand from CSP, with the remainder derived from PV. The vast majority of the CSP does not have thermal storage, so it produces output profiles similar to those from PV. The renewable generation profiles were derived from those developed for the Western Wind and Solar Integration Study (WWSIS) (GE Energy 2010) and refined for phase 2 of that study (Lew et al. 2013).

Figure 2 shows the profiles for March 29, which is the day in California with the lowest net load and likely the most challenges for PV integration and possible overgeneration. ${ }^{11}$ Because of the relatively low load, the potential proportion of generation from wind and solar on this day is higher than average-about $16 \%$ from wind and $0 \%, 12.5 \%$, and $18 \%$ from solar in the three solar cases. The figure also shows very low net loads that would need to be met by the remaining generation fleet, assuming all solar generation could be used. In this example, the new minimum net load point (as low as about 7,700 MW in the $11 \%$ solar case) is shifted from 4 am to noon.

\footnotetext{
${ }^{9}$ This represents a relatively small increase in wind generation. In 2014, California generated 12.7 TWh from wind in-state and imported another $12.7 \mathrm{TWh}$ of wind for a total of $25.4 \mathrm{TWh}$, which provides about $8.6 \%$ of the total demand (296.6 TWh).

${ }^{10}$ Penetration of utility-scale solar in 2014 was about $4.2 \%$, or about $6 \%$ including rooftop solar (CEC 2014). Based on recent projections, $11 \%$ solar penetration could be achieved as early as the end of 2017 (GTM \& SEIA 2015).

${ }^{11}$ Versions of several figures provided in this work have been previously presented in Denholm et al. (2015).
} 


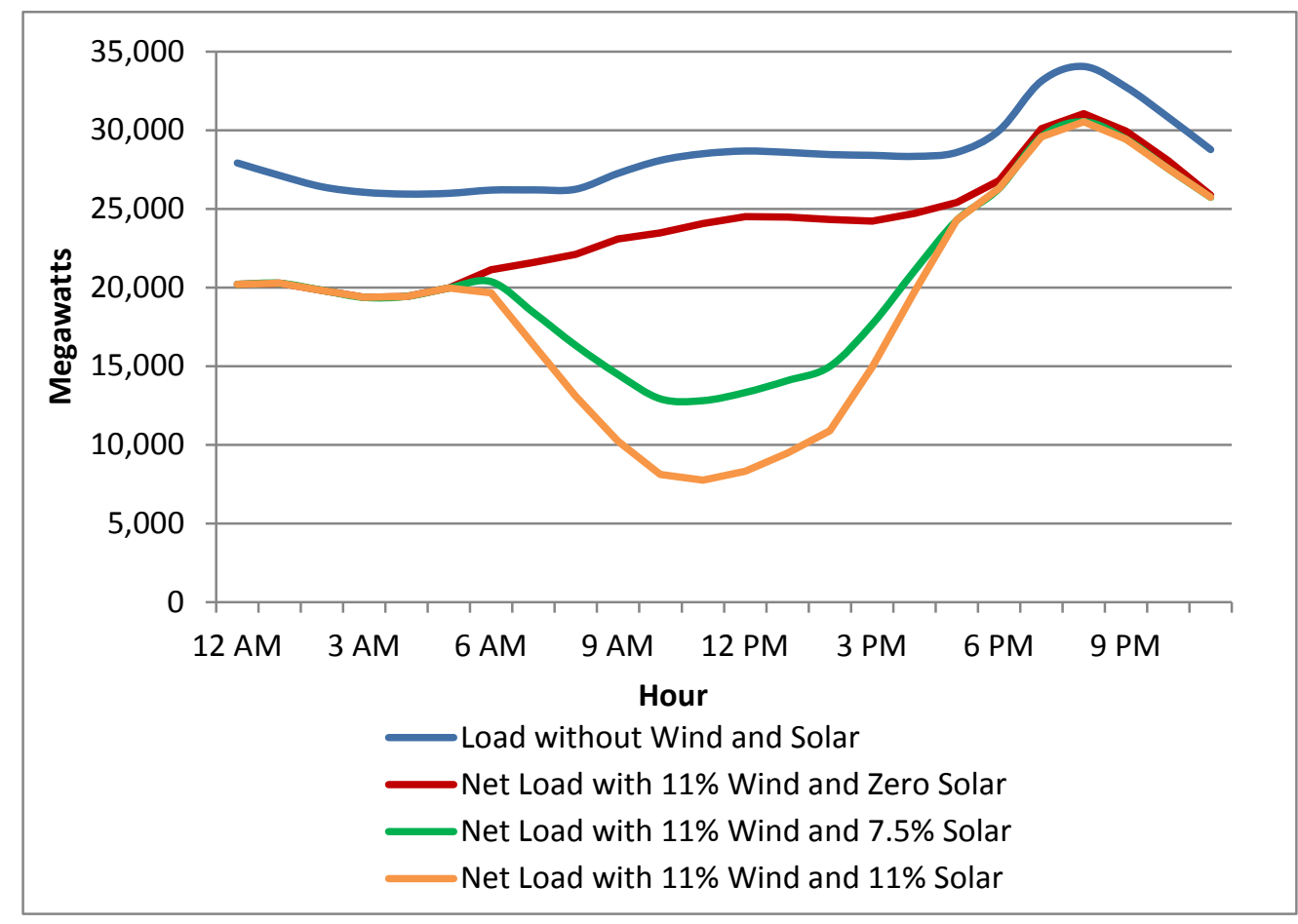

Figure 2. Net load profiles for California on March 29 in a scenario with increasing penetration of solar, assuming no curtailment (penetrations are based on annual potential)

The net load shown in Figure 2 does not consider the constraints that actually occur in operating the system. To examine the impact of PV on system operation, we simulate the California grid using the PLEXOS production-cost model. Note that our analysis considers the entire state of California, including the service territories of all investor-owned and publicly owned utilities. The model simulates the operation of all power plants throughout the Western Interconnection. The data and assumptions are derived from a combination of the Western Electricity Coordinating Council (WECC) Transmission Expansion Planning Policy Committee (TEPPC) 2024 Common Case (WECC 2014) and the CAISO 2014 Long-Term Procurement Plan (LTPP) data set $^{12}$ (CPUC 2013a), with significant modifications derived from Brinkman et al. (2016) and Denholm et al. (2015).

We generated two general scenarios. The first is a "limited flexibility" case that includes a set of restrictive assumptions about grid operations in California. Key assumptions in this limited flexiblity case include the following:

- There are no net exports of electricity from California. ${ }^{13}$

- No new DR or storage is installed beyond what is in service in $2015 .{ }^{14}$ While existing pumped storage (about 2,500 MW) is allowed to respond to net load, this simulation does not

\footnotetext{
12 Additional discussion of the California LTPP model can be found in Eichman et al. (2015).

13 This is based on the fact that California has historically been a net importer, and there are limited market mechanisms to allow California to sell excess renewable energy out of state. Further discussion is provided in Liu (2014a).
} 
consider the 1,325 MW of additional storage that will be deployed as part of the California storage mandates; this is evaluated in later sections.

- Twenty-five percent of all generation within certain zones must be met with local fossil or hydro generation. ${ }^{15}$

- Instantaneous penetration of VG (including PV, wind, and CSP without TES) is limited to $60 \%$ of the normal load. ${ }^{16}$

- VG cannot be used to provide reserves.

Grid simulations were performed with these assumptions for a variety of penetrations of solar to calculate the amount of curtailed energy. In the case with $7.5 \%$ annual solar, the system is flexible enough to accommodate changes in the net load without the need for significant curtailment. However, in the $11 \%$ annual solar case, the system is unable to accommodate all solar generation. Figure 3 shows the simulated net load resulting from the $11 \%$ solar case for March 29. In this case, the actual net load met by conventional generation is not allowed to drop below about 12,600 MW. This represents a California system-wide minimum generation constraint, meaning online generators in California - and certain contracted generators outside California - cannot reduce output below this level, in order to satisfy operating reserves from conventional resources and other "traditional" system limitations. ${ }^{17}$ This minimum generation level is an important measure of the overall flexibility of the power grid.

\footnotetext{
${ }^{14} \mathrm{Up}$ to about $1.3 \%$ of peak demand (as much as about $900 \mathrm{MW}$ during periods of peak demand) can be shifted via economic DR programs. This value is about equal to the existing "price response" DR available from the three investor-owned utilities in the CAISO territory (CPUC 2015).

${ }^{15}$ In the database from which our analysis is derived (the Low Carbon Grid Study from Brinkman et al. 2016), the zones that require the $25 \%$ local generation limit account for $77 \%$ of all California load. The Diablo Canyon nuclear power plant does not contribute to the local generation requirement, which is a conservative assumption based on the fact that nuclear power plants typically do not vary load to provide operating reserves. For additional analysis of the impact of the local generation requirement, see Nelson (2014) and Brinkman et al. (2015).

${ }^{16}$ This is based on the provision that renewables cannot provide reserves and the concern that, at $60 \% \mathrm{VG}$ penetration without VG providing reserves, "the grid may not be able to prevent frequency decline following the loss of a large conventional generator or transmission asset" (CAISO 2013).

17 This minimum generation value is below a CAISO-only estimate of the lowest net load point of about 15,000 MW in the current system (Bouillon 2014). The lower minimum generation point in this analysis results from several factors, including greater flexibility from customer-owned cogeneration and eliminating certain fixed-schedule contractual limitations on plant dispatch. We assume this flexibility will occur to avoid negative prices that may occur in the CAISO market under overgeneration conditions. Also, Diablo Canyon unit 2 was out for maintenance on this day in the simulation, which removed 1,122 MW of non-dispatchable capacity. The net load in the system is less than 15,000 MW during only 34 hours of the year in this simulation.
} 


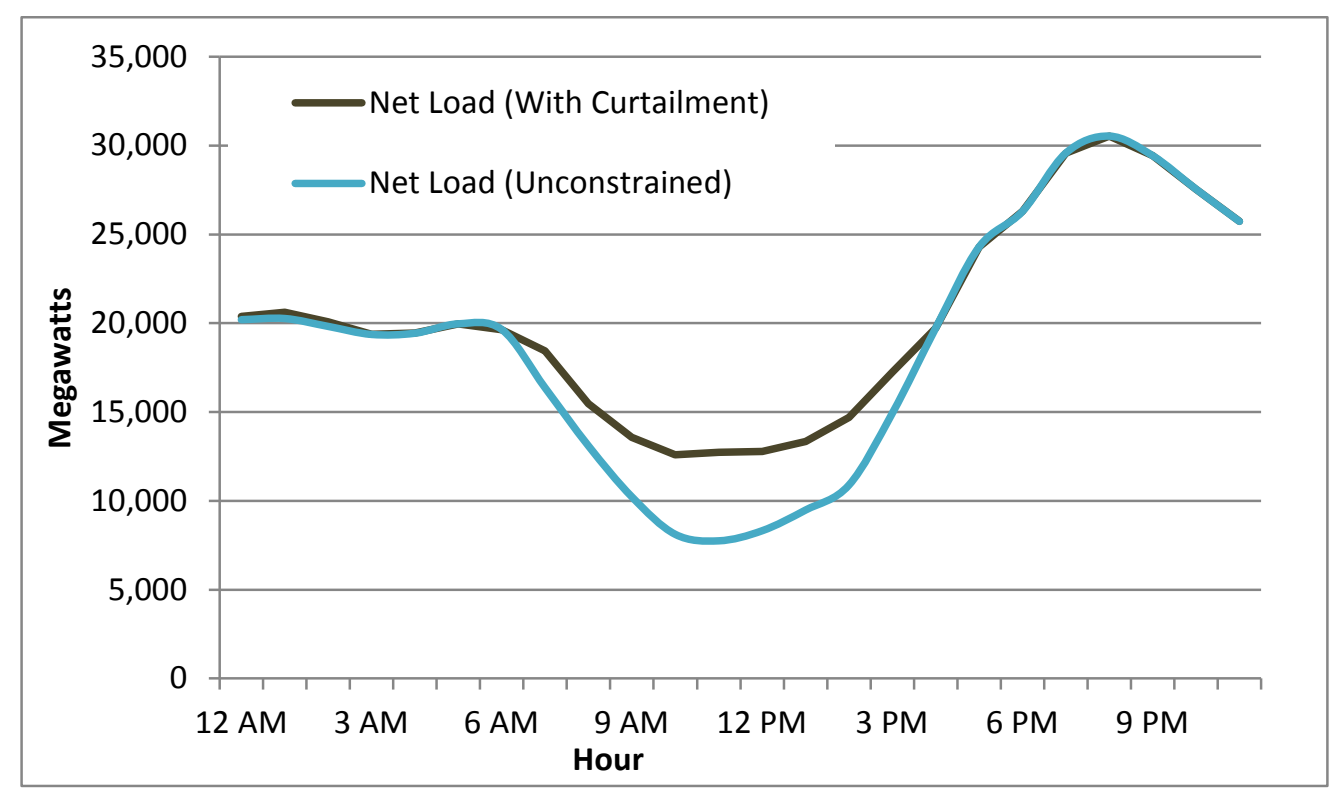

Figure 3. Modeled net load in California on March 29 in a scenario with $11 \%$ annual wind and $11 \%$ annual solar in a system with limited grid flexibility

These constraints result in the curtailed energy illustrated in Figure 4, which includes the combined solar potential, the amount of solar actually used by the system, and the curtailed solar. Overall, about $4 \%$ of the potential solar energy on this day is curtailed. However, during most days, there is little or no curtailment; over the entire year, only about $0.4 \%$ of potential solar generation is curtailed.

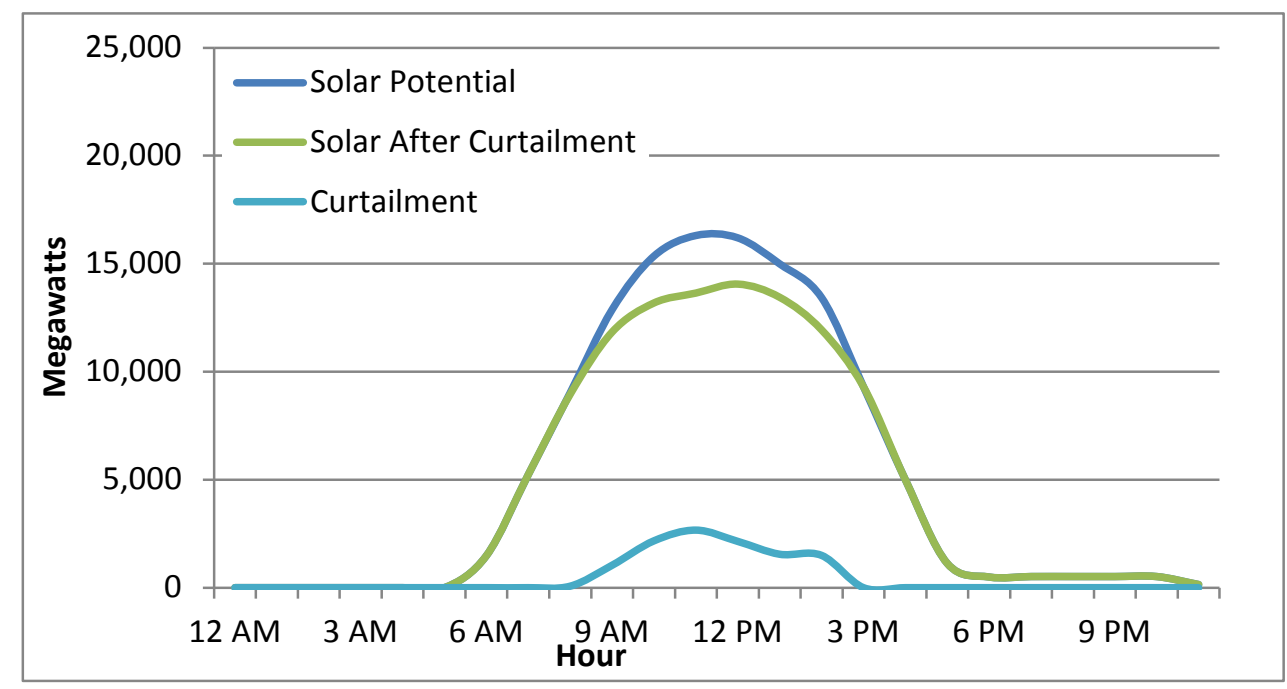

Figure 4. Used and curtailed solar in California on March 29 in a scenario with $11 \%$ annual wind and $11 \%$ annual solar in a system with limited grid flexibility 
Without flexibility changes that allow conventional generation to reduce output, only a relatively small amount of additional PV generation can be accommodated on March 29. As more PV is added, there will also be a greater number of days with PV curtailment. Figure 5 shows the fraction of daily solar energy curtailed for each day of the year for the $11 \%$ annual solar potential case (blue) as well as a $15 \%$ annual solar potential case (red). Note that we add only PV in these cases; the impact of adding CSP/TES is discussed in Section 4. In the 11\% solar potential case, solar energy is curtailed due to system flexibility limits on a total of 57 days, and on 49 of those days the amount of solar curtailed is less than $5 \%$ of potential generation. Moving to the $15 \%$ solar case increases the number of days of curtailed solar to 139 , and on 16 days greater than $10 \%$ of solar potential is curtailed.

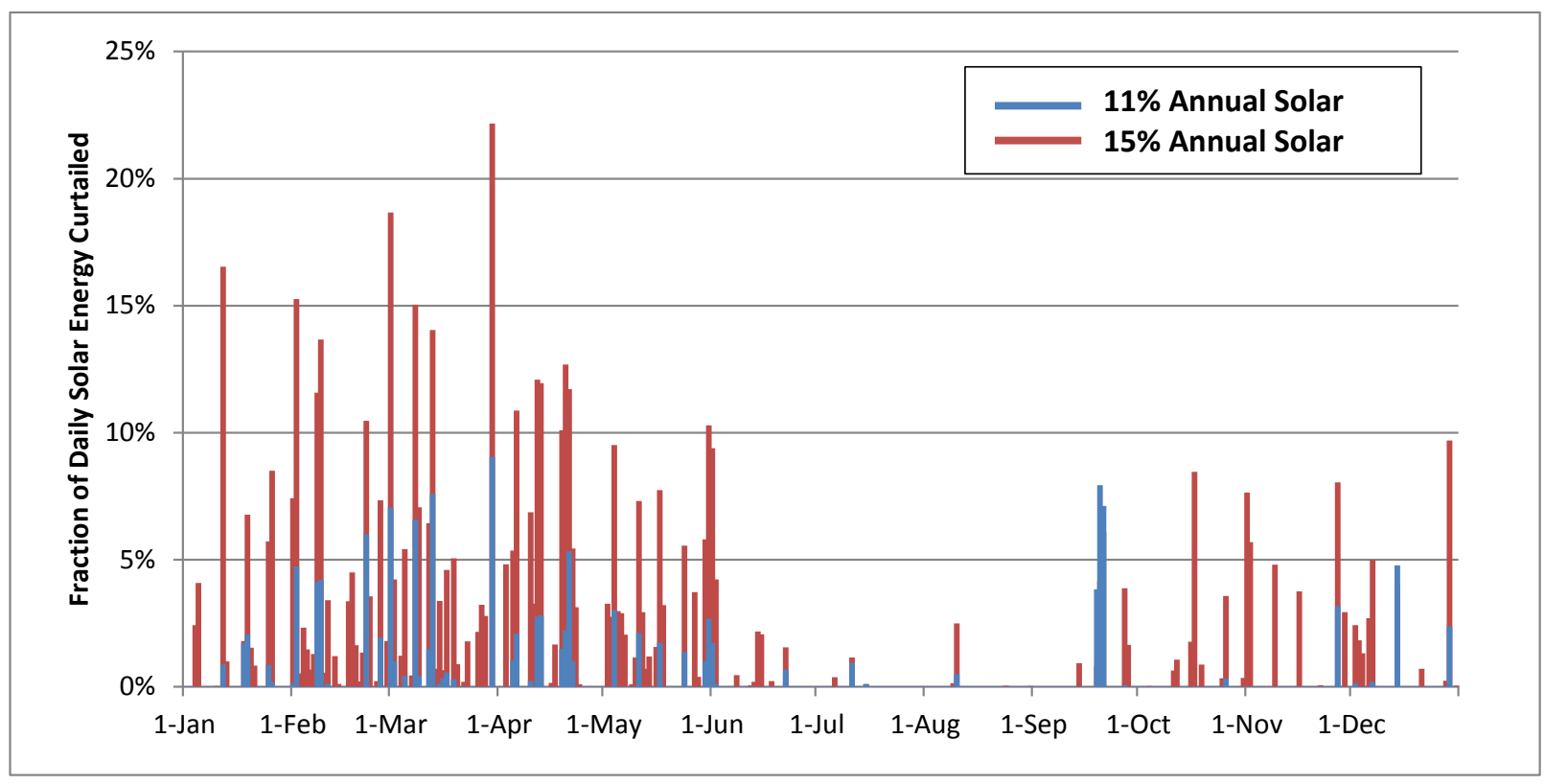

Figure 5. Fraction of daily solar energy potential curtailed in a scenario with $11 \%$ and $15 \%$ annual solar considering operational constraints in a system with limited grid flexibility

On an annual basis, increasing the annual solar potential from $11 \%$ to $15 \%$ increases the total curtailment from $0.4 \%$ to $1.6 \%$ of potential solar generation. However, marginal curtailmentthat is, the curtailment of additional PV required to increase solar potential from one level to the next-increases at a greater rate. Increasing annual solar potential from $7.5 \%$ to $11 \%$ requires that only $1.2 \%$ of the added PV generation be curtailed. However, increasing annual solar potential from $11 \%$ to $15 \%$ requires that about $5.5 \%$ of the added PV generation be curtailed. This illustrates the diminishing returns that can result from adding PV to a system with limited grid flexibility, and it highlights the importance of analyzing total and marginal curtailment rates in such systems. 
Figure 6 illustrates the total and marginal curtailment results from the addition of PV. The annual solar penetration is the fraction of total demand in California met by PV (plus the fixed amount of CSP), after removing curtailed solar energy. ${ }^{18}$ The points on the curve are the actual modeled scenarios.

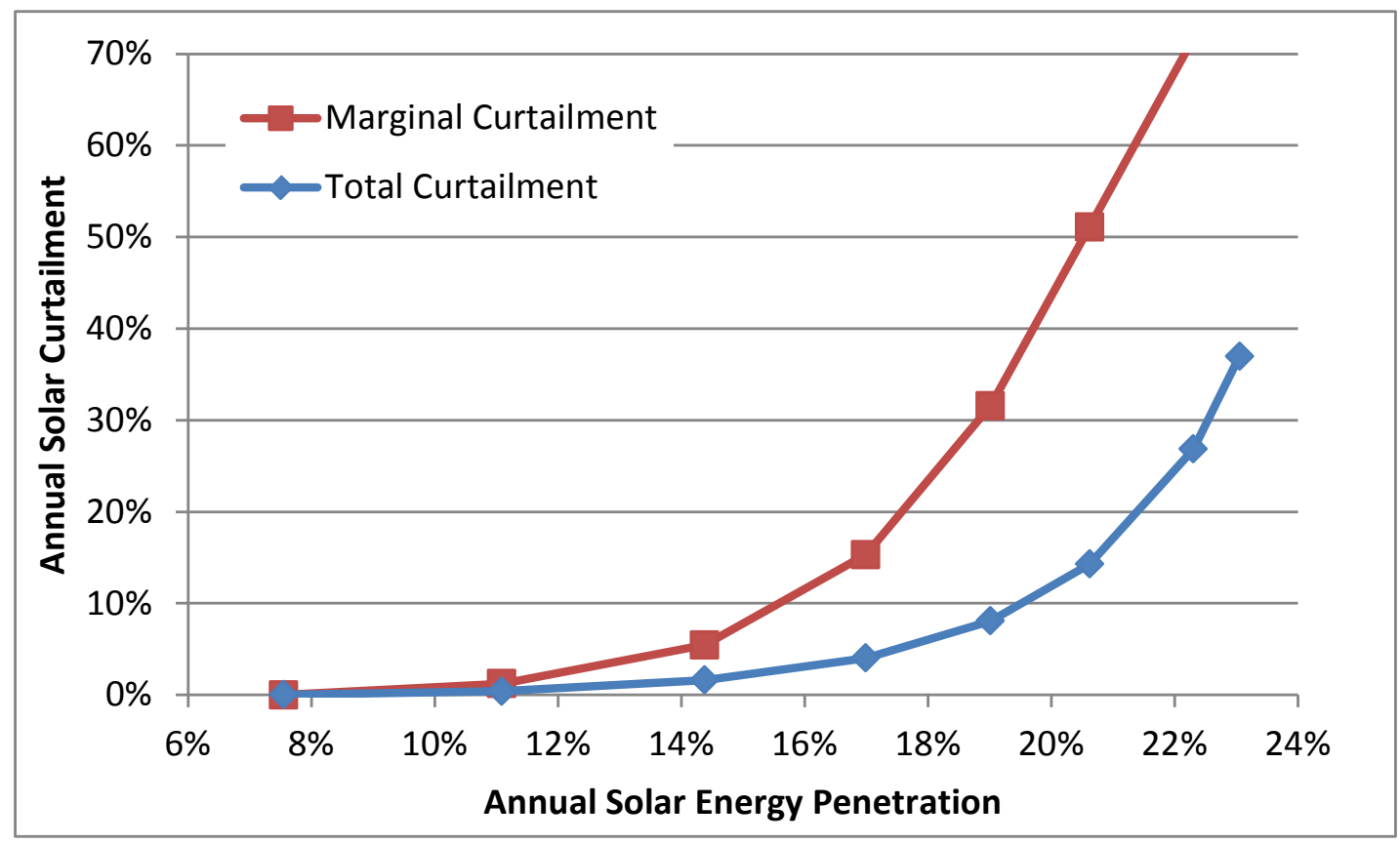

Figure 6. Annual marginal and total solar curtailment due to overgeneration under increasing penetration of PV in California in a system with limited grid flexibility

The rapid increase in marginal PV curtailment rates as a function of solar penetration is a significant limitation to PV remaining competitive with other sources of low-carbon energy once solar achieves a certain penetration (in this case, perhaps $15 \%-20 \%$ of annual demand). For example, previous analysis demonstrated that additional wind often has a lower curtailment rate than PV at increasing penetration (Denholm and Hand 2011; E3 2014). This challenge can be observed by examining the impact of curtailment on PV's LCOE. As curtailment increases and capacity factors decrease, the LCOE increases. This is illustrated in Figure 7, which provides PV LCOE as a function of solar penetration in the system without enhanced grid flexibility. In this figure, the PV cost is based on the SunShot utility-scale LCOE goal of $6 \varnothing / \mathrm{kWh}$, which largely depends on being able to use all the PV energy by minimizing curtailment.

\footnotetext{
${ }^{18}$ Where the total demand is equal to the consumer demand plus storage losses associated with pumped hydro.
} 


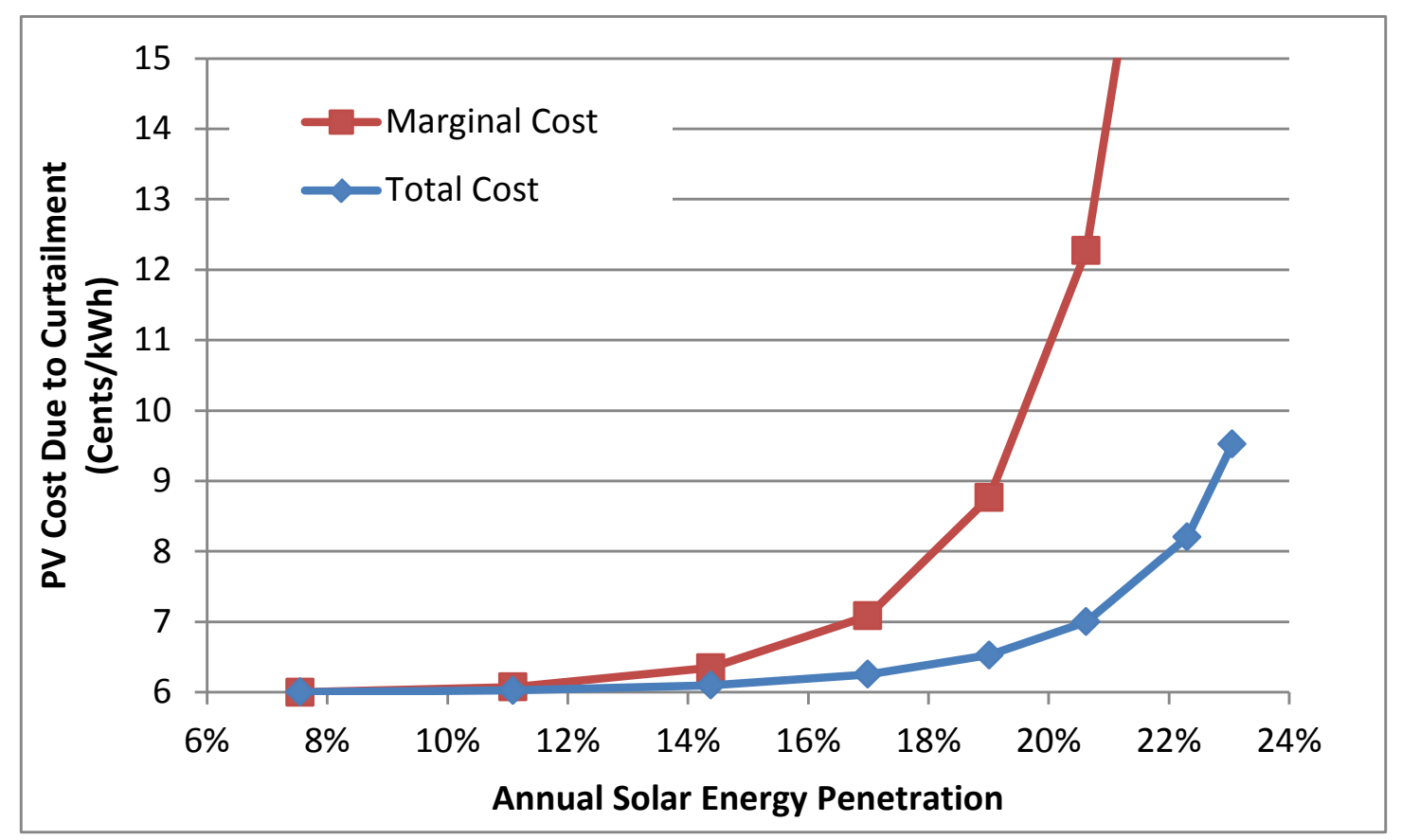

Figure 7. Marginal and average PV LCOE (based on SunShot goals) due to overgeneration under increasing penetration of PV in California in a system with limited grid flexibility

Figure 7 shows the importance of examining marginal curtailment rates. While average rates can remain relatively low, marginal rates determine the cost and value of adding the next unit of PV to the grid. There is no predefined "threshold" at which PV curtailment would prevent further deployment. However, as curtailment-related costs increase, additional units of PV become less competitive against additional units of other energy sources. Investment decisions may be driven by incremental costs and benefits, including the impact of curtailment. It is important to note that actual allocation of curtailment among different renewable generation sources (including existing or added generators) will be driven by various factors, including local grid conditions, underlying contractual agreements with suppliers, production tax credits, and other regulatory issues.

An alternative to measuring the impact of curtailment on PV LCOE (as shown in Figure 7) is to examine the value of PV in terms of avoided generation and how this value decreases as a function of penetration (Mills and Wiser 2012a. For example, at low penetration, each MWh of solar potential avoids $1 \mathrm{MWh}$ of conventional generation and associated fuel and emissions. However, as curtailment increases, each MWh of solar potential avoids less than $1 \mathrm{MWh}$ of conventional generation, thus decreasing its value. In systems with low flexibility, the avoided energy value of PV can drop rapidly, creating economic challenges for increased solar penetration (Mills and Wiser 2015).

Regardless of the performance metric used, the results in this subsection are similar to the results of previous analyses by a variety of groups studying the impact of flexibility options in the West. Analyses by Nelson and Wisland (2015), E3 (2014), and Brinkman et al. (2016) all demonstrate that, with limited flexibility, high solar penetration in California can result in very high curtailment rates. 
The very high marginal PV curtailment rates observed in Figure 6 would likely limit contributions from solar without changing system operation to accommodate VG resources. However, the significant number of flexibility options discussed in Section 3 can both accommodate and change the net load shape to facilitate higher solar penetration.

\subsection{Capacity Value-The Challenge of Meeting Peak Demand}

Section 2.1 discussed the ability of PV to provide energy and replace fossil fuel generation. This subsection discusses the second challenge associated with achieving significant PV penetration - replacing capacity with PV and thus displacing both fossil fuels and the plants that burn them. This information provides context for the presentation of options for maintaining PV's capacity value in Sections 3 and 4.

The capacity value (also called the capacity credit) of solar depends on the extent to which solar generation aligns with demand patterns. Solar energy provides capacity credit by reducing the demand that must be met by conventional generators during periods of high demand. Figure 8 shows normal load and net load for increasing levels of PV. The data are from the same studies discussed previously, but the solar profiles are scaled to provide potential annual PV penetrations from $0 \%$ to $14 \%$. These 3 days include the day with the highest demand of the year. ${ }^{19}$

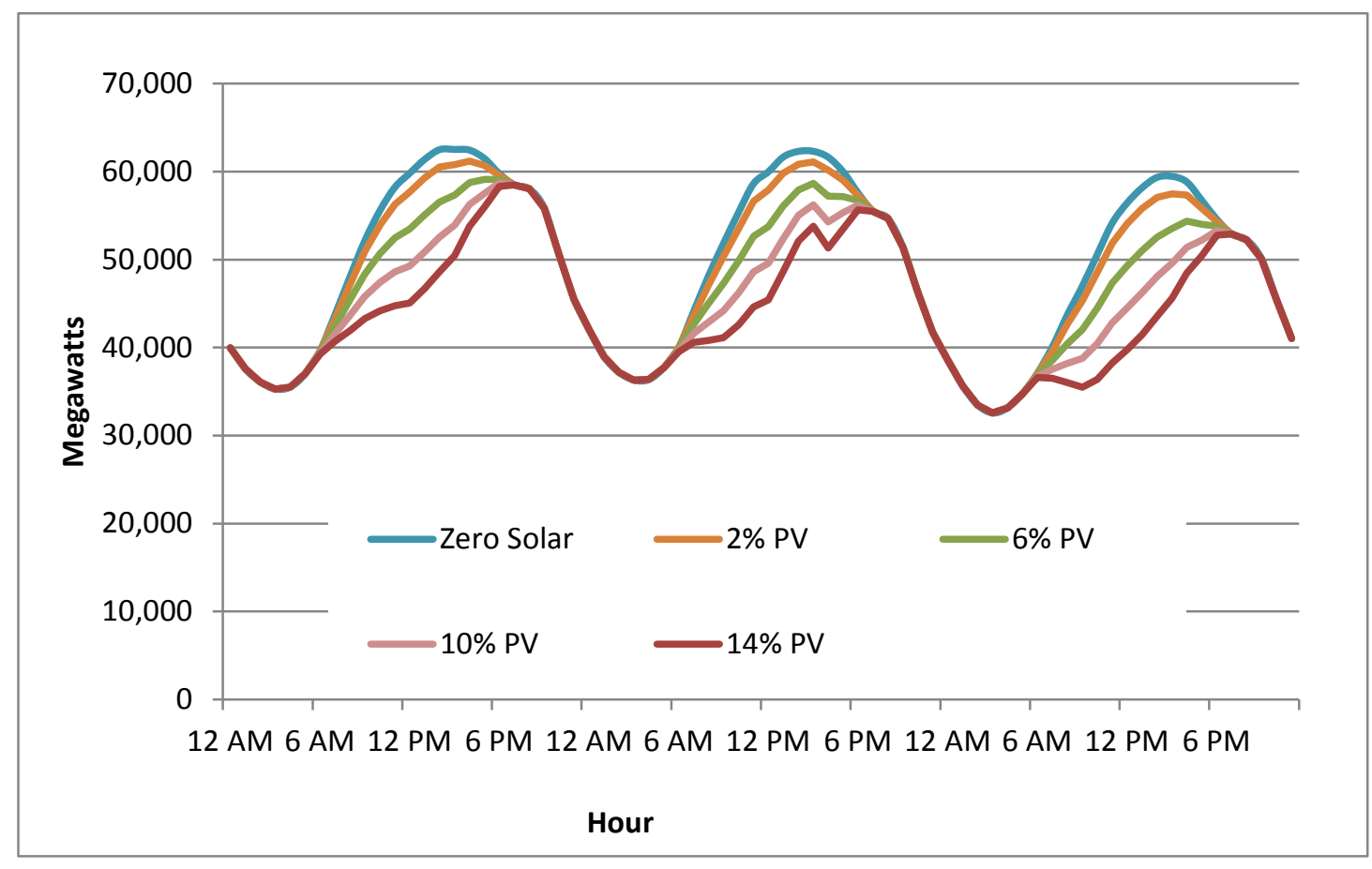

Figure 8. Load and net load profiles for increasing levels of PV in California, July 27-29

\footnotetext{
${ }^{19}$ This includes both the CAISO load and the load from the publicly owned utilities. For comparison, the noncoincident net peak demand from all utilities in California in 2014 was 62,454 MW (CEC 2015). The gross peak demand was 65,468 with 3,014 MW of self-generation, including 1,130 MW of PV. Because this is non-coincident demand, the coincident peak across the entire state would be lower.
} 
Figure 8 illustrates how PV can reduce the net load by generating electricity during the hours of peak demand (typically 4 to $6 \mathrm{pm}$ ). This results in a capacity credit— the ability of PV to replace conventional generation. However, Figure 8 also shows how the capacity credit of PV can decrease as PV penetration increases. Figure 9 shows this effect in more detail by demonstrating how adding PV shifts the net load pattern and results in a declining incremental capacity credit. The top chart in Figure 9 zooms into the middle day of Figure 8, as indicated by the scale change, showing only the load between 6 am and $11 \mathrm{pm}$. The bottom chart of Figure 9 shows the $\mathrm{PV}$ output during this same period as a fraction of its annual peak. Without solar, the demand peaks at about 62,500 MW between 2 and 3 pm Pacific standard time (3 to 4 pm daylight savings time). ${ }^{20}$ There is significant solar generation during this time, with the entire PV fleet producing about $73 \%$ of peak output. (This output is the aggregated output of all PV throughout the state and PV imports dedicated to California). As PV is added, the net load shape shifts. When enough $\mathrm{PV}$ is added to meet $2 \%$ of California's annual load (about 2,700 MWac), the demand between 2 and $3 \mathrm{pm}$ has been reduced by about 1,990 MW, to 60,500 MW. However, the actual load peak has been shifted 2 hours later. PV output during this period is only generating at about $45 \%$ of rated output. This means the incremental capacity credit of $\mathrm{PV}$ on this day has dropped from about $73 \%$ (at zero penetration) to $45 \%$ (when PV is providing $2 \%$ of annual generation). As more PV is added, the peak is shifted later, and at $10 \%$ annual PV the net peak demand has been shifted to between 6 and $7 \mathrm{pm}$. The aggregated PV output during this hour is only $10 \%$ of peak output, meaning beyond this point PV has little ability to offset the need for conventional capacity on this day.

${ }^{20}$ All data in the analysis have been shifted to standard time. 


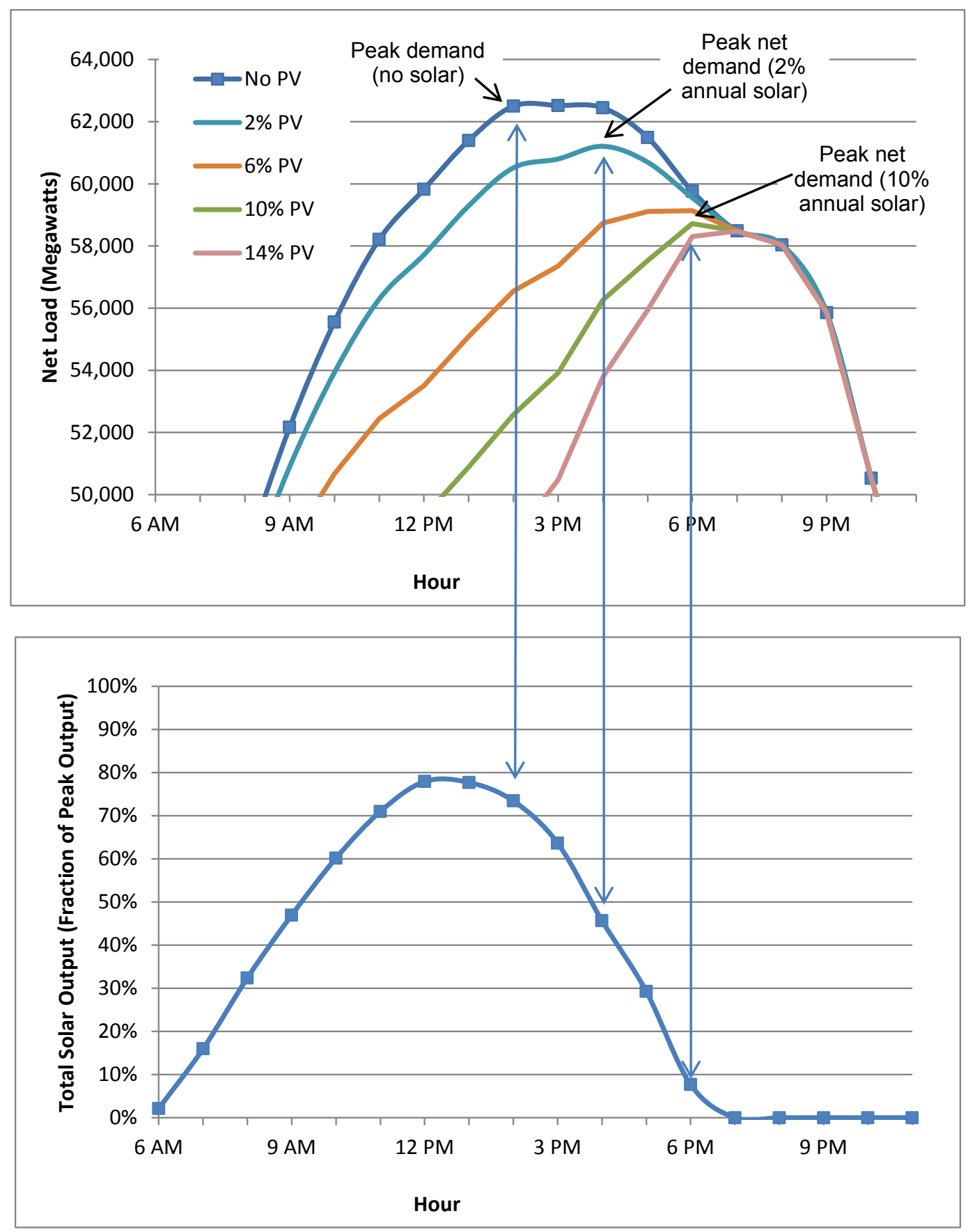

Figure 9. Impact of increased PV on net load in California and decline in capacity credit, July 28

Capacity credits translate directly to the amount of conventional generation capacity avoided by PV. Figure 9 shows that, at low penetration, each 100 MWac of PV capacity installed on the system would reduce the need for conventional capacity by as much as about $73 \mathrm{MW}$ on this day. However, as more PV is added, this number falls rapidly.

These figures provide a general overview of the drivers behind declining PV capacity credit, but they do not provide a detailed analysis of the resource adequacy impacts of PV. Utilities and system planners commonly use detailed reliability-based metrics to assess the capacity 
contribution of different resources. These methods use statistical approaches to determine the ability of a generation resource to maintain a reliable system and meet demand (NERC 2011; Madaeni et al. 2013a; Ibanez and Milligan 2014). These techniques are based on measuring the system loss of load probability (LOLP) with and without solar, and they examine how much additional load could be added with the addition of PV or CSP. This technique produces a capacity credit, expressed either in units of power $(\mathrm{kW}, \mathrm{MW})$ or as the annual fraction of the renewable generator's nameplate capacity, that adds to system reliability by offsetting conventional capacity. ${ }^{21}$

A number of previous analyses calculate PV and CSP capacity credits, some of which are summarized by Mills and Wiser (2012b) in Figure 10. Despite the range of analytic methods and results, these studies follow the two general trends described above. First, at low penetration, PV's capacity credit typically ranges from $50 \%-75 \%$ in the western United States. ${ }^{22}$ Second, PV's capacity credit drops significantly as a function of penetration. Similar analysis shows that wind provides a much lower capacity credit at low penetration, but it does not fall as significantly as PV with increasing penetration (Mills and Wiser 2012a).

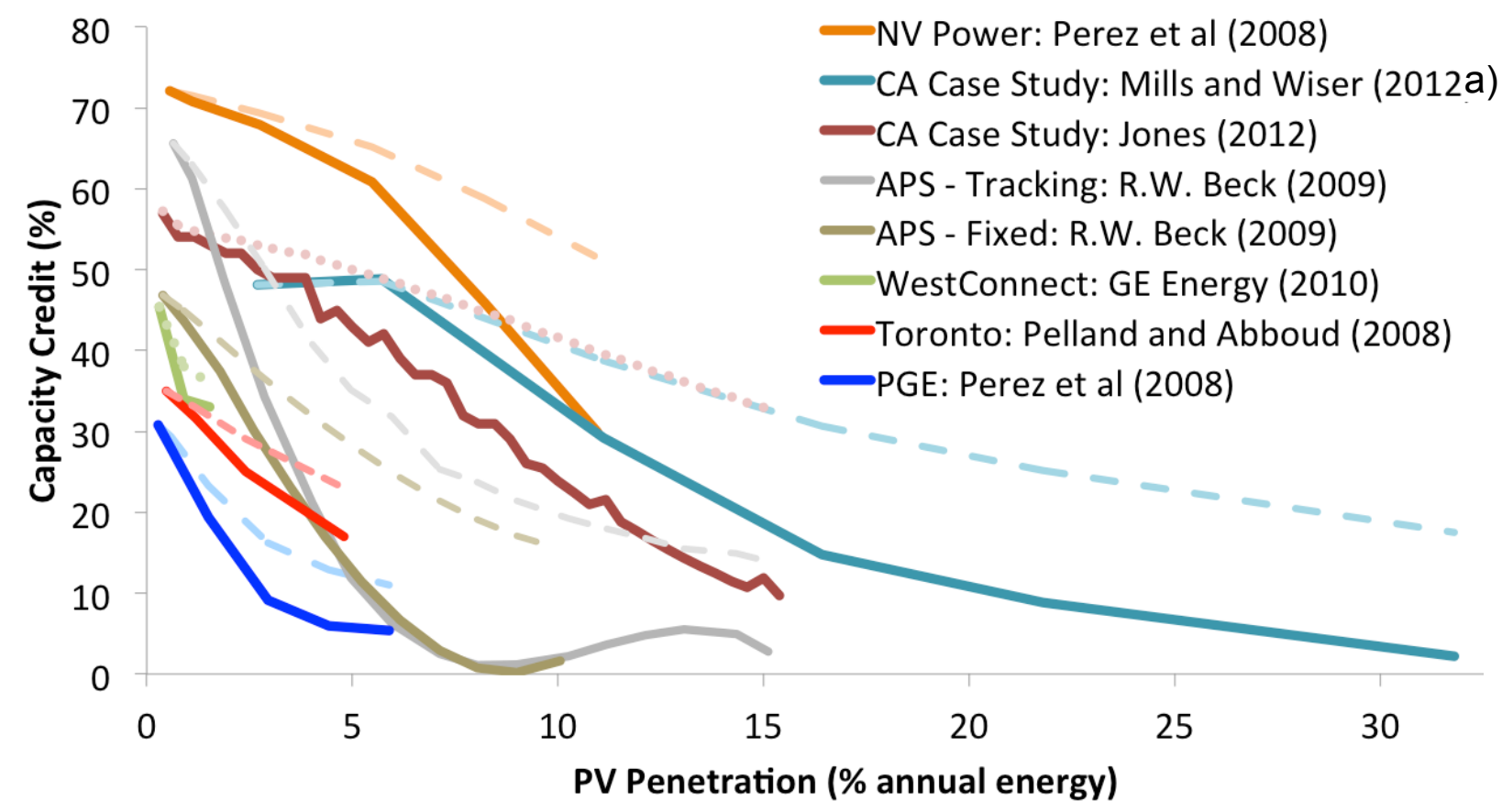

Figure 10. Summary of PV capacity credit estimates

Source: Mills and Wiser 2012b

Dashed lines indicate total capacity credit, while solid lines indicate marginal capacity credit.

\footnotetext{
21 This subsection provides a general discussion of capacity credit. Different regions of the country have adopted different methods to analyze capacity credit for the purposes of both reliability and compensation. For a Californiaspecific example, see CPUC (2014b).

${ }^{22}$ Relatively little analysis has been performed on the capacity credit of PV in the eastern United States, so it is unclear whether the trends observed in Figure 10 would be greatly different in that region.
} 
Previous analysis also shows that, despite the reduced capacity credit due to increasing solar, the net peak period is narrower (i.e., encompasses fewer hours) with higher solar penetrations. This increases the possibility that, at high PV penetrations, new flexibility options could help maintain high capacity credit for PV. The variety of approaches discussed in Section 3 can be deployed, including DR (which can shift demand to periods of greater renewable output), short-duration energy storage, and alternative solar technologies such as CSP with TES (Madaeni et al. 2013b). 


\section{Increasing System Flexibility}

Addressing the economic challenges of PV grid integration will require increasing the overall flexibility of the power system. Numerous grid integration studies have identified two major categories of tools for increasing grid flexibility: 1) resources that allow VG to be used directly to offset demand and increase instantaneous VG penetration, and 2) resources that improve the alignment of VG supply and demand (Cochran et al. 2014).

The first approach addresses the minimum generation problem. Figure 3 in Section 2.1 shows that, in the limited flexibility case, the system could not reduce the output of conventional generation below about 12,600 MW on March 29, resulting in up to 2,700 MW of curtailed solar energy. Reducing the system minimum generation level by this amount $(2,700 \mathrm{MW})$ would eliminate all curtailment on this day.

The second approach is to shift supply/demand patterns to allow solar energy to meet parts of the load that would not normally be provided in the middle of the day. This includes either shifting load via responsive demand or shifting supply by the use of energy storage (Lazar 2014).

These two general approaches are often discussed in terms of a more comprehensive set of flexibility options, as illustrated in Figure 11. The options are also sometimes expressed in terms of a flexibility supply curve to show they have varying costs and benefits.

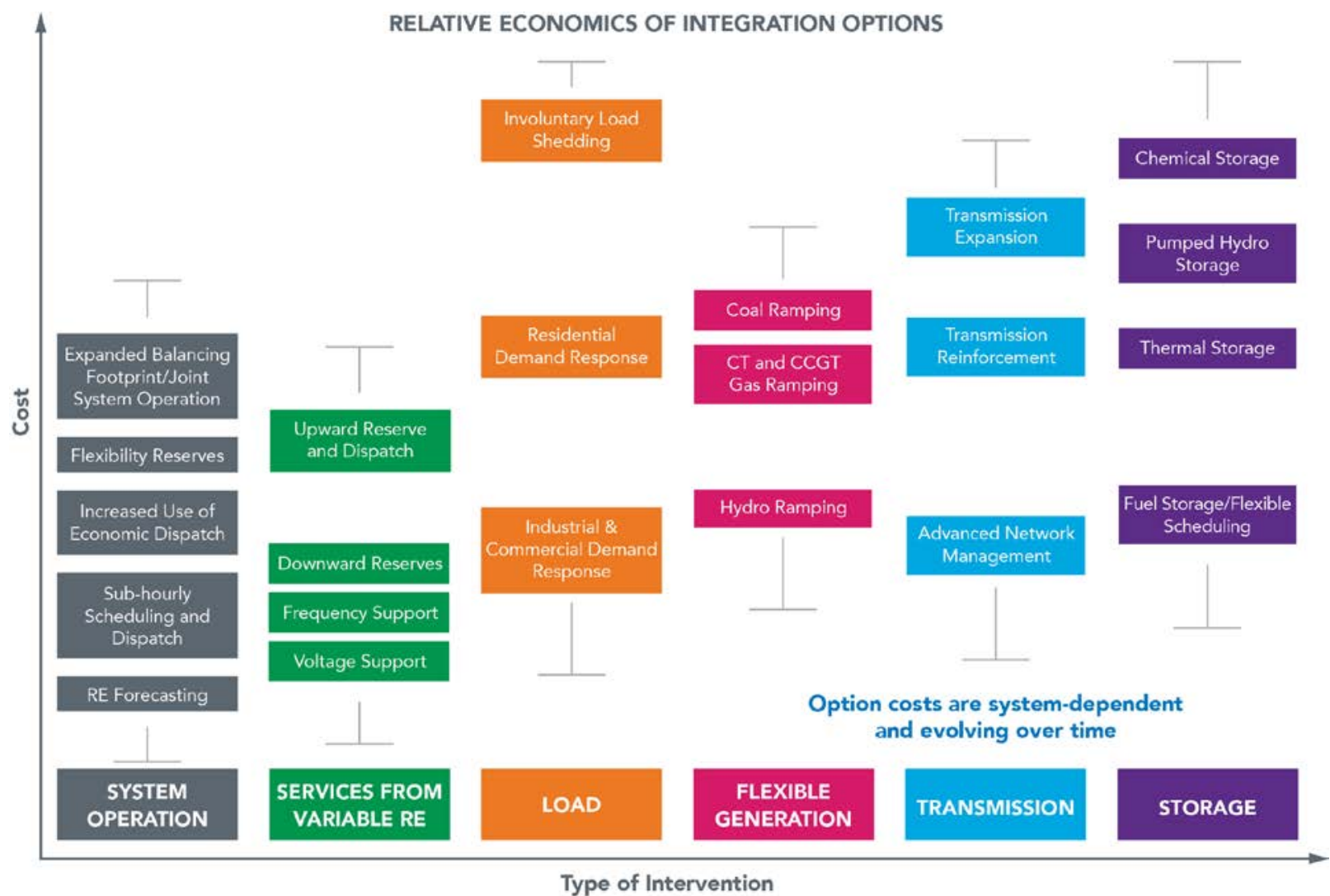

Figure 11. Flexibility options for integration of VG

Source: Modified from Cochran et al. 2014 
Many of the options in Figure 11 have already been implemented, or are in the process of being implemented, in the United States and in countries where wind and solar have achieved significant penetration. For example, Germany derived more than $6 \%$ of annual generation from $\mathrm{PV}$ in 2013 and has made a number of modifications to grid operations to maximize the benefits of PV (and wind) (Stetz et al. 2015). The costs and benefits of each flexibility option may vary based on grid conditions, renewable penetration, and generation mix among other factors, so analysis will be needed to determine the most cost-effective options for each specific region. Additional discussion of these options in a California-specific context is provided by Younghein and Martinot (2015).

The following subsections discuss six specific flexibility options, listed in Table 3 . Table 3 also briefly describes how each flexibility option can address an operational challenge associated with curtailment. The first two columns describe how flexibility options can reduce minimum generation constraints, while the third column describes how the option can improve the supply/demand coincidence of solar. Section 4 demonstrates how deploying these flexibility options can increase the economic deployment of PV. 
Table 3. Six Grid Flexibility Options and How They Mitigate Challenges that Lead to Solar Curtailment

\begin{tabular}{|c|c|c|c|}
\hline \multirow[b]{2}{*}{ Mitigation Measure } & \multicolumn{3}{|c|}{ Source of VG Curtailment and Mitigation Mechanism } \\
\hline & $\begin{array}{l}\text { Minimum Generation } \\
\text { from Thermal } \\
\text { Generation due to } \\
\text { Operating Constraints } \\
\text { including Ramp Rates } \\
\text { and Range }\end{array}$ & $\begin{array}{l}\text { Minimum Generation } \\
\text { from Thermal } \\
\text { Generation Held for } \\
\text { Operating Reserves } \\
\text { and Frequency } \\
\text { Stability }\end{array}$ & $\begin{array}{l}\text { Supply/Demand } \\
\text { Mismatch }\end{array}$ \\
\hline $\begin{array}{l}\text { Improved system operation } \\
\text { including VG forecasting and } \\
\text { flexibility reserves }\end{array}$ & $\begin{array}{l}\text { Improved forecasting } \\
\text { allows greater certainty } \\
\text { of supply, allowing for } \\
\text { de-commitment of long- } \\
\text { start units }\end{array}$ & $\begin{array}{l}\text { Reduces need for } \\
\text { operating reserves }\end{array}$ & - \\
\hline Flexible generation & $\begin{array}{l}\text { Lower minimum } \\
\text { generation, faster } \\
\text { starts, faster ramps }\end{array}$ & $\begin{array}{l}\text { Can provide greater } \\
\text { amounts of reserves } \\
\text { per unit of online } \\
\text { capacity. Can provide } \\
\text { some reserves while } \\
\text { not online. Smaller } \\
\text { plants reduce size of } \\
\text { large frequency events. }\end{array}$ & - \\
\hline $\begin{array}{l}\text { Transmission and coordination } \\
\text { (regional imports and exports) }\end{array}$ & $\begin{array}{l}\text { Reduces ramp rate via } \\
\text { spatial diversity of } \\
\text { resource }\end{array}$ & $\begin{array}{l}\text { Reduces reserves } \\
\text { requirement via spatial } \\
\text { diversity. Allows for } \\
\text { reserves sharing. }\end{array}$ & $\begin{array}{l}\text { Diversity can } \\
\text { potentially } \\
\text { increase supply } \\
\text { /demand } \\
\text { coincidence }\end{array}$ \\
\hline $\begin{array}{l}\text { Reserves and stability services } \\
\text { from VG }\end{array}$ & - & $\begin{array}{l}\text { Provides reserves } \\
\text { without needing } \\
\text { synchronous capacity } \\
\text { operating at part load }\end{array}$ & - \\
\hline Demand response & $\begin{array}{l}\text { Can change net load } \\
\text { shape to reduce ramp } \\
\text { rate }\end{array}$ & $\begin{array}{l}\text { Provides reserves } \\
\text { without needing } \\
\text { synchronous capacity } \\
\text { operating at part load }\end{array}$ & $\begin{array}{l}\text { Shifts demand to } \\
\text { periods of higher } \\
\text { VG output }\end{array}$ \\
\hline Energy storage & $\begin{array}{l}\text { Can change net load } \\
\text { shape to reduce ramp } \\
\text { rate }\end{array}$ & $\begin{array}{l}\text { Provides reserves } \\
\text { without needing } \\
\text { synchronous capacity } \\
\text { operating at part load }\end{array}$ & $\begin{array}{l}\text { Shifts supply of } \\
\text { VG to periods of } \\
\text { higher demand }\end{array}$ \\
\hline
\end{tabular}




\subsection{Improved System Operation}

A number of changes to system operations can improve PV integration. These largely represent changes to the way the grid is scheduled and dispatched, including changes to market rules. ${ }^{23}$ They often do not require new technologies, and they often represent "least cost" measures to aid VG integration. Because many of these changes also reduce system-operation costs regardless of VG deployment, they have already been implemented or are underway throughout the United States.

One such widely implemented change is reduced scheduling intervals. Some regions historically scheduled plants in 1-hour intervals that could not be easily changed to address the shorter-term variability of wind and solar. This in turn reduced access to physical flexibility and increased the need for operating reserves. Shifting to sub-hourly dispatch can improve the efficiency of operations and reduce the need for regulating resources (Milligan and Kirby 2010), and many market regions now use scheduling intervals as short as 5 minutes. ${ }^{24}$

Another approach to addressing the shorter-duration ramps, particularly those created by solar and wind resource uncertainty, is the creation of a flexibility reserve product. Very short-term variability and uncertainty in net load have historically been addressed through use of regulating reserves (detailed in Section 3.3). These reserves, which are designed to respond rapidly (within seconds), are often provided by partially loaded thermal generation, and this increases operating costs and contributes to the minimum-generation problem. Because the variability of wind and solar typically occurs on slightly longer time scales (minutes to tens of minutes), a reserve with longer response time is possible. While the specific technical requirements have yet to be defined in detail, several regions-including the CAISO, Midcontinent Independent System Operator (MISO), and Xcel (Colorado) service territory - have proposed a flexibility reserve product (Younghein and Martinot 2015; Navid and Rosenwald 2013; FERC 2014a). Flexibility reserve products will likely offer a lower-cost option compared with addressing variability via traditional regulating reserves (Hummon et al. 2013a).

Finally, improved solar and wind forecasting can enable greater VG penetration by improving scheduling and reducing reserve requirements. With more accurate forecasts, system operators can ensure adequate generation capacity is available without keeping excessive spare capacity online (spinning), which otherwise contributes to the minimum-generation problem. Integration of advanced renewable supply forecasting into dispatch and market operations has already reduced uncertainties and improved scheduling of other resources to reduce reserves and fuel consumption (IEA 2014; Lew et al. 2011; Porter et al. 2012). In particular, improvements in wind forecasting have demonstrated decreased operating costs and maintained reliability as wind penetration has increased (Ahlstrom et al. 2013), and solar forecasts are now being incorporated into system operations (Tuohy et al. 2015).

\footnotetext{
${ }^{23}$ Formal wholesale markets cover about two-thirds of U.S. electricity demand and are operated by an ISO or RTO. The remainder of the U.S. is served by traditional vertically-integrated utilities. These utilities can still interact through market mechanisms including bilateral markets and new markets such as the western energy imbalance market (CAISO 2015; IRC 2015).

${ }^{24}$ All restructured markets (i.e., ISOs/RTOs) in the United States have a 5-minute economic dispatch with at least 15-minute interchange scheduling (scheduling with neighboring regions), per Federal Energy Regulatory Commission (FERC) Order 764 as discussed below. Regulated markets have varying time intervals for dispatch and scheduling (e.g., hourly in much of the western United States).
} 
As solar forecasts are integrated into market operations, visibility and forecasts of all PV systems - including distributed rooftop PV—will be required (Wu et al. 2015). A common theme of VG integration research is that participation of all resources in providing grid services (discussed in Section 3.3), will enable the most cost-effective solutions to the challenges of balancing supply and demand.

\subsection{Flexible Generation}

Flexible generation refers to increasing the ramp rate and range of conventional generators to respond better to the net load shape created by additional PV. It also refers to increasing the ability to start and stop generators more frequently (Palchak and Denholm 2014; Venkataraman et al. 2013).

Increasing generator flexibility can require institutional and technical changes. Grid-integration studies have found that, in many cases, the existing generator fleet has the technical ability to operate more flexibility and integrate significant additional variability. Analysis of systems with up to $35 \%$ VG tends to demonstrate that existing resources that are "backed down" to accommodate VG can typically ramp fast enough to provide load following on the dispatch time scales typically analyzed (5 minutes) (Lew et al. 2013; Bloom et al. 2015). This means that, while VG increases ramping requirements, the existing generation fleet is largely adequate to meet these requirements. However, this flexibility may not be fully accessible in today's grid without changes to power system operations or other institutional factors. Many plant owners may "self-schedule" or generate with fixed output that does not vary in response to economic conditions. Existing long-term contracts may limit output changes. Thus, accessing generator flexibility is closely linked to changes in system operation discussed in the previous subsection.

The increase in net load variability has also created incentives for new reliability rules and standards, and several regions are creating flexibility standards. One example is the California Public Utilities Commission (CPUC) flexible capacity requirement, which requires that loadserving entities under CPUC jurisdiction (primarily the state's three large investor-owned utilities) procure capacity with sufficient flexibility to address the largest predicted 3-hour ramp rate in each month (CPUC 2014a).

Technical changes can also provide more flexibility from individual generators. New gas-fired generation typically can provide significant ramp rates and multiple operating reserves (Venkataraman et al. 2013). Certain new gas-fired combustion turbines and reciprocating engines are capable of very short start times, and these units could even provide some fraction of traditional synchronized (spinning) reserves without being online (Wärtsilä and Energy Exemplar 2014). Thus, a large amount of the uncertainty and variability of net load created by solar could potentially be met by units that are not online, reducing concerns that increased partload operation of the generation fleet will lessen the benefits of VG.

As the generation mix evolves, the challenge of meeting VG-induced variability will change depending on what plants are retired. If older baseload coal units are retired and replaced with more flexible gas-fired units, the ability to adjust generation rapidly would increase. Equilibrium analysis of the evolving grid (which evaluates the optimal mix of capacity needed as VG penetration increases) indicates that due to reduced capacity factors of thermal resources, the 
economically optimal mix tends to include a greater proportion of inherently flexible plants (Mills and Wiser 2012a).

\subsection{Transmission and Coordination}

One of the significant changes that has accompanied formation of restructured markets is larger area coordination and cooperation. Balancing supply and demand over larger areas reduces net variability of both load and renewable resources such as PV owing to greater spatial diversity of VG resources. An example of this is provided in Figure 12, which shows the normalized output from an individual PV generator compared to the aggregated output from multiple PV systems (Lew et al. 2013). When considering the aggregated output, system operators can respond to a much "smoother" generation profile, not significantly increase the amount of operating reserves. This reduces the need for operation of partially loaded conventional generators and can increase instantaneous penetration of solar.

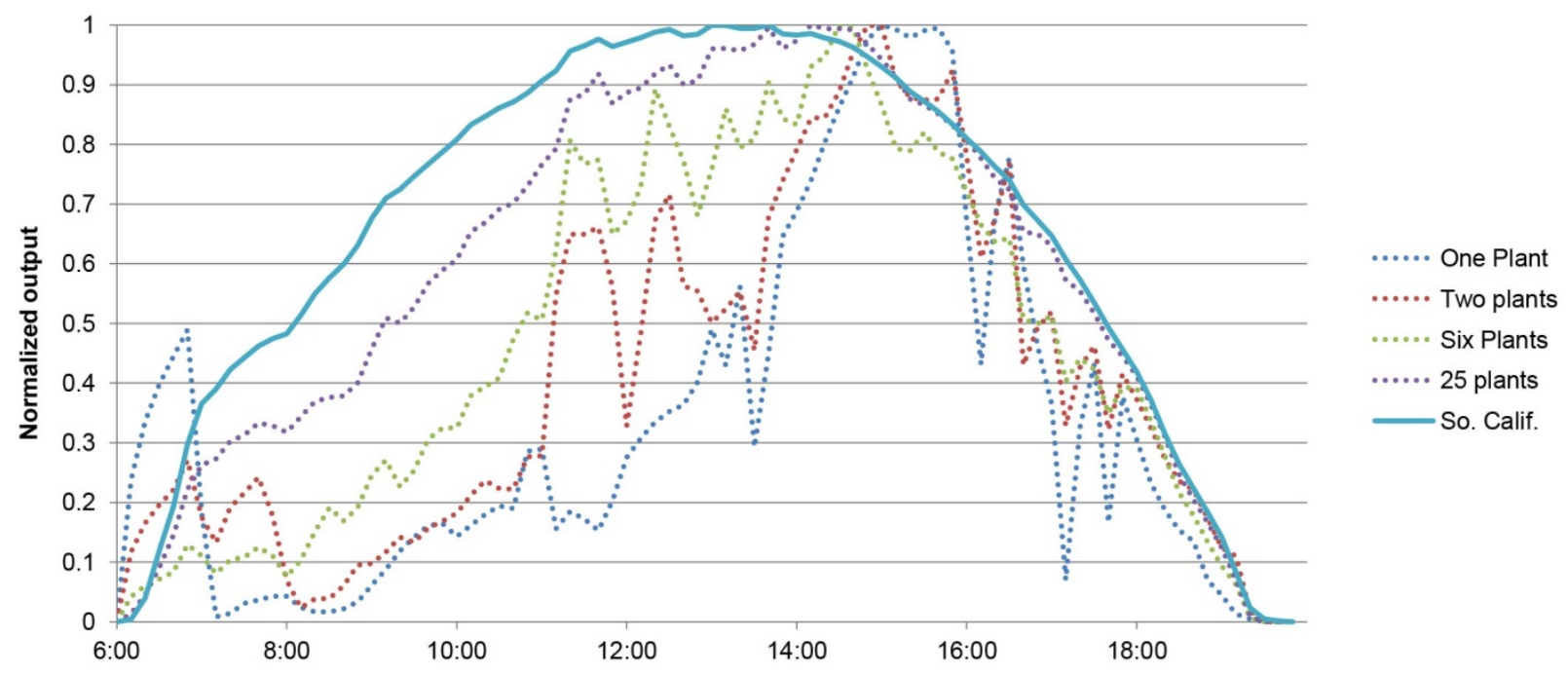

Figure 12. Reduction in solar variability due to spatial diversity

Source: Lew et al. 2013

Coordination over larger areas can have additional benefits, such as decreasing the contingency requirements in any individual region by creation of larger reserve-sharing areas. There are opportunities for significant increases in coordination in several regions of the U.S. including the Western Interconnection. The Western Energy Imbalance Market is an example of an effort to improve efficiency of interchange over shorter time intervals, which can lead to a reduction in reserve requirements (CAISO 2015; King et al. 2012).

Regional interchange could also help address local minimum generation issues by exporting surplus PV generation to surrounding regions. For example, greater interchange could potentially take advantage of the significant transmission capacity between California and surrounding states and substantially reduce curtailment (Nelson and Wisland 2015). This may require broader implementation of various market mechanisms that allow for exchanging energy across regions. A long-term challenge may occur when surrounding states also adopt increasing amounts of wind and PV, leading to regional surpluses of renewable energy during spring afternoons. 
Transmission upgrades and new transmission can increase opportunities for even greater spatial diversity and, in the long term, allow significant exports of solar energy from areas with highquality solar resources. The SunShot Vision Study (DOE 2012), as well as the Renewable Electricity Futures studies (NREL 2012), identified opportunities for exports of very low-cost solar and wind energy despite challenges of constructing new transmission. Alternatives to new transmission include various technologies that enhance the capacity or utilization of existing transmission lines, including dynamic line ratings and flexible AC transmission (CEC 1999).

\subsection{Reserves and Frequency Stability Services from VG}

The major challenges of integrating PV at high penetration include the need to derive operating reserves from new sources and the need to maintain grid stability after a system disturbance. One concern associated with high instantaneous penetration of $\mathrm{VG}$ is the impact on frequency stability (CAISO 2013). Frequency stability refers to the ability of the grid to maintain constant frequency. Analysis of grid stability is highly technical; we provide a primer on issues associated with grid stability in the Appendix, and a technical definition of the different aspects of power system stability is provided in (Kundur et al. 2004). However this section provides an overview of how system operators use operating reserves to maintain system frequency and provide reliable electric service. This section also provides a brief description of transient stability.

The frequency of the U.S. power system is determined by the rotational speed of synchronous generators. All synchronous generators spin at a multiple of $60 \mathrm{~Hz}$ and are electromagnetically coupled so they all spin at the same rate and same phase angle. A variety of disturbances can affect overall system frequency. For example, a transmission line outage may disconnect a large industrial customer; as a result, the total electricity generation exceeds the total electricity demand, and frequency rises. Alternatively, loss of a large generating plant can result in the total electricity demand exceeding the total electricity generated, and frequency drops. In general, a power grid is designed to withstand the loss of the single largest generator. However, the loss of multiple generators or plants may cause the frequency to drop significantly.

Most industrial, commercial, and residential equipment is designed to receive $60-\mathrm{Hz}$ electricity, and, if the frequency were to change, machines and electronics can be damaged. When frequency drops beyond a certain point, protection systems automatically initiate "under-frequency load shedding" to disconnect customers and preserve the bulk of the system. This causes an unscheduled blackout for some of the grid.

To maintain system frequency and avoid load shedding, system operators employ operating reserves that can respond to unplanned events. Operating reserves in general represent spare capacity available to respond to unplanned variability of demand or generator supply, including unplanned outages that can occur rapidly. If one of the generators were to fail unexpectedly, the other generators must have enough capacity to provide the needed demand.

Maintaining frequency requires a number of types of operating reserves, including the following:

- Inertial response-Inertia is the physical property of spinning machines that reduces the rate of frequency change. The inherent stored energy in spinning synchronous machines can be extracted from the grid in fault conditions, slowing the decline in frequency and providing time for systems to detect changes in frequency and respond accordingly. A system with zero 
inertia could in theory collapse instantaneously, with no time for systems to respond. Inertia is derived from all synchronous spinning generators, synchronous condensers, and certain loads including large synchronous motors.

- Primary frequency (governor) response/reserves - Primary frequency response (PFR) is provided by systems that automatically detect and respond to changes in frequency by increasing or decreasing output. While inertia responds instantaneously and automatically, PFR typically responds automatically within seconds to arrest frequency deviations. PFR is obtained from all synchronized (spinning) generation/storage resources that can rapidly ramp and have operating governors (devices that sense and respond to frequency changes).

- Regulation reserves - Regulation (or regulating) reserves (also called frequency regulation) correct frequency deviations or regional power flow imbalances that can result from unpredicted variability in supply and demand. Short-term variability in supply/demand balance can result in both a change in frequency and change in transmission flow, as electricity flows into the region where generation is less than demand. This imbalance of both frequency and power flow is measured by the area control error (ACE). Computers monitor the ACE and send out automatic generation control (AGC) signals every few seconds to correct each region's unscheduled supply/demand balance. Regulating reserves are provided by any synchronized (spinning) generation/storage resources that can rapidly ramp (begin changing output within seconds and reach the new desired setpoint within minutes) and have the necessary communications equipment to receive AGC signals.

- Contingency spinning reserves - Contingency reserves are designed to meet unplanned outages. These reserves are provided by partially loaded conventional generation/storage resources, with enough spare capacity (in aggregate) to meet the unexpected outage of the single largest power plant or transmission line in the system.

Large penetrations of inverter-based, or non-synchronous, generation technologies complicate the estimation of reserve requirements as well as the provision of reserves. Variable generators such as wind and solar do not use large synchronous generators that inherently store rotational energy and provide physical inertia. Instead, they use power electronics (inverters) to inject electrical energy onto the grid. As a result, replacing conventional generation with VG reduces real inertia and traditional frequency response, potentially below what is needed to maintain stability. As a result, system operators have expressed concern about allowing wind and solar to provide more than a certain fraction of grid electricity. For example, the CAISO has stated that, beyond $60 \%$ instantaneous penetration, "the grid may not be able to prevent frequency decline following the loss of a large conventional generator or transmission asset. This situation arises because renewable generators are not currently required to include automated frequency response capability and are operated at full output (they can not increase power)" (CAISO 2013). In the United States, penetration of wind or solar is currently too low to evaluate the impact of high instantaneous penetration on system stability. Several regions, such as the Xcel service territory in Colorado, have achieved high penetration. In October 2014, Xcel provided 61.1\% of demand with wind (Pierce 2014). Because this system is connected to the larger Western Interconnection, it does not provide a realistic example of high penetration of non-synchronous generation across a large balancing area or interconnection. Isolated regions outside the United States have greater experience, and at least one region (Ireland) has capped the penetration of wind based on concerns regarding grid stability (Milligan et al. 2015). 
To understand the impact of VG on grid stability requirements in the United States, researchers are beginning to study the issue in detail. Phase 3 of the WWSIS (WWSIS-3) analyzed two aspects of dynamic performance of the Western Interconnection with high solar and wind penetration: large-scale transient stability and frequency response (GE Energy 2014). The study evaluated dynamic performance of the grid in the fractions of a second to 1 minute following a large disturbance (e.g., loss of a large power plant or a major transmission line).

Frequency stability is the overall ability of the power system to compensate for large sudden mismatches of generation and load in the first 60 seconds after an event; the minimum frequency during the worst credible generating plant outages should not cause under-frequency load shedding, or customer power interruptions. Maintaining frequency stability allows enough time for the various operating reserves described above to act to bring frequency back to $60 \mathrm{~Hz}$ over the subsequent minutes.

Transient stability is a faster phenomenon. It is the ability of the grid to successfully transition from normal operation (i.e., all transmission lines and generating units are in service), through a disturbance (e.g., an abrupt outage of a major transmission line or large generator), and into a new stable operating condition in the 10-20 seconds immediately following a disturbance.

WWSIS-3 focused on a small set of credible yet relatively extreme system conditions. The study scenarios were based on 2023 system conditions (e.g., transmission topology, generation retirements, load forecast) as developed through the WECC stakeholder process, with 33\% solar and wind penetration on an annual energy basis. Half of the renewable generation (16.5\%) was provided by solar, including CSP, utility-scale PV, and rooftop PV. This investigation focused on light spring conditions because of the relatively low level of synchronous generation and relatively high level of wind and PV generation. The instantaneous penetrations of solar and wind for this snapshot of a windy, sunny morning in the spring were significantly higher than the annual energy penetration described above. The Hi-Mix case had 56\% instantaneous penetration (based on the total U.S. generation in WECC), and the Extreme case had 64\% instantaneous penetration. The detailed siting of the wind and solar plants was based on previous work in Phase 2 of WWSIS (Lew et al. 2013).

For the conditions studied, WWSIS-3 demonstrated that both frequency response and transient stability can be maintained with high instantaneous penetrations of inverter-based generation on the western U.S. grid. The system-wide frequency response exceeded the interconnection frequency response obligation specified by the North American Electric Reliability Corporation (NERC) for all cases, and the frequency nadir remained above the highest under-frequency load shedding threshold for all cases. This means that, at the levels of penetration simulated, the system could maintain enough PFR to avoid blackouts after severe events, including the instantaneous loss of two Palo Verde units in Arizona, equivalent to about 2,750 MW.

The study also concluded that, while not needed to meet system-wide performance criteria, the use of active power controls in wind turbines and PV could improve frequency response by improving both frequency nadir and settling frequency. This could allow even greater instantaneous penetration of VG than examined in the study. Currently available wind turbines are now being deployed that can provide active power control, including both synthetic inertia and PFR. Synthetic inertia is enabled by power electronics that can sense frequency and 
automatically and rapidly increase energy output from a generator. Wind turbines can draw stored energy from the rotor to help arrest a frequency decline, or they can be operated at reduced output during periods of high VG penetration to provide primary frequency (governor) response.

WWSIS-3 also did not identify any fundamental reasons why the Western Interconnection cannot meet transient stability performance criteria with high levels of wind and solar generation. However, good system planning and power system engineering practices must be followed, and will likely require some transmission system improvements. The study also pointed to the need for greater understanding of the impact of distribution-sited PV on multiple aspects of system operation, including the ability of rooftop PV to provide grid services. The use of active-power controls from VG to provide frequency response represents the next phase of evolution in the operation of power systems with VG. Historically, VG was operated as a "must-take" energy resource, with limited consideration of how VG could be used to provide grid services. VG resources historically have not provided significant amounts of any type of reserves in the current grid. However, both wind and solar with fast-responding, inverter-based generators can be used to add flexibility to the system. Inverter-based controls are not constrained by the physics and long time-constants of synchronous machines - they can be designed to provide faster frequency response.

With changes to controls, wind and solar plants can participate in the regulation of grid frequency. Grid code requirements are evolving in response to technological advances and anticipation of high renewable energy penetration. For example, the Texas interconnection (ERCOT - the Electric Reliability Council of Texas) is the smallest of the three U.S. interconnections and more vulnerable to frequency excursions, and it now requires wind generators to provide inertial response, which helps keep a system stable in the initial moments after a disturbance (Bird et al. 2014).

A key element of the provision of operating reserves from solar is the need for curtailed energy. ${ }^{25}$ As with any generator, PV needs to be operated at below full output to provide the upward reserve capacity most important for providing frequency response. At low penetration, the energy value of PV greatly exceeds the value of reserves, so it is uneconomic to curtail PV to provide reserves. However, at increased penetration, it may make sense to curtail PV selectively to provide a variety of reserve services. By providing reserves using curtailed energy, PV can actually help reduce overall curtailments, because otherwise reserves would need to be provided by partially loaded synchronous generators, which increases the minimum-generation problem.

Provision of reserves from PV will require new mechanisms - whether market incentives, interconnection requirements, or other means - to ensure that inverter-based wind and solar plants can provide the grid's frequency response needs as they become a larger proportion of the generation fleet and displace traditional synchronous machines.

\footnotetext{
${ }^{25}$ Wind can provide inertial response by drawing stored energy from the spinning rotor. PV has no such inherent storage, so any increase in output must be obtained by employing curtailment.
} 


\subsection{Demand Response}

DR refers to voluntary (and compensated) load reduction or load shifting. There are two general categories of DR mechanisms. First, price-based DR programs vary the price of electricity over time to encourage consumers to change their electricity use patterns. Price-based mechanisms include time-of-use pricing (which assigns prices for consumption during different blocks of time), critical peak pricing (which specifies a very high rate for a limited number of hours), and real-time pricing (which varies rates in response to wholesale market prices, often on an hourly basis) (FERC 2014b). Second, incentive- or event-based DR programs provide financial compensation to customers who allow the program administrators to control certain electricityconsuming equipment directly and/or reduce their electricity demand upon request. Examples of incentive- and event-based mechanisms include interruptible load rates, demand bidding or buyback programs, emergency DR programs, and ancillary services markets (Ma et al. 2013).

By providing both event-driven load reduction and load shifting, DR can provide multiple benefits to integrating solar and reducing curtailment. When providing load reduction, DR can reduce the dependence on partially loaded synchronous generators for providing frequency stability and operating reserves. Several U.S. regions already derive a significant amount of operating reserves from DR. Some regions, such as ERCOT, employ frequency-responsive loads that disconnect when they sense a drop in frequency, allowing them to provide a combined PFR/contingency reserves service. The ERCOT grid now derives 50\% of its contingency reserves from DR in the form of this "fast frequency response," which is the maximum currently allowed by ERCOT market rules (Potomac Economics 2014). The emergence of restructured markets, new communication (smart grid) technologies, and rules allowing smaller entities to participate via the use of DR aggregation programs will likely increase the role of DR in providing reserves (Cappers et al. 2013).

When providing load shifting, DR can change the shape of the net load, which can reduce ramp rates, better align solar supply with demand, and reduce peak capacity needs. In many cases, retail rate reform will be required to increase consumer participation in providing grid services (Younghein and Martinot 2015; Cappers 2013). New controllable electricity uses, such as electric vehicles, may provide additional opportunities to improve the timing of demand to match the supply of solar energy (Denholm et al. 2013). 


\subsection{Energy Storage}

Similar to DR, energy storage can provide reserves, change net load shape to minimize ramping requirements, and shift supply of VG to periods of increased net load. There are about $22 \mathrm{GW}$ of pumped storage capacity in the U.S. power grid, including about $4.7 \mathrm{GW}$ in the West (EIA 2015). Most existing pumped storage typically responds to existing demand patterns, charging during periods with lowest demand (and lowest prices) occurring in the early morning and then discharging in the late afternoon. As PV penetration increases, pumped storage operation can be modified to respond to changes in net load patterns. Figure 13 shows the results of the simulations discussed in Section 2, demonstrating how pumped storage operation on March 29 can be modified to avoid curtailment. In this example, the existing pumped storage is used to store otherwise curtailed energy in the middle of the day. This energy is then used later in the day during periods of higher net load. ${ }^{26}$

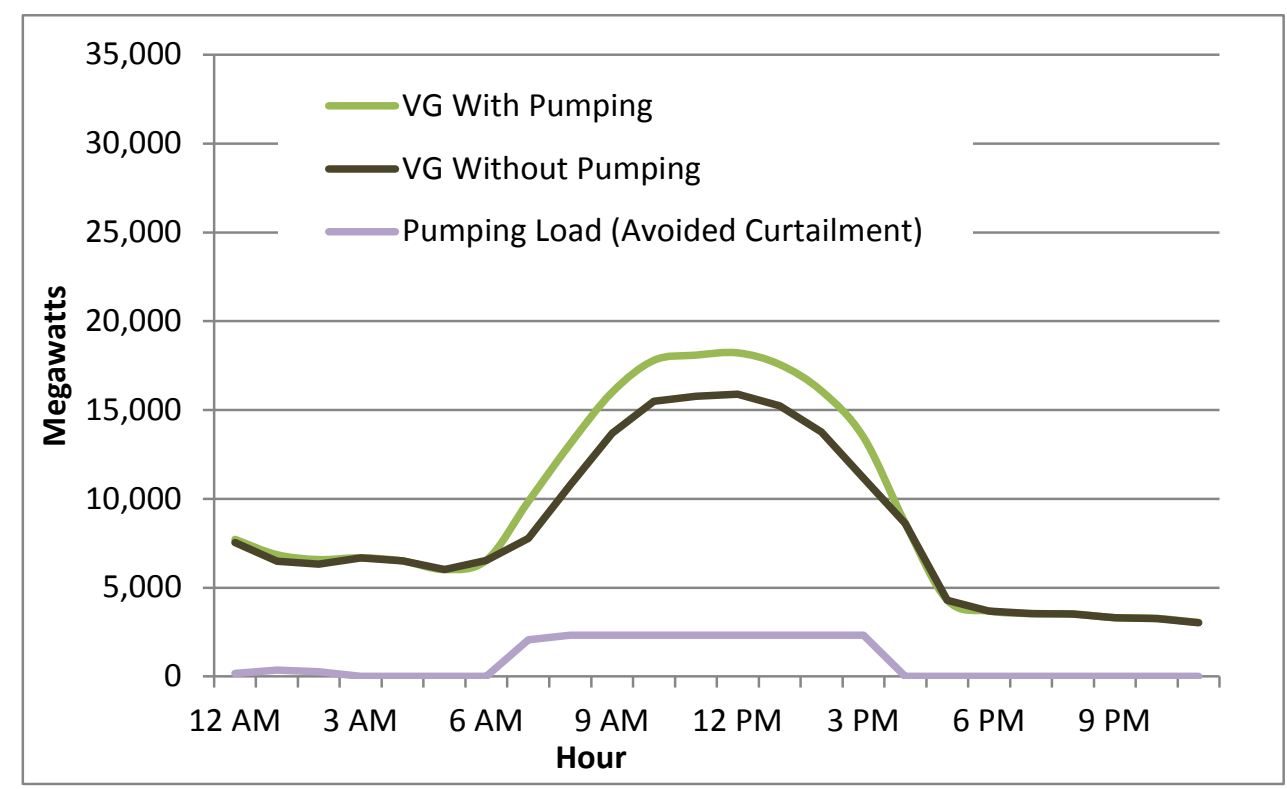

Figure 13. Impact of existing pumped-hydro storage in California on March 29th in a simulated system with $11 \%$ solar penetration

Using existing pumped storage in this manner will require increased flexibility of these plants as well as deviation from historical practices. Furthermore, storage plants operating in wholesale market regions may be unable to receive the full market value of providing multiple grid services, including rescheduling, to address variability and uncertainty of net load. This issue is discussed extensively by Koritarov et al. (2014), Sioshansi et al. (2012), and Bhatnagar et al. (2013). These limitations include the need for a system operator to optimize the storage resource to minimize overall system production cost. In U.S. wholesale markets, only PJM allows the system operator to optimize the charge/discharge patterns of storage operation completely (Koritarov et al. 2014). All other U.S. electricity markets require some degree of self-scheduling by storage operators. Furthermore, most behind-the-meter (customer-sited) storage will dispatch storage to relatively simple time-of-use or demand-based tariffs that only approximate real grid conditions that would signal the appropriate time to charge and discharge in response to

\footnotetext{
${ }^{26}$ Storage does not completely avoid curtailment due to storage losses. Assuming a 20\% loss rate, $1 \mathrm{MWh}$ of stored PV electricity only displaces $0.8 \mathrm{MWh}$ of conventional generation.
} 
changing net load. Market changes proposed or underway will address some, but not all, of the limitations in how storage can help integrate VG.

New storage will provide additional benefits. While pumped storage can respond rapidly to variations in demand (typically faster than most forms of conventional generation), new technologies being deployed can respond even faster and potentially provide significant amounts of frequency stability services. Pumped storage and compressed-air energy storage (CAES) use synchronous generators that provide real inertia and can provide PFR. Other types of storage, including flywheels and batteries, do not use synchronous generators but can provide synthetic inertia and PFR. In addition, devices such as flywheels and batteries have been installed specifically to provide regulation reserves (Akhil et al. 2015).

The CPUC has created procurement targets and requirements for 1,325 MW of "viable and costeffective" energy storage systems by 2020 , as directed by the California State Legislature in 2010 (Eichman et al. 2015; CPUC 2013b). The mandate expects a mix of transmission-, distribution-, and customer-sited storage (Liu 2014a).

The amount of new storage in the California storage mandate significantly exceeds the WWSIS3 estimated frequency response obligation for California, and WWSIS-3 found that a relatively small amount of storage (less than that in the California storage mandate) could provide significant benefits across the entire Western Interconnection. Adding storage can both shift load and provide multiple grid flexibility services, including fast frequency response. However, using storage in this manner would deviate from the expected applications of the storage mandate, with much of the distribution- and customer-sited storage not expected to provide reserves (Liu 2014a).

Unlocking the full potential of existing or near-future energy storage deployment via new market mechanisms could enhance its ability to integrate renewables. By fully optimizing storage in both day-ahead and real-time scheduling as well as providing operating reserves including frequency stability, storage can shape the net load while reducing the need for thermal generation - reducing the minimum generation problem and associated curtailment. 


\section{Impacts of Increased Flexibility}

By deploying grid flexibility options such as those discussed in Section 3, the value of PV to the grid can be increased for provision of both energy and capacity. Section 4.1 presents the results of grid simulations that examine the impact of "near term" flexibility options, including several grid changes that will likely occur by 2020 to help reduce the impact of solar generation on grid operations and reduce curtailment. Section 4.2 examines how grid flexibility options can provide system capacity. Section 4.3 examines additional changes that could enable greater penetrations beyond the 2020 timeframe.

\subsection{Impact of Enhanced Flexibility on PV Curtailment}

To demonstrate how commercially available grid flexibility options can effectively allow greater penetration of PV, this subsection considers an "enhanced flexibility" case. This case considers how control of VG, storage, and responsive demand allows for increased instantaneous penetration of VG. The analysis uses the same approach as in Section 2.1 but with the following changes, representing the implementation of three grid-flexibility measures. Additional discussion of these scenarios is provided in Brinkman et al. (2016) and Denholm et al. (2015).

- New storage

We consider the addition of 1,290 MW of storage, roughly following the California storage mandate and consisting of $550 \mathrm{MW}$ with 2-hour discharge duration, $520 \mathrm{MW}$ with 4-hour discharge duration, and $220 \mathrm{MW}$ with 6-hour discharge duration. ${ }^{27}$ The devices are assumed to have $83 \%$ round-trip efficiency and are distributed among the three California investorowned utility zones in accordance with the storage mandate. We assume all of the storage added is optimized by the system operator to minimize the overall cost of system operation and can provide multiple services including provision of reserves. ${ }^{28}$ This is a critical assumption, and it would require optimization either 1) directly by a system operator in the case of utility-scale storage, or 2) indirectly through real-time pricing or other mechanisms that would optimize behind-the-meter storage.

- New DR

We assume a greater fraction of load (up to about $11 \%$ of instantaneous demand on peak days) can be incentivized to shift demand to times of lower energy prices (corresponding to low net demand and high PV output) based on profiles discussed in Hummon et al. $(2013 b){ }^{29}$

- Provision of grid stability services from alternative sources

We removed the $60 \%$ penetration limit and local generation requirements, representing the availability of frequency-responsive reserves from new storage, DR, and curtailed wind and

\footnotetext{
${ }^{27}$ The 40-MW Lake Hodges plant is eligible for the storage mandate, and it existed in the base case, so the additional storage is less than the $1,325-\mathrm{MW}$ requirement.

${ }^{28}$ This is a deviation from the current assumptions in the LTPP model, which assumes a mix of transmission-, distribution-, and customer-sited storage, of which only a fraction can provide reserves (Liu 2014a).

${ }^{29}$ This and other changes to system operation will likely require new market mechanisms. Hogan and Paulos (2014) discuss several of these.
} 
solar. We also allow curtailed VG to provide upward regulation, contingency, and flexibility reserves. Use of distributed resources and load to provide frequency response will require loads to sense system frequency and automatically reduce load during low-frequency events. ${ }^{30}$ This incurs both an implementation cost and any costs associated with paying customers when load is curtailed.

Additional discussion of these scenarios is provided in Brinkman et al. (2016) and Denholm et al. (2015). Figure 14 compares how the net load and use of PV changes with these measures in a case with $15 \%$ annual PV potential. The top curve shows the net load in the limited flexibility case, roughly corresponding to today's grid conditions. The lower curve shows the case with enhanced flexibility, where the minimum generation point has been reduced to about 10,000 MW.

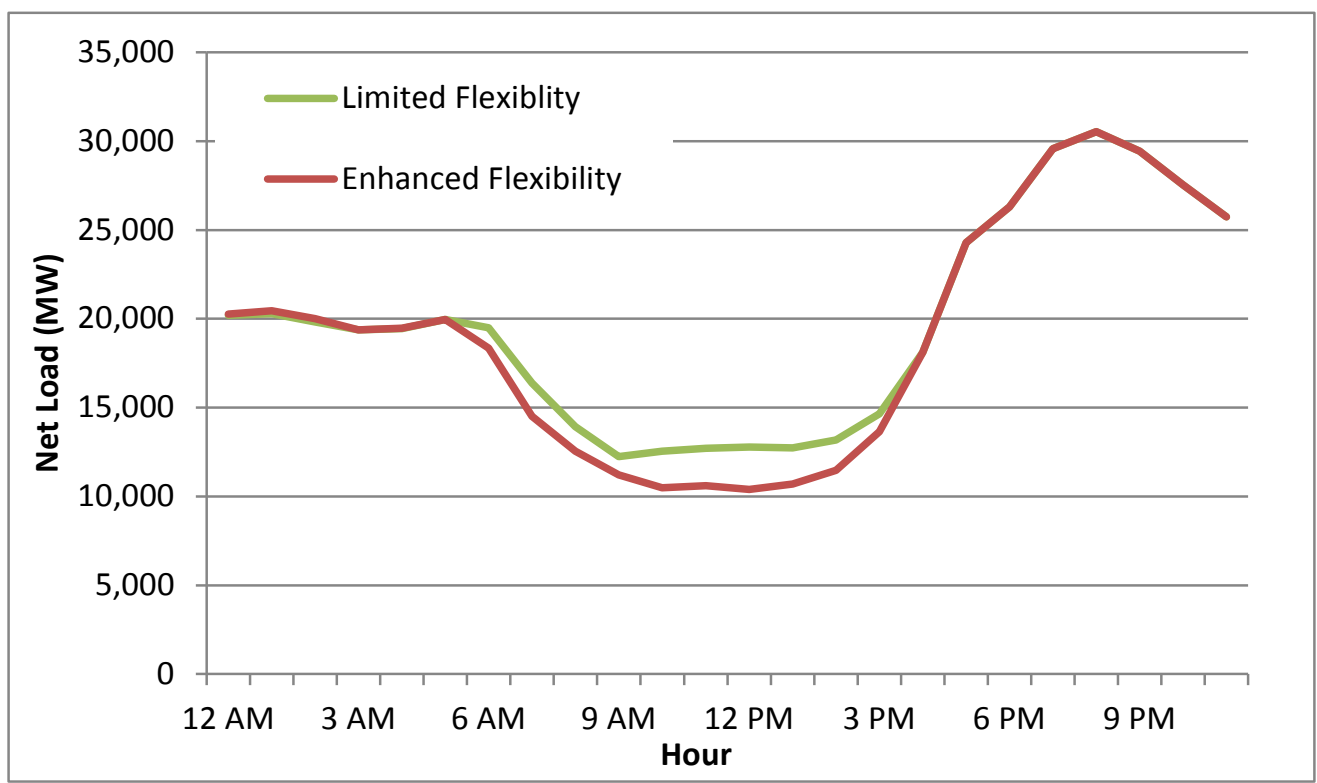

Figure 14. Net load on March 29 in a scenario with $15 \%$ annual solar and limited or enhanced grid flexibility

The reduction in minimum generation level, along with added storage, results in the decrease in PV curtailment shown in Figure 15. Over 3,000 MW of additional PV generation can be accommodated, and total curtailment on this day drops from $13 \%$ to $7 \%$. While curtailment has been reduced, it has not been eliminated due to other constraints on the system. The 10,000 MW net load in Figure 14 is close to the minimum output of "must-run" capacity in the system. Overall, the model identifies about 8,000-9,000 MW of minimum generation from nuclear, geothermal, hydro, biomass, and gas-fired combined heat and power units. ${ }^{31}$

\footnotetext{
${ }^{30}$ An example of an existing program that uses frequency-responsive loads is the ERCOT Responsive Reserve Service, which pays loads to reduce output automatically when the frequency drops below a certain threshold (ERCOT 2014).

${ }^{31}$ As noted previously, this low level is made possible in part by the fact that one unit of the Diablo Canyon nuclear power plant was out for maintenance on this simulated day, reducing the minimum generation level by $1,122 \mathrm{MW}$.
} 


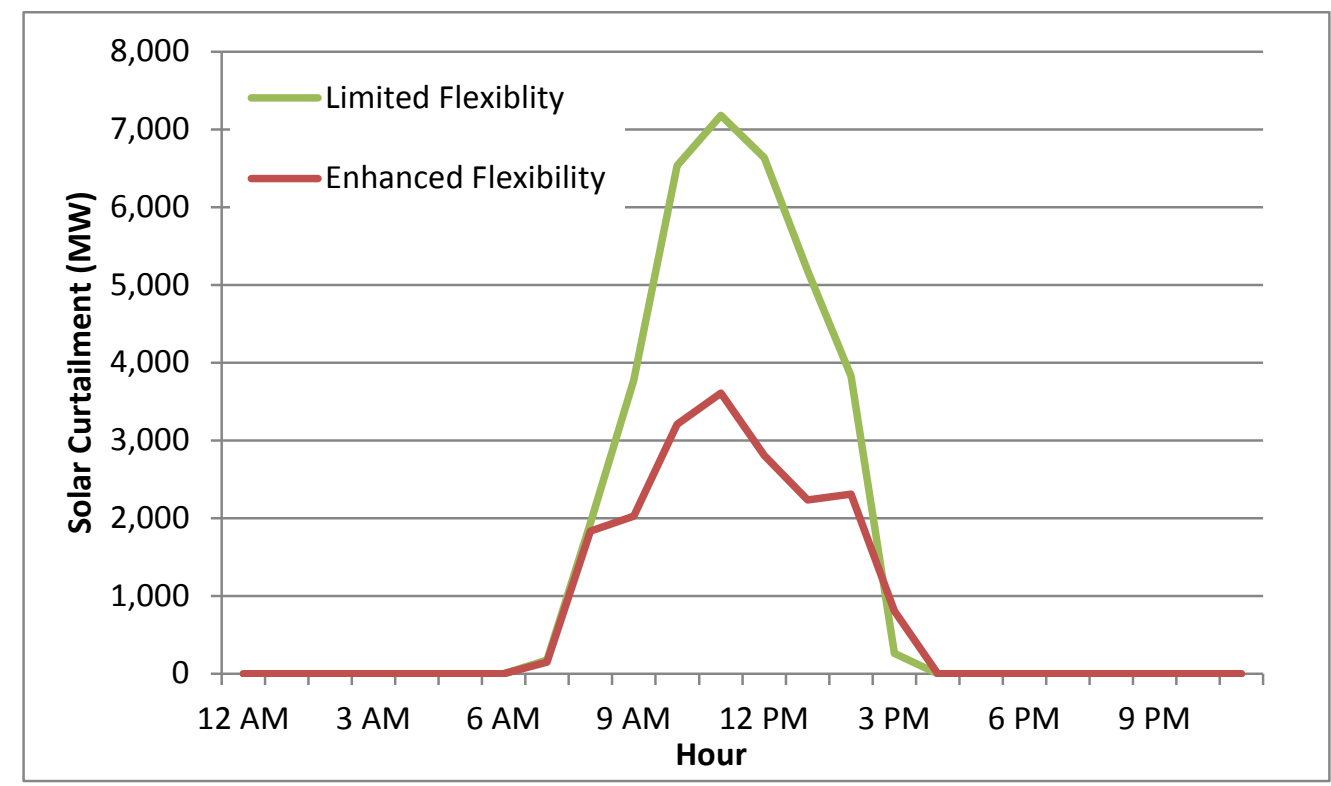

Figure 15. Impact of enhanced flexibility on PV curtailment on March 29 in a scenario with $15 \%$ annual PV generation

The overall impact of the enhanced-flexibility case on PV curtailment is illustrated in Figure 16. Compared to the limited-flexibility case, the curtailment curves are shifted to the right, meaning increased PV penetration can be achieved at the same level of curtailment.

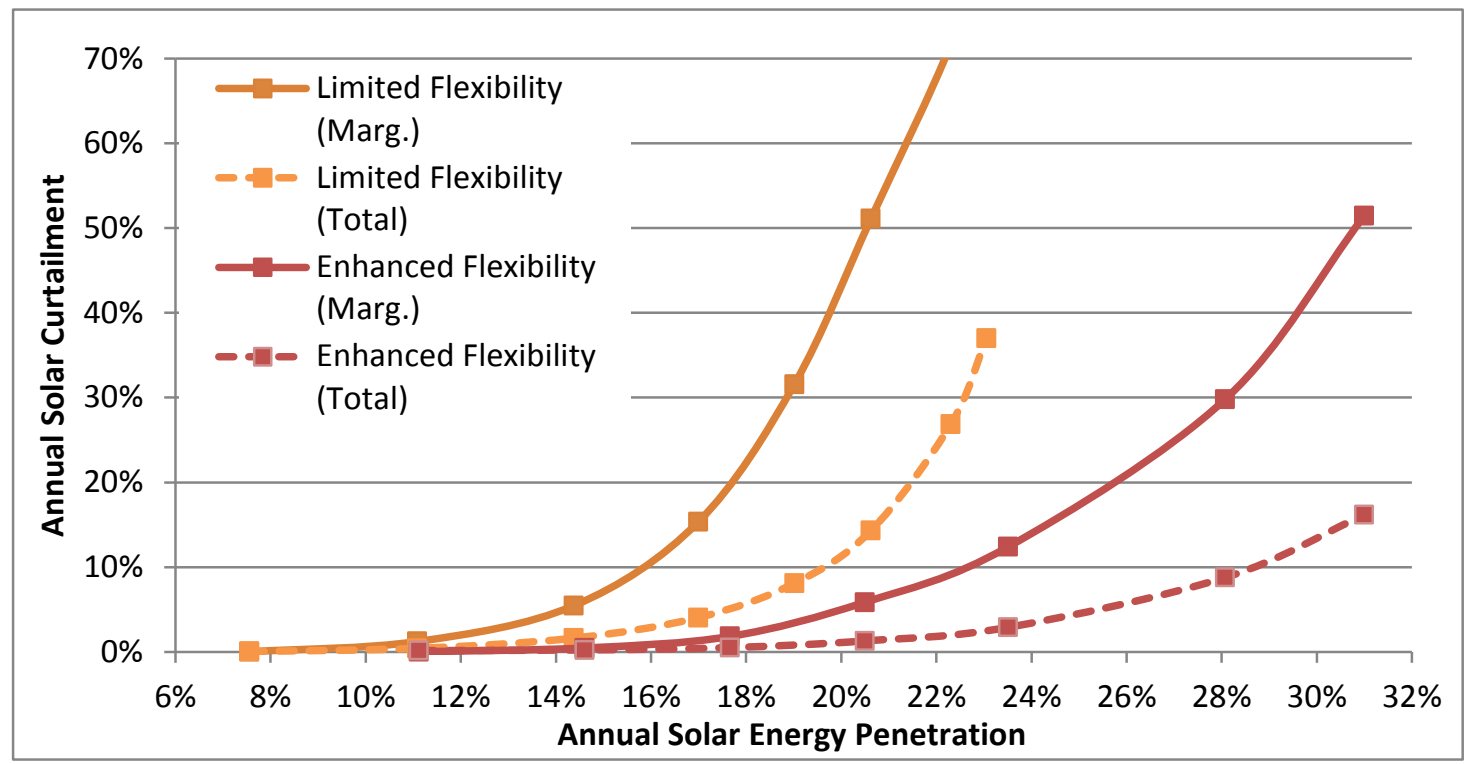

Figure 16. Marginal and average curtailment due to overgeneration under increasing penetration of PV with limited and enhanced grid flexibility

Overall, the results in this subsection imply that deploying new communications and control technologies allows distributed resources (including storage) to participate in grid functions and could potentially allow solar penetrations in California of $25 \%$ on an annual energy basis with less than 20\% marginal (and well under 5\% total) curtailment rates. The corresponding PV LCOE curves (based on the SunShot $6 \notin / \mathrm{kWh}$ target) are provided in Figure 17. This figure shows that PV could remain cost competitive at higher penetrations. 


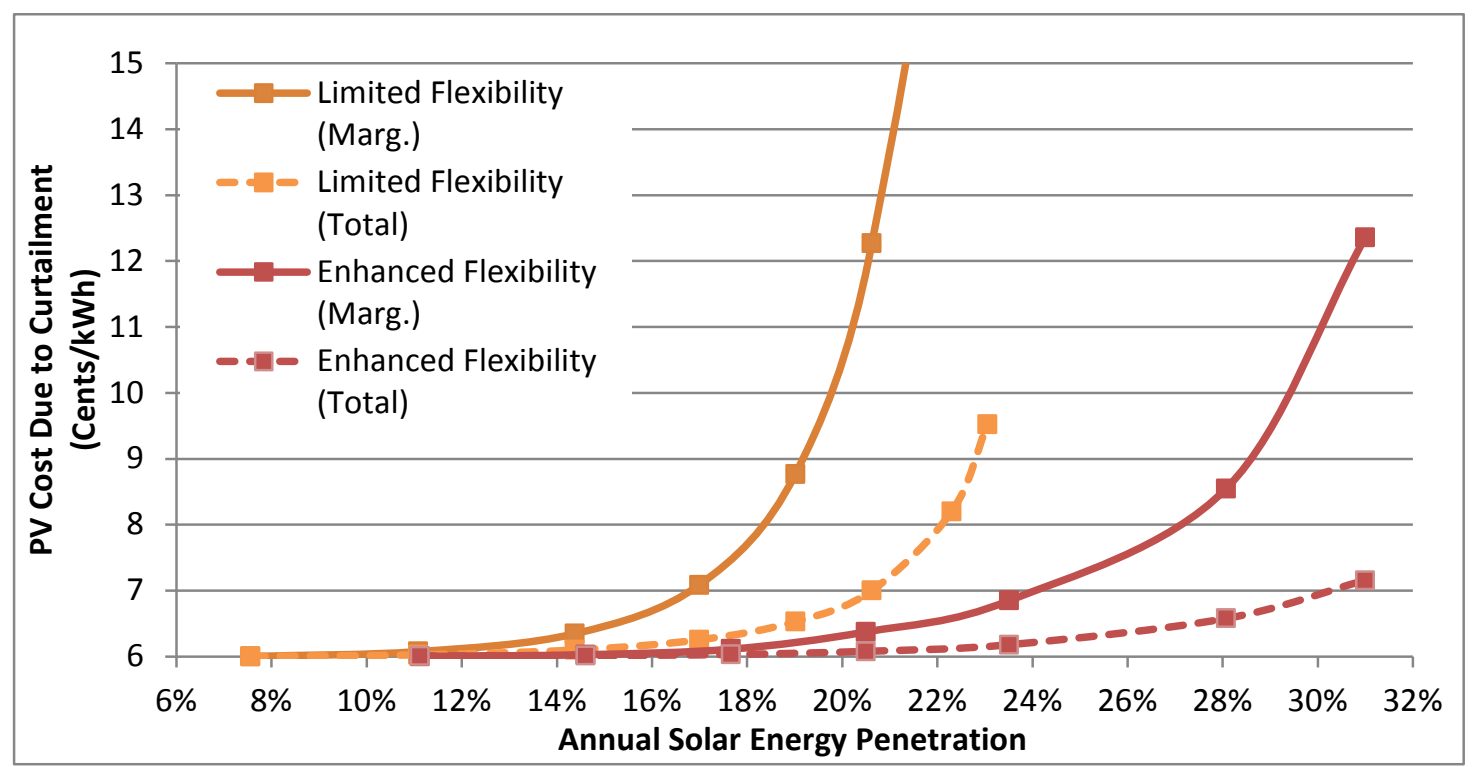

Figure 17. Marginal and average PV LCOE (based on SunShot goals) due to overgeneration under increasing penetration of PV in California with limited and enhanced grid flexibility

Previous analysis also demonstrates the importance of grid flexibility to reduce renewable curtailment. The studies mentioned in Section 2-including Nelson and Wisland (2015), E3 (2014), Mills and Wiser (2015), and Brinkman et al. (2016) — all evaluate multiple flexibility measures and show substantial reduction in curtailment when grid flexibility is increased.

Achieving this level of PV penetration requires new services from load and distributed resources, which in turn requires the system operators to have greater visibility and control of multiple distributed resources, including PV and storage. These distributed resources likely will be required to perform many functions currently performed by conventional generation resources, with appropriate controls and market mechanisms put in place to compensate owners for providing these services.

\subsection{Impact of Enhanced Flexibility on PV Capacity Value}

In addition to avoiding curtailment, another important aspect of grid flexibility is maintaining a high PV capacity credit. While the capacity credit of PV in isolation drops rapidly as a function of penetration, PV's impacts on net load shape may make it easier for load-shifting technologies - including DR and storage - to provide firm capacity.

The ability of PV to enable capacity from DR and storage is due to two factors: the reduced amount of time between on-peak and off-peak periods as well as the overall narrowing of the onpeak period. These issues are illustrated in Figure 18, which shows the impact of PV on net load shape for a summer and winter period. The reduced amount of time between on-peak and offpeak periods is especially useful for DR. DR (particularly load-shifting) requires a load that can be used earlier or later than would normally occur. A large fraction of demand during peak periods in the summer and winter is associated with cooling and heating. One method of shifting cooling demand is pre-cooling. Pre-cooling, or cooling a building at or below a desired setpoint before the cooling is needed, depends on the ability of a building to store thermal energy. It is 
easier to pre-cool a building with a shorter delay between the pre-cooling period and when the building must stay at the desired temperature.

Figure 18a shows the load for two days in July. Without PV, the lowest net load occurs in the early morning (1-4 am), and the highest load occurs in the late afternoon (4-6 pm). This means there is a roughly 12-hour time difference between the "ideal" period to pre-cool (increase load) and when this "stored" cooling load is used. With added PV, there is reduced demand in the late morning and early afternoon that provides spare capacity that could provide energy from load shifting. Thus, the time needed for pre-cooling or other load-shifting applications is substantially reduced. Similarly, the winter load pattern creates another low net-demand period shortly before the peak demand in the early evening. This may create additional opportunities for demand shifting.

The second impact of solar on net load shape is the narrowing of the peak period (Jorgenson et al. 2014). Figure 18 demonstrates how, in the summer (the period of highest absolute demand), the number of peak-demand hours is shorter. Historically, utilities have relied on pumped storage with many hours of capacity for provision of peak capacity, and Sioshansi et al. (2014) suggest that, in a system with very low PV, as much as 8 hours of storage capacity may be needed to achieve the same level of reliability as a traditional generator. However, the narrowing of the peak demand period could allow shorter-duration batteries to provide the same level of service under increased penetration of PV. This general concept has also been referred to as the "minimum buffer energy storage capacity" (Perez et al. 2008). 


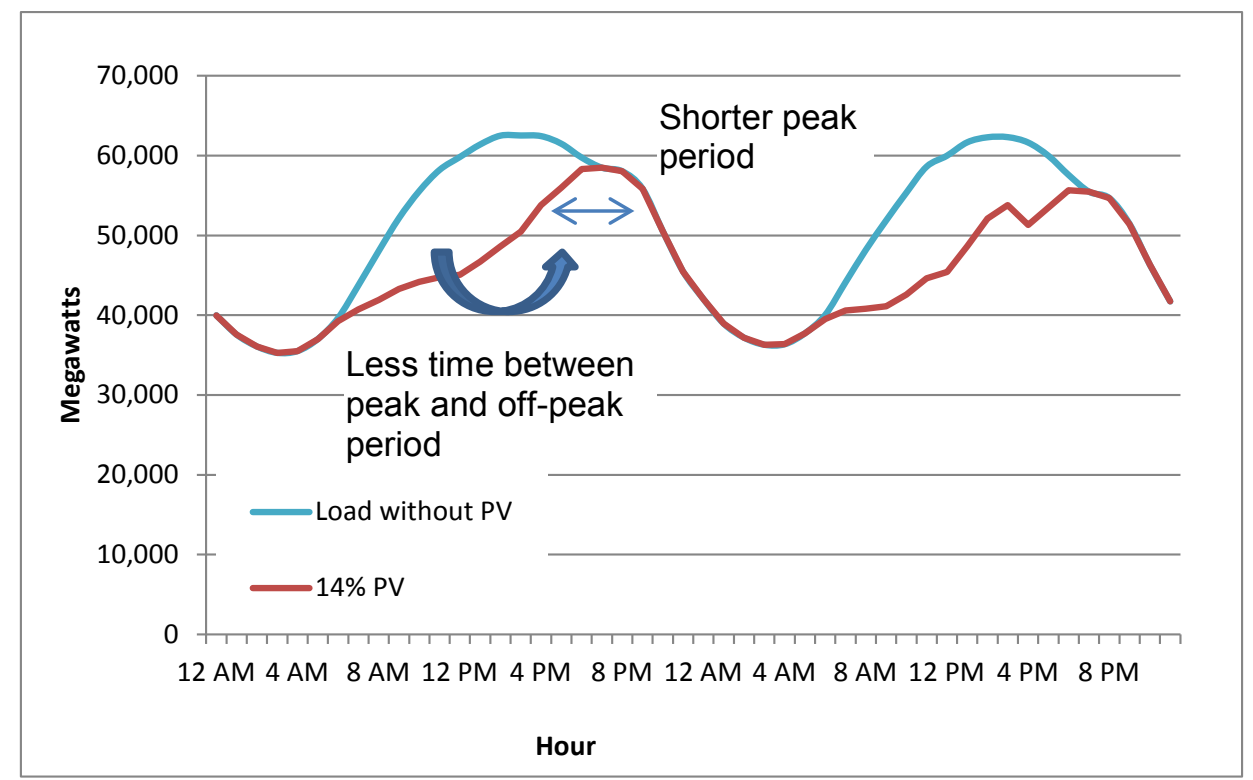

(a) July 29-30

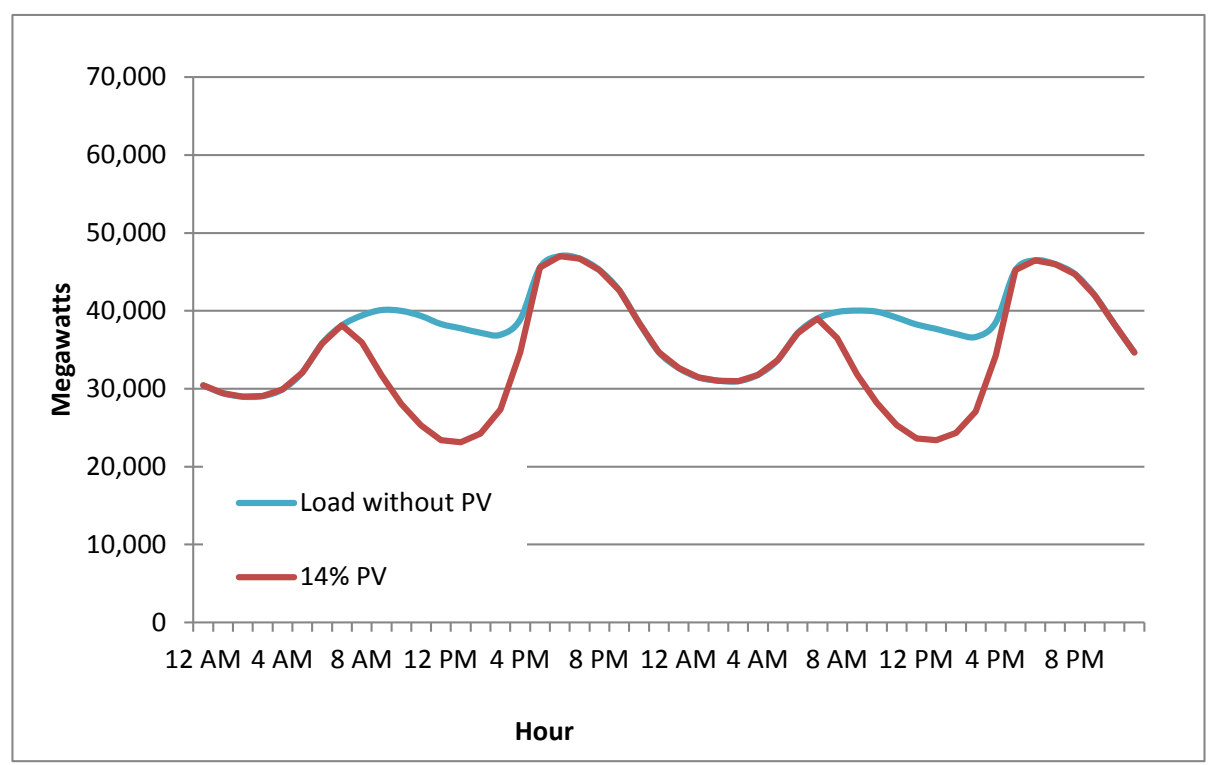

(b) December 21-22

Figure 18. Load with and without PV

Figure 19 shows in greater detail how the narrower peak period allows for less stored energy to reduce the net load and allow for a lower-cost storage device to provide system capacity. It shows the load with and without added solar as well as the amount of stored energy needed to reduce the peak demand by 1,325 MW (equal to the California storage mandate), which is represented by the shaded area under the demand curves. 


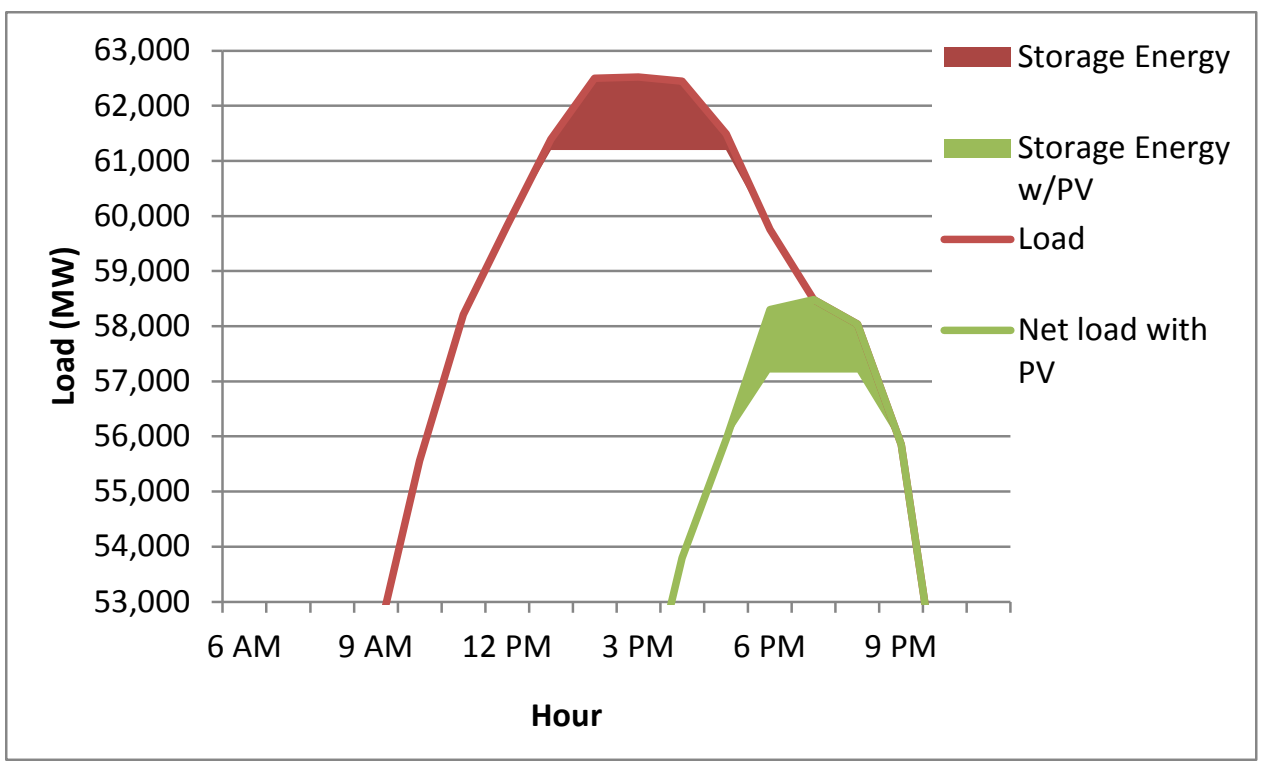

Figure 19. Narrowing of net peak and amount of storage needed to deliver a 1,325-MW peak demand reduction on July 30

In the no-PV case, the normal demand would require about 4,367 MWh of stored energy, or 3.3 hours of capacity for a 1,325-MW battery or other storage device. This amount is reduced by about $23 \%$ to 3,347 MWh (2.5 hours of capacity) in the case with the added PV. Figure 20 shows the trend in storage energy capacity needed for two amounts of storage power capacity $(1,325$ MW and 2,650 MW). This figure estimates the storage capacity needed (in hours) to reduce the net demand by the full capacity of the storage device for the top 50 demand days of the year. At low penetration of PV, about 4-6 hours of battery capacity are needed to reduce load reliably by the rated capacity of the storage device, assuming an optimally scheduled battery (requiring perfect foresight of demand during the peak period). Note this does not mean that the battery operates at full output during the entire period of discharge; the battery output is assumed to follow the shape of the demand curve, often discharging at partial output. As PV penetration increases, the battery capacity requirement decreases, to the point where about 3 hours of storage capacity are needed at penetrations beyond $10 \%{ }^{32}$

The combined impact of midday off-peak energy availability and shortened peak periods should increase the availability of DR while decreasing the costs of storage used for meeting peak demand. Further analysis is needed to estimate the actual potential for demand shifting and associated costs under increased PV penetration.

\footnotetext{
${ }^{32}$ Beyond $15 \%-20 \%$ PV penetration, the net demand peak does not narrow further, which is why the hours of storage needed do not decrease.
} 


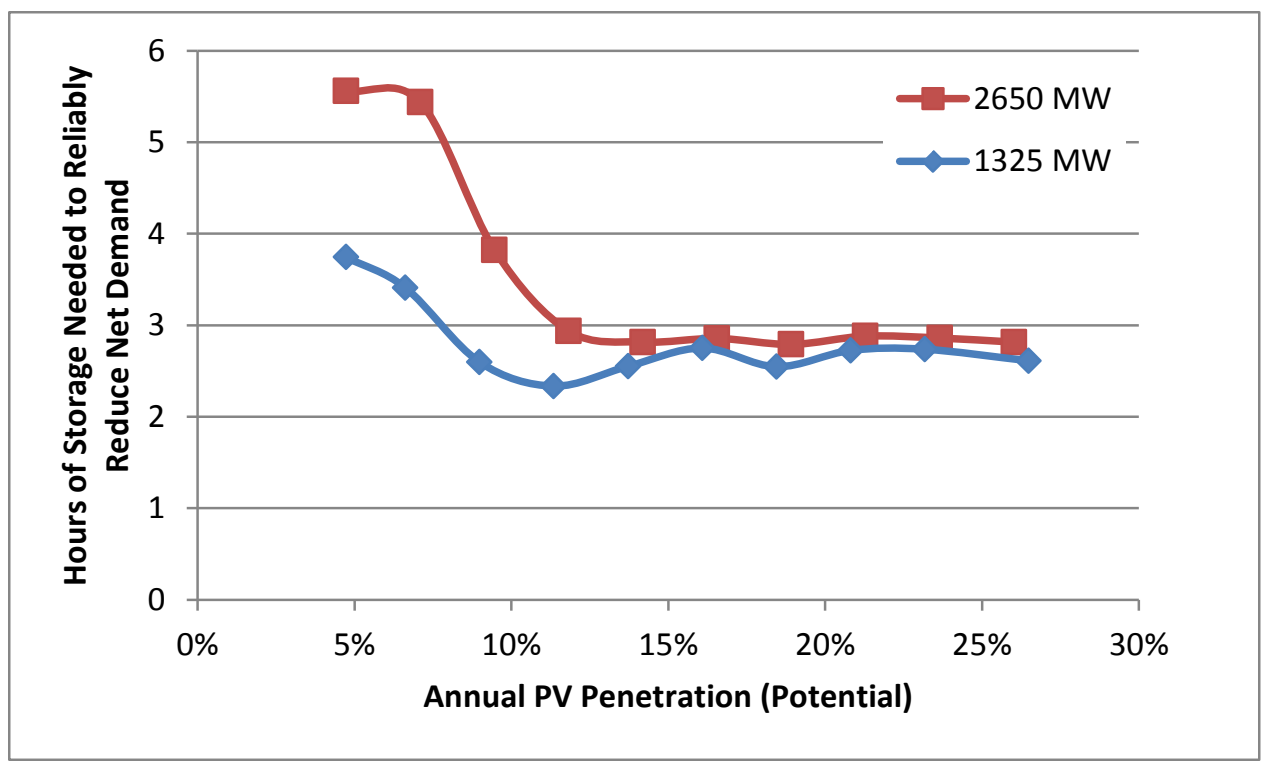

Figure 20. Hours of storage needed to reduce peak demand by 1,325 MW and 2,650 MW as a function of PV penetration

\subsection{Beyond SunShot: Further Increasing Solar Deployment}

The previous subsections consider the ability of near-term technologies (deployable by 2020) to enhance grid flexibility and increase both the energy and capacity value of PV. This can enable PV penetration as high as $25 \%$, with modest curtailment. Moving beyond this point with exclusively PV becomes increasingly challenging; however, several additional options can help enable additional solar generation.

While there are potentially many additional enabling technologies, this subsection uses the example of energy storage, which may emerge as a source of cost-competitive grid flexibility at higher levels of PV penetration in the post-2020 timeframe. Traditional electricity storage includes a number of technologies — such as batteries, advanced pumped storage, and CAESthat can shift energy over a few hours. International R\&D efforts continue to explore new technologies, and projections have the installed cost of batteries continually declining as a function of deployment at scale (Nykvist and Nilsson 2015). Another form of storage is the use of TES with CSP. The U.S. Department of Energy (DOE) has aggressive goals to reduce the costs of CSP, and this resource can be deployed with integrated, high-efficiency TES that produces dispatchable energy with a high capacity credit (Jorgenson et al. 2014). Another On the Path to SunShot report (Mehos et al. 2016) describes this technology in detail.

Figure 21 shows an example of how CSP with TES can shift solar generation to periods of high net demand to avoid curtailment and provide high capacity credit. The figure shows the net load in a $25 \%$ solar case with enhanced flexibility on March 29 before the addition of CSP. Virtually all dispatchable generation in the system has been turned off, and any additional PV generation on this day would be almost entirely curtailed. The inflow of solar energy to the aggregated set of CSP generators, designated in the figure as “Available Solar Energy for CSP”, occurs during the period of overgeneration conditions (due to large PV production) and very low net load. CSP with TES stores this available solar energy and shifts it to periods of high demand, while providing fast-ramping capability (Jorgenson et al. 2014). 


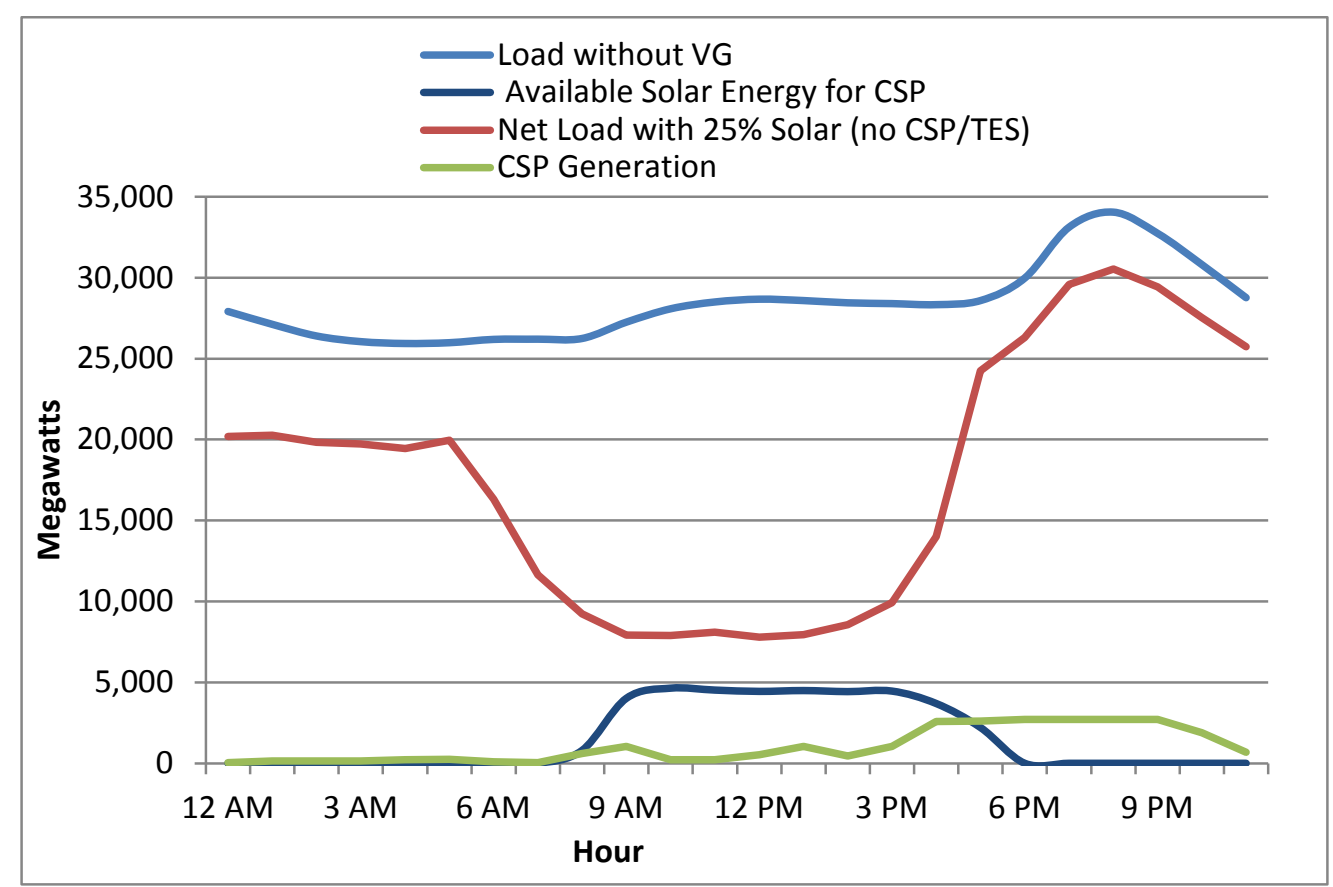

Figure 21. Dispatch of CSP with TES on March 29

During periods of highest overall net demand, CSP also provides firm system capacity. Figure 22 shows the same scenario as the previous figure, except it is for July 29, the day with the peak net demand. In this case, the net demand peaks in the hour beginning at $7 \mathrm{pm}$, when PV output is close to zero. However CSP/TES generates at nearly full output, reducing peak net demand. Storage with high capacity credit could enable further retirements of the thermal generation fleet and thus reduce minimum generation constraints (Denholm and Mehos 2011).

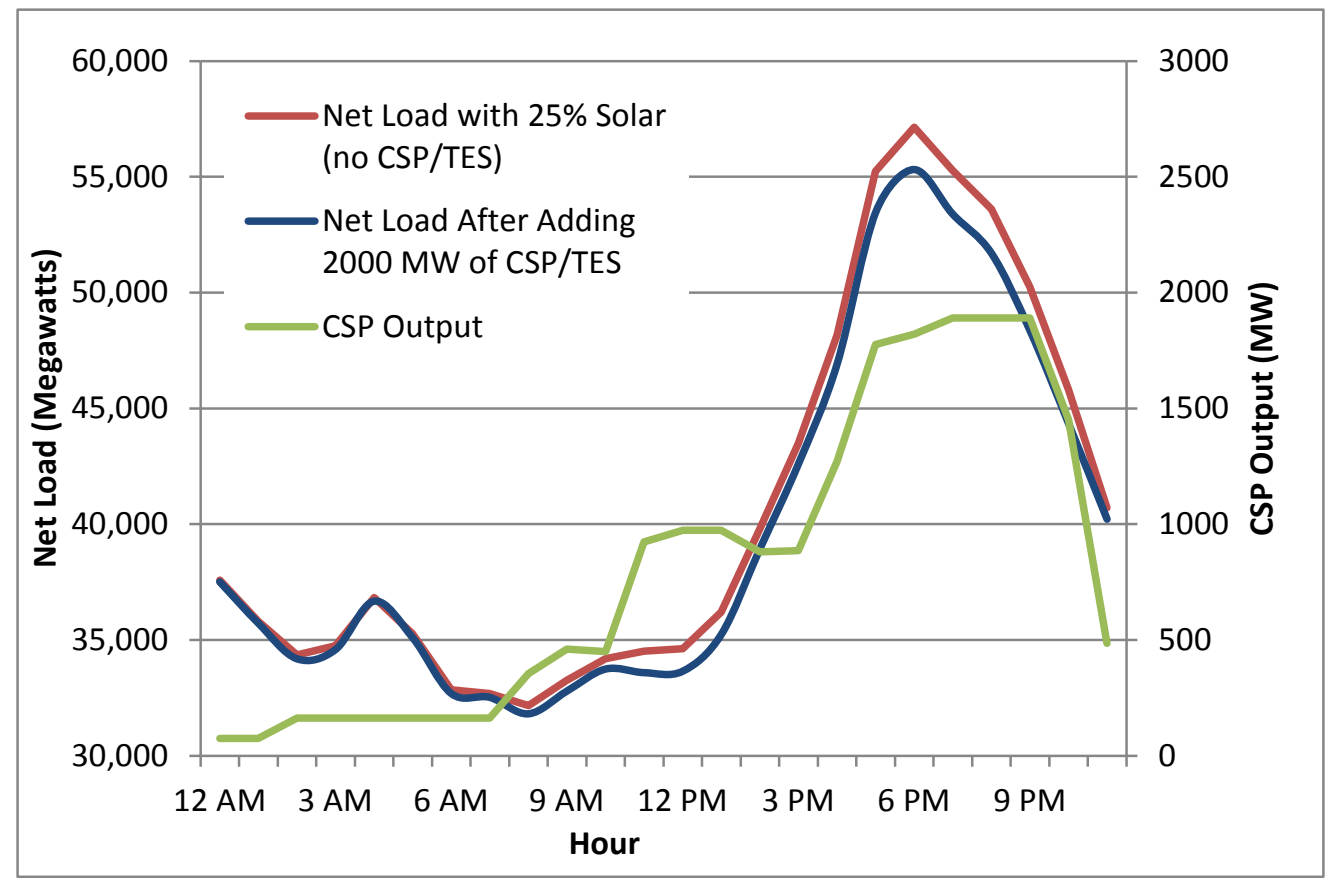

Figure 22. Dispatch of CSP with TES on July 29 
Figure 23 shows the marginal curtailment curve when CSP with TES is added to a system with significant PV. In this case, CSP is added starting when solar provides $28.4 \%$ of total demand and marginal curtailment of PV is $30 \%$. Adding significantly more PV to this system will produce very high curtailment (greater than 50\%). The dashed line shows the transition to the addition of CSP with TES. Adding a unit of CSP with 6 hours of TES and enough capacity to provide about $1 \%$ of additional solar generation will reduce marginal curtailment to about $10 \%$, and this value could be lower with greater amounts of TES. A change in the curtailment curve could also be obtained by deploying electricity storage, but stored PV energy will still have effective curtailment (and a corresponding increase in costs) due to losses in the storage process (typically $20 \%$ or greater) (Akhil et al. 2015).

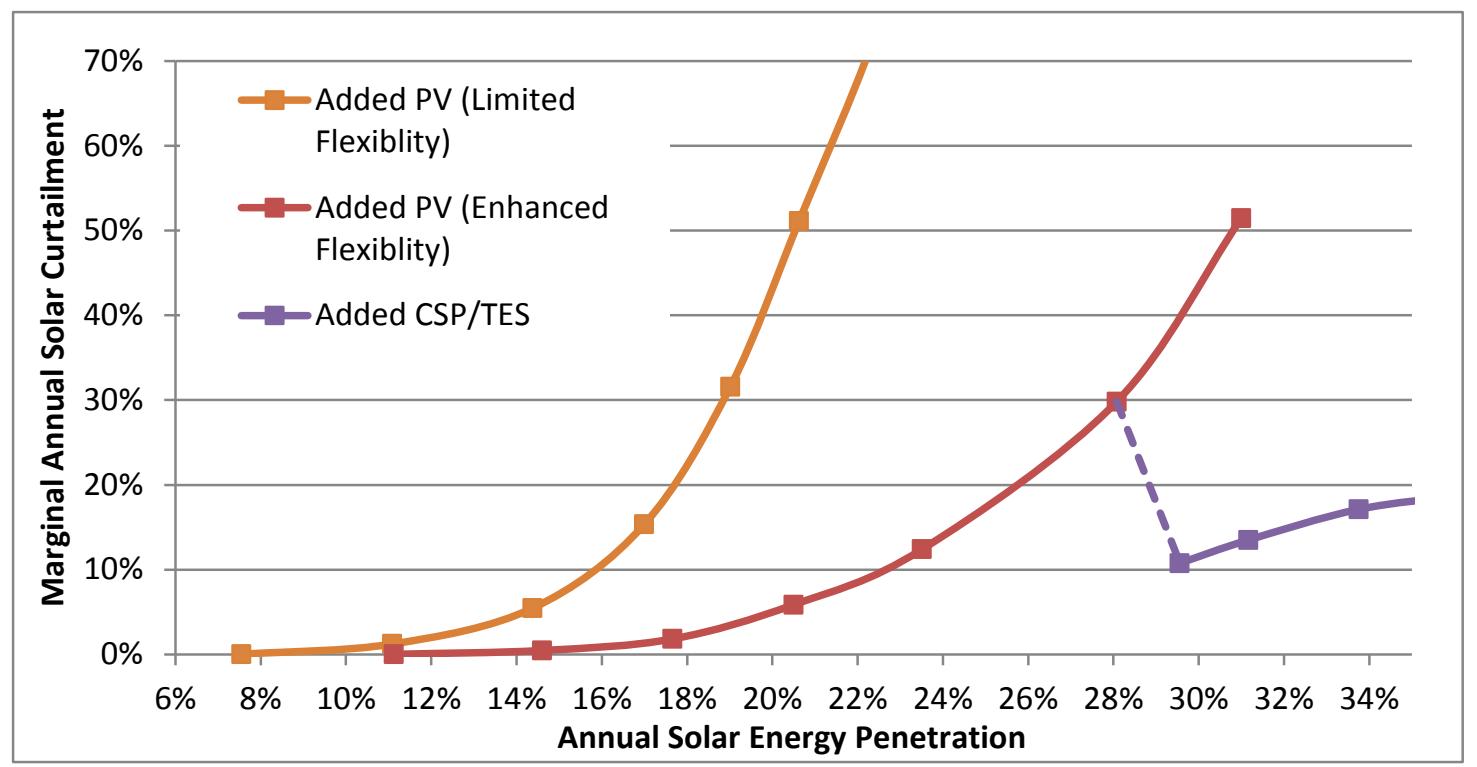

Figure 23. Marginal solar curtailment due to overgeneration under increasing penetration of solar when adding PV (first two cases) or CSP/TES

Figure 23 provides an example of a possible deployment scenario, but a more comprehensive analysis of different solar energy technologies is required. CSP generally has a higher LCOE than PV, but it avoids curtailment and provides firm capacity adding additional value (Mehos et al. 2016). Previous studies suggest much greater near-term deployment of lower-cost PV, with increased deployment of CSP beyond 2020 when a combination of increased PV curtailment and decreased CSP technology costs is realized (Denholm et al. 2012). Finally, while this analysis focuses primarily on enabling high solar penetration, a more balanced portfolio could also more generally reduce the challenges of integrating VG (Denholm and Hand 2011). When PV is at $30 \%$ penetration, additional wind has significantly lower levels of marginal curtailment than PV. This has been noted previously (E3 2014; Brinkman et al. 2016), and it suggests the need for a more comprehensive analysis of different renewable portfolios to achieve the most cost-effective mix of generation technologies. 


\section{Conclusions}

More than a decade of experience with wind integration in the United States, along with growing international solar-integration experience, has demonstrated the ability to cost effectively integrate VG resources into the nation's electricity generation and transmission systems. A critical aspect of VG integration is recognizing and implementing cost-effective flexibility resources. This includes ensuring generation resources on the grid are committed and dispatched economically, with the ability to respond to variations in net demand. Operating the generation fleet in the most economic manner will unlock inherent flexibility in the system.

Such insights will increase the value of solar generation in terms of both energy and capacity. Increased operator experience with solar, improved forecasting, and new market flexibility products will also reduce the need for excessive and costly regulating reserves that may prevent full use of solar resources. Increasingly, recognition that solar and wind must be integral parts of the electricity system, actively providing multiple grid services, will also decrease dependence on traditional generators for reserves and grid-stability services.

Orderly and economic development and deployment of flexibility options will require a variety of stakeholder actions. While many flexibility options are currently being deployed, others will require new market rules and mechanisms. Economic integration of widespread solar will require that distributed resources, including rooftop PV and distributed storage, be visible to system operators, and it may require operators to control their output to maintain grid stability. Updated grid codes and use of existing technologies such as smart inverters will allow PV to participate in system dispatch and the maintaining of grid frequency and voltage. The natural evolution of markets - including increased, cost-effective responsiveness of demand more variable grid conditions - will also create new opportunities to integrate solar. Finally, multiple storage technologies now being deployed or under development, including CSP with TES, can drive solar technologies toward SunShot-level deployment and beyond-making solar a primary component of the de-carbonized electricity future. 


\section{References}

Ahlstrom, M., D. Bartlett, C. Collier, J. Duchesne, D. Edelson, A. Gesino, M. Keyser, D. Maggio, M. Milligan, C. Mohrlen, J. O'Sullivan, J. Sharp, P. Storck, and M. de la Torre Rodriguez. 2013. "Knowledge is Power: Efficiently Integrating Wind Energy and Wind Forecasts." IEEE Power and Energy Magazine 11(6):45-52. http://dx.doi.org/10.1109/ MPE.2013.2277999.

Akhil, A. A., G. Huff, A. B. Currier, B. C. Kaun, D. M. Rastler, S. B. Chen, A. L. Cotter, D. T. Bradshaw, and W. D. Gauntlett. 2015. DOE/EPRI Electricity Storage Handbook in Collaboration with NRECA. Albuquerque NM: Sandia National Laboratories. SAND2015-1002. http://www.sandia.gov/ess/publications/SAND2015-1002.pdf.

Barbose, G., J. Miller, B. Sigrin, E. Reiter, K. Cory, J. McLaren, J. Seel, A. Mills, N. Darghouth, and A. Satchwell. 2016. On the Path to SunShot: Utility Regulatory and Business Model Reforms for Addressing the Financial Impacts of Distributed Solar on Utilities. Golden, CO: National Renewable Energy Laboratory. NREL/TP-6A20-65670. http:/www.nrel.gov/docs/fy16osti/ 65670.pdf.

Bhatnagar, D., A. Currier, J. Hernandez, O. Ma, and B. Kirby. 2013. Market and Policy Barriers to Energy Storage Deployment: A Study for the Energy Storage Systems Program. Albuquerque, NM: Sandia National Laboratories. SAND2013-7606. http://www.sandia.gov/ess/publications/ SAND2013-7606.pdf.

Bird, L., J Cochran, and X. Wang. 2014. Wind and Solar Energy Curtailment: Experience and Practices in the United States. Golden, CO: National Renewable Energy Laboratory. NREL/TP6A20-60983. http://www.nrel.gov/docs/fy14osti/60983.pdf.

Bloom, A., A. Townsend, and D. Palchak. 2015. Eastern Renewable Generation Integration Study: Flexibility and High Penetrations of Wind and Solar. Golden, CO: National Renewable Energy Laboratory. NREL/PR-6A20-64795. http://www.nrel.gov/docs/fy15osti/64795.pdf.

Bouillon, B. 2014. Prepared Statement of Brad Bouillon on behalf of the California Independent System Operator Corporation United States of America before the Federal Energy Regulatory Commission Reliability Technical Conference, Docket No. AD14-9-000. http://www.ferc.gov/ CalendarFiles/20140610083142-Bouillon,\%20CAISO.pdf.

Brinkman, G., J. Jorgenson, A. Ehlen, and J. Caldwell. 2016. The California 2030 Low Carbon Grid Study. Golden, CO: National Renewable Energy Laboratory. NREL/TP- 6A20-64884. http://www.nrel.gov/docs/fy16osti/64884.pdf.

CAISO (California Independent System Operator). 2010. Integration of Renewable Resources: Operational Requirements and Generation Fleet Capability at 20\% RPS. Folsom, CA: CASIO. http://www.caiso.com/Documents/Integration-RenewableResources-

OperationalRequirementsandGenerationFleetCapabilityAt20PercRPS.pdf. 
- 2011a. Summary of Preliminary Results of 33\% Renewable Integration Study-2010 CPUC LTPP Docket No. R.10-05-006. Folsom, CA: CAISO.

http://www.cpuc.ca.gov/NR/rdonlyres/E2FBD08E-727B-4E84-BD987561A5D45743/0/LTPP_33pct_initial_results_042911_final.pdf.

- 2011b. Track I Direct Testimony of Mark Rothleder on Behalf of the California Independent System Operator Corporation (Corrected). Before the Public Utilities Commission of the State of California, Order Instituting Rulemaking to Integrate and Refine Procurement Policies and Consider Long-Term Procurement Plans, Rulemaking 10-05-006. http://www.caiso.com/Documents/2011-08-10_ErrataLTPPTestimony_R10-05-006.pdf.

-2013. Fast Facts: What the Duck Curve Tells Us About Managing a Green Grid. Folsom, CA: CASIO. https://www.caiso.com/Documents/ FlexibleResourcesHelpRenewables FastFacts.pdf.

—. 2015. "Energy Imbalance Market (EIM) Overview." Accessed December 2015: https://www.caiso.com/informed/Pages/EIMOverview/Default.aspx.

Cappers, P., J. MacDonald, and C. A. Goldman. 2013. Market and Policy Barriers for Demand Response Providing Ancillary Services in U.S. Markets. Berkeley, CA: Ernest Orlando Lawrence Berkeley National Laboratory. LBNL-6155E. http://drrc.lbl.gov/sites/all/files/lbnl-6155e.pdf.

CEC (California Energy Commission). 1999. Flexible AC Transmission Systems Benefits Study. P600-00-037. http://www.energy.ca.gov/reports/2002-01-10_600-00-037.PDF.

- 2014. California Electricity Statistics and Data. Sacramento, CA. Accessed January 30, 2014: "California Electrical Energy Generation: Total Production, by Resource Type" (http://energyalmanac.ca.gov/electricity/electricity_generation.html) and "2014 Total System Power in Gigawatt Hours" (http://energyalmanac.ca.gov/electricity/total_system_power.html).

—. 2015. "Historical California Electricity Demand." Sacramento, CA. Accessed December 30, 2014: http://energyalmanac.ca.gov/electricity/historic_peak_demand.html.

Chung, D., K. Horowitz, and P. Kurup. 2016. On the Path to SunShot: Emerging Opportunities and Challenges in U.S. Solar Manufacturing. Golden, CO: National Renewable Energy Laboratory. NREL/TP-7A40-65788. http://www.nrel.gov/docs/fy16osti/65788.pdf.

Cochran, J., M. Miller, O. Zinaman, M. Milligan, D. Arent, B. Palmintier, M. O'Malley, S. Mueller, E. Lannoye, A. Tuohy, B. Kujala, M. Sommer, H. Holttinen, J. Kiviluoma, S. K. Soonee. 2014. Flexibility in 21st Century Power Systems. 21st Century Power Partnership. NREL/TP-6A20-61721. http://www.nrel.gov/docs/fy14osti/61721.pdf.

Cochran, J., P. Denholm, B. Speer, and M. Miller. 2015. Grid Integration and the Carrying Capacity of the U.S. Grid to Incorporate Variable Renewable Energy. Golden, CO: National Renewable Energy Laboratory. NREL/TP-6A20-62607. http://www.nrel.gov/docs/fy15osti/ 62607.pdf. 
CPUC (California Public Utilities Commission). 2013a. Order Instituting Rulemaking to Integrate and Refine Procurement Policies and Consider Long-Term Procurement Plans. California Public Utilities Commission Rulemaking 13-12-010. http://docs.cpuc.ca.gov/PublishedDocs/Published/G000/M084/K241/84241040.PDF.

_. 2013b. Decision Adopting Energy Storage Procurement Framework and Design Program. 2013, October 17. California Public Utilities Commission Decision 13-10-040. http://docs.cpuc.ca.gov/PublishedDocs/Published/G000/M079/K533/79533378.PDF.

- 2014a. 2015. Filing Guide for System, Local and Flexible Resource Adequacy (RA) Compliance Filings. Issued: September 9, 2014.

- 2014b. Effective Load Carrying Capacity and Qualifying Capacity Calculation Methodology for Wind and Solar Resources. Resource Adequacy Proceeding R.11-10-023. California Public Utilities Commission Energy Division, January 16, 2014.

—. 2015. "Demand Response Monthly Reports." Accessed December 2015: http://www.cpuc.ca.gov/general.aspx?id=6299.

Denholm, P., K. Clark, and M. O'Connell. 2016. On the Path to SunShot: Emerging Issues and Challenges in Integrating High Levels of Solar into the Electrical Generation and Transmission System. Golden, CO: National Renewable Energy Laboratory. NREL/TP-6A20-65800. http://www.nrel.gov/docs/fy16osti/65800.pdf.

Denholm, P., and M. Hand. 2011. "Grid Flexibility and Storage Required to Achieve Very High Penetration of Variable Renewable Electricity." Energy Policy 39:1817-1830.

Denholm, P., M. Hand, T. Mai, R. Margolis, G. Brinkman, E. Drury, M. Mowers, and C. Turchi. 2012. The Potential Role of Concentrating Solar Power in Enabling High Renewables Scenarios in the United States. Golden, CO: National Renewable Energy Laboratory. NREL/TP-6A2056294. http://www.nrel.gov/docs/fy13osti/56294.pdf.

Denholm, P., M. Kuss, and R. M. Margolis. 2013. "Co-Benefits of Large Scale Plug-In Hybrid Electric Vehicle and Solar PV Deployment." Journal of Power Sources 236:350-356.

Denholm, P., and M. Mehos. 2011. Enabling Greater Penetration of Solar Power via the Use of Thermal Energy Storage. Golden, CO: National Renewable Energy Laboratory. NREL/TP6A20-52978. http://www.nrel.gov/csp/pdfs/52978.pdf.

Denholm, P., M. O'Connell, G. Brinkman, and J. Jorgenson. 2015 Overgeneration from Solar Energy in California: A Field Guide to the Duck Chart. Golden, CO: National Renewable Energy Laboratory. NREL/TP-6A20-65023. http://www.nrel.gov/docs/fy16osti/65023.pdf.

DOE (U.S. Department of Energy). 2012. SunShot Vision Study. Washington, DC: U.S. Department of Energy. DOE/GO-102012-3037. http://www.nrel.gov/docs/fy12osti/47927.pdf. 
E3 (Energy and Environmental Economics, Inc.). 2014, January. Investigating a Higher Renewables Portfolio Standard in California. San Francisco, CA: E3. https://ethree.com/ documents/E3_Final_RPS_Report_2014_01_06_with_appendices.pdf.

EIA (U.S. Energy Information Administration). 2015. "Electric Power Annual with Data for 2013." Release Date: March 23, 2015.http://www.eia.gov/electricity/annual/.

Eichman, J., P. Denholm, J. Jorgenson, and U. Helman. 2015 Operational Benefits of Meeting California's Energy Storage Targets. Golden, CO: National Renewable Energy Laboratory. NREL/TP- 5400-65061. http://www.nrel.gov/docs/fy16osti/65061.pdf.

Ela, E., M. Milligan, A. Bloom, A. Botterud, A. Townsend, and T. Levin. 2014. Evolution of Wholesale Electricity Market Design with Increasing Levels of Renewable Generation. Golden, CO: National Renewable Energy Laboratory. NREL/TP-5D00-61765. http://www.nrel.gov/docs/ fy14osti/61765.pdf.

ERCOT (Electric Reliability Council of Texas). 2014. Demand Response in ERCOT: 2014 Operators Training Seminar. http://www.ercot.com/content/wcm/training_courses/104/ ercot_demand response 2014 ots.pptx.

Feldman, D., and M. Bolinger. 2016. On the Path to SunShot: Emerging Opportunities and Challenges in Financing Solar. Golden, CO: National Renewable Energy Laboratory.

NREL/TP-6A20-65638. http://www.nrel.gov/docs/fy16osti/65638.pdf.

FERC (Federal Energy Regulatory Commission). 2014a. Order Conditionally Accepting and Suspending Proposed Tariff Revisions, Subject to Refund, and Establishing Hearing and Settlement Judge Procedures. http://www.ferc.gov/CalendarFiles/20141205151516-ER14-1969000.pdf.

- 2014, December. Assessment of Demand Response and Advanced Metering. Washington, DC: Federal Energy Regulatory Commission.

GE Energy. 2010. Western Wind and Solar Integration Study. Golden, CO: National Renewable Energy Laboratory. NREL/SR-550-47434. http://www.nrel.gov/docs/fy10osti/47434.pdf.

GE Energy. 2014. Western Wind and Solar Integration Study Phase 3: Frequency Response and Transient Stability. Golden, CO: National Renewable Energy Laboratory. NREL/SR-550-62906. http://www.nrel.gov/docs/fy15osti/62906.pdf.

GTM (Greentech Media), and SEIA (Solar Energy Industries Association). U.S. Solar Market Insight Q2 2015. September 2015.

Hogan, M., and B. Paulos. "Dealing With the Duck." Fortnightly Magazine January 2014:22-25.

Hummon, M. R., P. Denholm, J. Jorgenson, D. Palchak, B. Kirby, and O. Ma. 2013a. Fundamental Drivers of the Cost and Price of Operating Reserves. Golden, CO: National Renewable Energy Laboratory. NREL/TP-6A20-58491. http://www.nrel.gov/docs/fy13osti/ 58491.pdf. 
Hummon, M., D. Palchak, P. Denholm, J. Jorgenson, D. J. Olsen, S. Kiliccote, N. Matson, M. Sohn, C. Rose, J. Dudley, S. Goli, and O. Ma. 2013b. Grid Integration of Aggregated Demand Response, Part 2: Modeling Demand Response in a Production Cost Model. Golden, CO: National Renewable Energy Laboratory. NREL/TP-6A20-58492. http://www.nrel.gov/docs/ fy14osti/58492.pdf.

Ibanez, E., and Milligan, M. 2014. Comparing Resource Adequacy Metrics: Preprint. Goldemn, CO: National Renewable Energy Laboratory. NREL/CP-5D00-62847. http:/www.nrel.gov/docs/ fy14osti/62847.pdf.

IEA (International Energy Agency). 2014. The Power of Transformation: Wind, Sun and the Economics of Flexible Power Systems. Paris, France: International Energy Agency.

IRC (ISO/RTO Council). 2015. “About the IRC.” Accessed December 2015: http://www.isorto.org/about/default.

Jones, R. 2012. "Diversity Benefit of Solar and Wind with Increasing Market Penetration." Intersolar North America. July 12.

Jorgenson, J., P. Denholm, and M. Mehos. 2014. Estimating the Value of Utility-Scale Solar Technologies in California Under a 40\% Renewable Portfolio Standard. Golden, CO: National Renewable Energy Laboratory. NREL/TP-6A20-61685. http://www.nrel.gov/docs/fy14osti/ 61685.pdf.

King, J., B. Kirby, M. Milligan, and S. Beuning. 2012. Operating Reserve Reductions from a Proposed Energy Imbalance Market with Wind and Solar Generation in the Western Interconnection. Golden, CO: National Renewable Energy Laboratory. NREL/TP-5500-54660. http://www.nrel.gov/docs/fy12osti/54660.pdf.

Koritarov, V., T. D. Veselka, J. Gasper, B. M. Bethke, A. Botterud, J. Wang, M. Mahalik, Z. Zhou, C. Milostan, J. Feltes, Y. Kazachkov, T. Guo, G. Liu, B. Trouille, P. Donalek, K. King, E. Ela, B. Kirby, I. Krad, and V. Gevorgian. 2014. Modeling and Analysis of Value of Advanced Pumped Storage Hydropower in the United States. Argonne, IL: Argonne National Laboratory. ANL/DIS-14/7. http://www.ipd.anl.gov/anlpubs/2014/07/105786.pdf.

Kundur, P., J. Paserba, V. Ajjarapu, G. Andersson, A. Bose, C. Canizares, N. Hatziargyriou, D. Hill, A. Stankovic, C. Taylor, T. Van Cutsem, and V. Vittal. 2004. "Definition and Classification of Power System Stability." IEEE Transactions on Power Systems 19(2):13871401.

Lazar, J. 2014. Teaching the “Duck” to Fly. Montpelier, VT: Regulatory Assistance Project.

Lew, D., M. Milligan, G. Jordan, and R. Piwko. 2011. The Value of Wind Power Forecasting: Preprint. Presented at the 91st American Meteorological Society Annual Meeting, the Second Conference on Weather, Climate, and the New Energy Economy, January 26, 2011. Golden, CO: National Renewable Energy Laboratory. NREL/CP-5500-50814. http://www.nrel.gov/docs/ fy110sti/50814.pdf. 
Lew, D., G. Brinkman, E. Ibanez, A. Florita, M. Heaney, B.-M. Hodge, M. Hummon, G. Stark, J. King, S. A. Lefton, N. Kumar, D. Agan, G. Jordan, and S. Venkataraman. 2013. The Western Wind and Solar Integration Study Phase 2. Golden, CO: National Renewable Energy Laboratory. NREL/TP-5500-55588. http://www.nrel.gov/docs/fy13osti/55588.pdf.

Lew, D., M. Schroder, N. Miller, and M. Lecar. 2015. Integrating Higher Levels of Variable Energy Resources in California. Schenectady, NY: GE Energy Consulting. http://www.largescalesolar.org/files/Final-CA-VER-Integration-6-15-15.pdf.

Liu, S. 2014a. Phase 1.A. Direct Testimony of Dr. Shucheng Liu on Behalf of the California Independent System Operator Corporation. Proceeding R.13-12-010, August 13. San Francisco, CA: California Public Utilities Commission. http://www.caiso.com/Documents/ Aug13 2014 InitialTestimony ShuchengLiu Phase1A LTPP R13-12-010.pdf.

Liu, S. 2014b. Phase 1.A. Reply Testimony of Dr. Shucheng Liu on Behalf of the California Independent System Operator Corporation. Proceeding R.13-12-010, October 22. San Francisco, CA: California Public Utilities Commission. http://www.caiso.com/Documents/Oct22 2014 _ReplyTestimony_ShuchengLiu_Phase1ALong-TermProcurementPlans_R13-12-010.pdf.

Liu, S. 2014c. Review of the ISO 2014 LTPP System Flexibility Study. https://www.caiso.com/ Documents/Presentation 2014LTPPSystemFlexibilityStudy SHcall.pdf

Ma, O., N. Alkadi, P. Cappers, P. Denholm, J. Dudley, S. Goli, M. Hummon, S. Kiliccote, J. MacDonald, N. Matson, D. Olsen, C. Rose, M. D. Sohn, M. Starke, B. Kirby, and M. O’Malley. 2013. "Demand Response for Ancillary Services.” IEEE Transactions on Smart Grid 4(4):1988-1995.

Madaeni, S. H., R. Sioshansi, and P. Denholm. 2013a. "Comparing Capacity Value Estimation Techniques for Photovoltaic Solar Power.” IEEE Journal of Photovoltaics 3(1):407-415.

Madaeni, S. H., R. Sioshansi, and P. Denholm. 2013b. "Estimating the Capacity Value of Concentrating Solar Power Plants with Thermal Energy Storage: A Case Study of the Southwestern United States." IEEE Transactions on Power Systems 28(2):1205-1215.

Mehos, M., C. Turchi, J. Jorgenson, P. Denholm, C. Ho, and K. Armijo. 2016. On the Path to SunShot: Advancing Concentrating Solar Power Technology, Performance, and Dispatchability. Golden, CO: National Renewable Energy Laboratory. NREL/TP-5500-65668. http://www.nrel.gov/docs/fy16osti/65668.pdf.

Milligan, M., and B. Kirby. 2010. Market Characteristics for Efficient Integration of Variable Generation in the Western Interconnection. Golden, CO: National Renewable Energy Laboratory. NREL/TP-550-48192. http://www.nrel.gov/docs/fy10osti/48192.pdf.

Milligan, M., B. Frew, B. Kirby, M. Schuerger, K. Clark, D. Lew, P. Denholm, B. Zavadil, M. O'Malley, and B. Tsuchida, B. 2015. "Alternatives No More: Wind and Solar Power Are Mainstays of a Clean, Reliable, Affordable Grid.” IEEE Power and Energy Magazine 13(6) 78-87. 
Mills, A., and R. Wiser. 2012a. Changes in the Economic Value of Variable Generation at High Penetration Levels: A Pilot Case Study of California. Berkeley, CA: Ernest Orlando Lawrence Berkeley National Laboratory. LBNL-5445E. http:/emp.lbl.gov/sites/all/files/lbnl-5445e.pdf.

Mills, A., and R. Wiser. 2012b. An Evaluation of Solar Valuation Methods Used in Utility Planning and Procurement Processes. Berkeley, CA: Ernest Orlando Lawrence Berkeley National Laboratory. LBNL-5933E. http://emp.lbl.gov/sites/all/files/lbnl-5933e 0.pdf.

Mills, A. D., and R. H. Wiser. 2015. "Strategies to Mitigate Declines in the Economic Value of Wind and Solar at High Penetration in California." Applied Energy 147:269-278.

Navid, N., and G. Rosenwald. 2013. Ramp Capability Product Design for MISO Markets: Market Development and Analysis. https://www.misoenergy.org/Library/Repository/ Communication $\% 20$ Material/Key $\% 20$ Presentations $\% 20$ and $\% 20$ Whitepapers/Ramp $\% 20$ Product \%20Conceptual $\% 20$ Design $\% 20$ Whitepaper.pdf

Nelson, J. 2014. Prepared Opening Testimony of Dr. Jimmy Nelson on Behalf of the Union of Concerned Scientists and Sierra Club, including Errata. Proceeding R.13-12-010, September 24. San Francisco, CA: California Public Utilities Commission. https://content.sierraclub.org/coal/sites/content.sierraclub.org.coal/files/docs/2014-0930\%20Testimony $\% 20$ Dr. $\% 20$ Jimmy $\% 20$ Nelson $\% 20$ on $\% 20$ behalf $\% 20$ of $\% 20$ the $\% 20$ UCS $\% 20$ an d\%20SC.pdf.

Nelson, J., and L. Wisland. 2015. Achieving 50 Percent Renewable Electricity in California. Union of Concerned Scientists: The Role of Non-Fossil Flexibility in a Cleaner Electricity Grid. Union of Concerned Scientists. http://www.ucsusa.org/sites/default/files/attach/2015/08/ Achieving-50-Percent-Renewable-Electricity-In-California.pdf.

NERC (North American Electric Reliability Corporation). 2011. Methods to Model and Calculate Capacity Contributions of Variable Generation for Resource Adequacy Planning. Princeton, NJ: NERC. http://www.nerc.com/docs/pc/ivgtf/IVGTF1-2.pdf.

NREL (National Renewable Energy Laboratory). 2012. Renewable Electricity Futures Study. Golden, CO: National Renewable Energy Laboratory. NREL/TP-6A20-52409.

Nykvist, B., and M. Nilsson. 2015. "Rapidly Falling Costs of Battery Packs for Electric Vehicles.” Nature Climate Change 5:329-332.

Palchak, D., and P. Denholm. 2014. Impact of Generator Flexibility on Electric System Costs and Integration of Renewable Energy. Golden, CO: National Renewable Energy Laboratory. NREL/TP-6A20-62275. http://www.nrel.gov/docs/fy14osti/62275.pdf.

Palmintier, B., R. Broderick, B. Mather, M. Coddington, K. Baker, F. Ding, M. Reno, M. Lave, and A. Bharatkumar. 2016. On the Path to SunShot: Emerging Issues and Challenges in Integrating Solar with the Distribution System. Golden, CO: National Renewable Energy Laboratory. NREL/TP-5D00-65331. http://www.nrel.gov/docs/fy16osti/65331.pdf. 
Pelland, S., and I. Abboud. 2008. "Comparing Photovoltaic Capacity Value Metrics: A Case Study for the City of Toronto." Progress in Photovoltaics: Research and Applications 16 (8): 715-724. doi:10.1002/pip.864.

Perez, R., M. Taylor, T. Hoff, and J. P. Ross. 2008. "Reaching Consensus in the Definition of Photovoltaics Capacity Credit in the USA: A Practical Application of Satellite-Derived Solar Resource Data." IEEE Journal of Selected Topics in Applied Earth Observations and Remote Sensing 1(1):28-33. http://dx.doi.org/10.1109/JSTARS.2008.2004362.

Pierce, E. 2014. “Inside Colorado's Wind Integration Success Story.” North American Windpower 11(12). http://www.nawindpower.com/issues/NAW1412/FEAT_01_InsideColorado-s-Wind-Integration-Success-Story.html

Porter, K., C. Mudd, S. Fink, J. Rogers, L. Bird, L. Schwartz, M. Hogan, D. Lamont, B. Kirby. 2012. Meeting Renewable Energy Targets in the West at Least Cost: The Integration Challenge. Denver, CO: Western Governors' Association. http://www.westgov.org/component/docman/ doc download/1610-meeting-renewable-energy-targets-in-the-west-at-least-cost-the-integrationchallenge-full-report?Itemid.

Potomac Economics. 2014, September. 2013 State of the Market Report for the ERCOT Wholesale Electricity Markets.

R.W. Beck. 2009. Distributed Renewable Energy Operating Impacts and Valuation Study. Arizona Public Service. http://www.solarfuturearizona.com/.

Schuerger, M., H. Johal, L. Roose, M. Matsuura, and R. Piwko. 2013. "Catching Some Rays: Variable Generation Integration on the Island of Oahu." IEEE Power and Energy Magazine 11(6):33-44. http://dx.doi.org/10.1109/MPE.2013.2277998.

Sioshansi, R., P. Denholm, and T. Jenkin. 2012. "Market and Policy Barriers to Deployment of Energy Storage." Economics of Energy and Environmental Policy 1(2):47-63.

Sioshansi, R., S. H. Madaeni, and P. Denholm. 2014. "A Dynamic Programming Approach to Estimate the Capacity Value of Energy Storage" IEEE Transactions on Power Systems 29(1) 395-403.

Stetz, T., J. von Appen, F. Niedermeyer, G. Scheibner, R. Sikora, and M. Braun. 2015. "Twilight of the Grids: The Impact of Distributed Solar on Germany's Energy Transition." IEEE Power and Energy Magazine 13(2):50-61. http://dx.doi.org/10.1109/MPE.2014.2379971.

Tuohy, A., J. Zack, S. E. Haupt, J. Sharp, M. Ahlstrom, S. Dise, E. Grimit, C. Mohrlen, M. Lange, M. Garcia Casado, J. Black, M. Marquis, and C. Collier. 2015. "Solar Forecasting: Methods, Challenges, and Performance." IEEE Power and Energy Magazine 13(6)50-59. http://dx.doi.org/10.1109/MPE.2015.2461351. 
Venkataraman, S., G. Jordan, M. O'Connor, N. Kumar, S. Lefton, D. Lew, G. Brinkman, D. Palchak, and J. Cochran. 2013. Cost-Benefit Analysis of Flexibility Retrofits for Coal and Gas-Fueled Power Plants: August 2012 - December 2013. Golden, CO: National Renewable Energy Laboratory. NREL/SR-6A20-60862. http://www.nrel.gov/docs/fy14osti/60862.pdf.

Vittal, V. 2003. Transient Stability and Control of Large Scale Power Systems. Power Systems Engineering Research Center Background Paper. Ames: IA: Iowa State University.

Wärtsilä and Energy Exemplar. 2014. Incorporating Flexibility in Utility Resource Planning. Helsinki: Wärtsilä Corporation. http://energyexemplar.com/wp-content/uploads/publications/ 2014 EnergyExemplar/IOU\%20white\%20paper\%209.7.pdf.

WECC (Western Electricity Coordinating Council). 2014. 2014 TEPPC Study Program by Transmission Expansion Planning and Policy Committee. Salt Lake City, UT: Western Electricity Coordinating Council.

Wiser, R., T. Mai, D. Millstein, J. Macknick, A. Carpenter, S. Cohen, W. Cole, B. Frew, and G. A. Heath. 2016. On the Path to SunShot: The Environmental and Public Health Benefits of Achieving High Penetrations of Solar Energy in the United States. Golden, CO: National Renewable Energy Laboratory. NREL/TP-6A20-65628. http://www.nrel.gov/docs/fy16osti/ 65628.pdf.

Woodhouse, M., R. Jones-Albertus, D. Feldman, R. Fu, K. Horowitz, D. Chung, D. Jordan, and S. Kurtz. 2016. On the Path to SunShot: The Role of Advancements in Solar Photovoltaic Efficiency, Reliability, and Costs. Golden, CO: National Renewable Energy Laboratory. NREL/TP-6A20-65464. http://www.nrel.gov/docs/fy16osti/65464.pdf.

Wu, J., A. Botterud, A. Mills, X. Zhou, B. Hodge, M. Heaney. 2015. "Integrating Solar PV (Photovoltaics) in Utility System Operations: Analytical Framework and Arizona Case Study." Energy 85(1, June):1-9.

Younghein, M., and E. Martinot 2015. Beyond 33\% Renewables: Grid Integration Policy for a Low-Carbon Future. A CPUC Staff White Paper. November 25, 2015. 


\section{Appendix: Grid Stability}

Acceptable dynamic performance of the grid in the fractions of a second to 1 minute following a large disturbance (e.g., loss of a large power plant or a major transmission line) is critical to system reliability. The Western Interconnection has a long history of dynamic performance constraints on system operation - so any dynamic performance changes due to increased solar and wind generation could have substantial impact on all aspects of renewable integration. Thus, WWSIS-3 examined two aspects of dynamic performance of the Western Interconnection with high solar and wind penetration: large-scale transient stability and frequency response (GE Energy 2014). A technical definition of the different aspects of power system stability is provided in Kundur et al. (2004). Less technical descriptions of both frequency and transient stability are provided below.

Owing to the uncertainties embedded in analyzing future scenarios (e.g., renewable penetration levels and siting, load forecasts, transmission system reinforcements, generation retirements or additions), this work focused on a small set of credible yet relatively extreme system conditions. The study scenarios were based on 2023 system conditions (e.g., transmission topology, generation retirements, load forecast) as developed through the WECC stakeholder process with $33 \%$ solar and wind penetration on an annual energy basis. Half of the renewable generation (16.5\%) was provided by solar, including CSP, utility-scale PV, and rooftop PV. This investigation focused on light spring conditions because of the relatively low level of synchronous generation and relatively high level of wind and PV generation. The instantaneous penetrations of solar and wind for this snapshot of a windy, sunny morning in the spring were significantly higher than the annual energy penetration described above. The Hi-Mix case had $56 \%$ instantaneous penetration (based on the total U.S. generation in WECC), and the Extreme case had $64 \%$ instantaneous penetration. The detailed siting of the wind and solar plants as well as the re-dispatch or de-commitment of conventional generation were based on previous work in WWSIS Phase 2 (Lew et al. 2013).

\section{Frequency Stability}

To operate a large, interconnected power grid such as the Western Interconnection reliably requires a constant balancing of electricity generation with electricity demand. Electricity must be generated at the same instant it is used, so operating procedures have developed to forecast electricity demand, schedule electric generators to meet that demand, and ensure sufficient generating reserves are available to respond to forecast errors and system disturbances. The measure of success in this balancing act is frequency. In North America, that means maintaining system frequency at or very close to $60 \mathrm{~Hz}$.

However, disturbances do occur, including large ones that affect overall system frequency (e.g., abrupt outage of a large generator or a major transmission line). For example, a transmission line outage may disconnect a large industrial customer; as a result, the total electricity generation exceeds the total electricity demand, and frequency rises. Because operators, in general, have more control over generation than demand, they can execute a generation reduction to regain the balance and return system frequency to near $60 \mathrm{~Hz}$.

A potentially more significant problem is the loss of a large generating plant. During this type of disturbance, the total electricity demand exceeds the total electricity generated, and frequency 
drops, as shown in Figure 24. In general, a power grid is designed to withstand the loss of the single largest generator. However, the loss of multiple generators or plants may cause the frequency to drop significantly such that protective devices act to disconnect customers in order to preserve the bulk of the system. It is a serious reliability failure when operators lose the ability to supply all the electricity needed to meet demand.

In summary, frequency response is the overall response of the power system to large, sudden mismatches between generation and load. The primary concern is that the minimum frequency during the worst credible disturbances should not cause under-frequency load shedding, or customers being dropped from the grid.

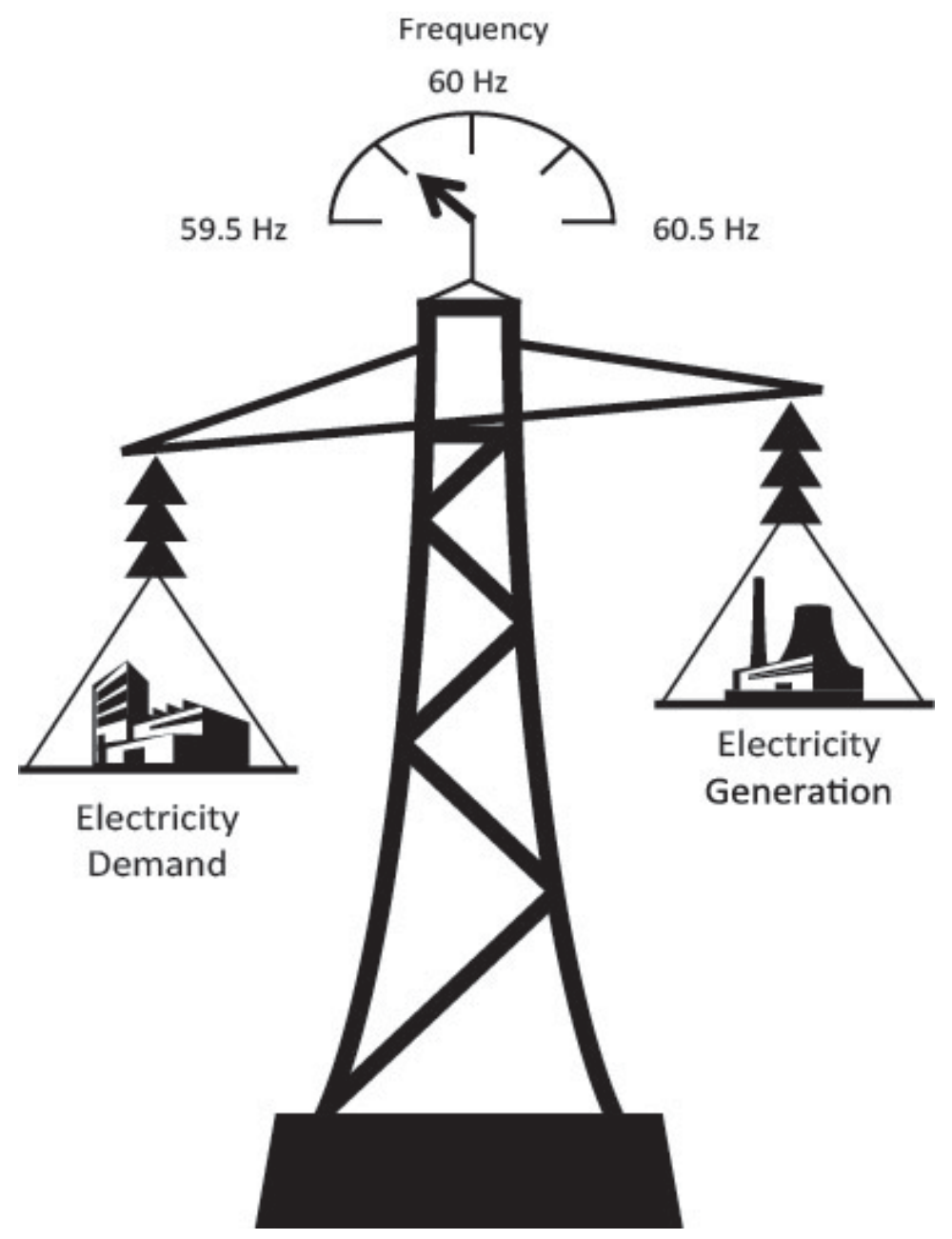

Figure 24. Electricity demand exceeds electricity generation, and frequency drops

\section{Transient Stability}

In addition to maintaining the balance between electricity generation and electricity demand, power system operators must ensure that the grid can successfully transition from normal operation (e.g., all transmission lines and generating units are in service), through a disturbance (e.g., an abrupt outage of a major transmission line or large generator), and into a new stable operating condition in the 10-20 seconds immediately following a disturbance. The ability to make this successful transition is called transient stability. 
Figure 25 shows an updated visualization of the problem originally presented in Vittal (2003). The round masses represent synchronous generators, and the various springy lines connecting the masses represent transmission lines. The rubbery mass-spring system bounces around a little as generation responds to load variations - and a lot if there is a disturbance. The scissors represent such a disturbance, which might cut a line or disconnect a generator. If the event is too severe or some of the lines are stretched too tight (i.e., are overloaded), more lines will break. It is easy to imagine a cascading failure in which each successive break leads to another. A substantial part of system planning is aimed at avoiding such unacceptable consequences.

To extend the example to PV and wind generation, the hands represent the controllable nature of inverter-based generation. These controls can be tuned to provide a specific response to disturbances, with the objective of maintaining or improving system performance.

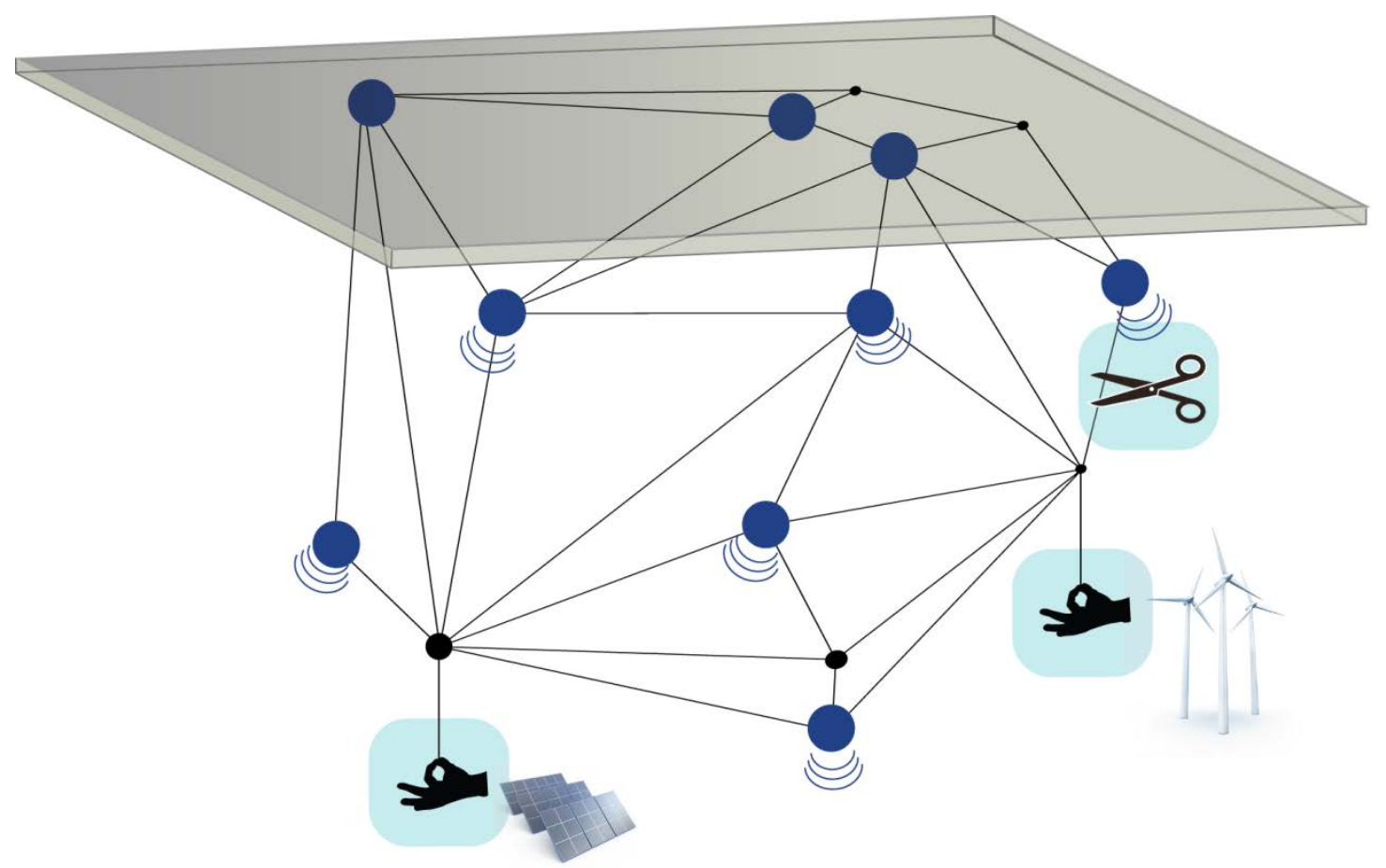

Figure 25. Visualization of transient stability with synchronous generators and wind power plants

The Western Interconnection has a long history of constraints because of transient stability limitations that vary depending on system characteristics such as the level of electricity demand (e.g., peak summer load), the amount of power flowing on the transmission system (e.g., heavy flows on critical paths), and the location of the generating plants in operation (e.g., remote from population centers). The primary criteria of acceptable transient stability are according to reliability standards set by NERC and WECC. 


\section{Impact of Inverter-Based Generation}

There is general concern among power system operators and utilities regarding the degradation of frequency response in North America over the past two decades. The decline is due to various factors, including the withdrawal of primary or governor response by synchronous machines shortly after an event, the lack of in-service governors on conventional generation, and the unknown and changing nature of load-frequency characteristics. Large penetrations of inverterbased, or non-synchronous, generation technologies further complicate this issue. Without special operation or controls, wind and solar plants do not inherently participate in the regulation of grid frequency. By contrast, synchronous machines always contribute to system inertia, and some fraction of the synchronous generation in operation at any point has governor controls enabled. When wind and solar generation displaces conventional synchronous generation, the mix of the remaining synchronous generators changes and has the potential to impact overall frequency response adversely. Similarly, large penetrations of inverter-based, or nonsynchronous, wind and solar generation may substantially alter system stability as a result of changes in system swing behavior caused by reduced inertia, changes in voltage swing behavior because of different voltage-control systems, different power flow patterns, and the displacement of synchronous generation at key locations.

However, for the conditions studied, WWSIS-3 demonstrated that both frequency response and transient stability can be maintained with high instantaneous penetrations of inverter-based generation on the western U.S. grid. The system-wide frequency response exceeded the NERCspecified interconnection frequency response obligation for all cases, and the frequency nadir remained above the highest under-frequency load-shedding threshold for all cases. While not needed to meet system-wide performance criteria, frequency-responsive controls on wind, PV, and energy storage plants were shown to improve both frequency nadir and settling frequency and thus frequency response. Appropriate application of these commercially available controls would allow individual areas or reserve-sharing groups to meet their frequency response obligations with their own resources.

System-wide transient stability was maintained by using traditional transmission system reinforcements (e.g., transformers, shunt capacitors, local lines) to address local stability, voltage, and thermal problems. With these reinforcements, an $80 \%$ reduction in coal plant commitment resulted in acceptable transient stability performance. With further reinforcements, including non-standard items such as synchronous condenser conversions, a $90 \%$ reduction in coal plant commitment resulted in acceptable transient stability performance. CSP generation with frequency-responsive controls was also effective at improving transient stability, due to an advantageous location.

WWSIS-3 suggests that neither panic nor complacency about high penetrations of inverter-based generation is warranted. Good system planning and sound engineering practices must be followed. The existing grid evolved over decades of integrated planning with large central station power plants at key transmission substations. Inverter-based wind and solar generation will be more geographically dispersed. Thus, local voltage and thermal problems will inevitably occur and require local transmission upgrades. However, these new, fast-responding, inverter-based resources also add flexibility to the system. Inverter-based controls are not constrained by the 
physics and long time-constants of synchronous machines - they can be designed to provide faster frequency response.

However, mechanisms are needed - be they market incentives, interconnection requirements, or other means - to ensure that inverter-based wind and solar plants can provide the frequency response needs of the grid as they become a larger proportion of the generation fleet and displace traditional synchronous machines with active governors. 